ALEXANDRE ICHIRO HASHIMOTO

ESTUDO DA DEPOSIÇÃO QUÍMICA DE COBALTO EM SUPERFÍCIES DE SILÍCIO PRÉ-ATIVADAS POR PALÁDIO 


\section{ESTUDO DA DEPOSIÇÃO QUÍMICA DE COBALTO EM SUPERFÍCIES DE SILÍCIO PRÉ-ATIVADAS POR PALÁDIO}

Tese apresentada à Escola Politécnica da Universidade de São Paulo para a obtenção do título de Doutor em Engenharia. 
Este Exemplar foi revisado e alterado em relação à versão original, sob a responsabilidade única do autor e com anuência de seu orientador.

São Paulo, 25 de agosto de 2008

Alexandre Ichiro Hashimoto (autor)

Prof. Dr. Sebastião Gomes Dos Santos Filho (orientador)

FICHA CATALOGRÁFICA

Hashimoto, Alexandre Ichiro

Estudo de deposição química de cobalto em superfícies de silício pré-ativadas por paládio / A.I. Hashimoto. -- São Paulo, 2008.

$98 \mathrm{p}$.

Tese (Doutorado) - Escola Politécnica da Universidade de São Paulo. Departamento de Engenharia de Sistemas Eletrônicos.

1. Cobalto 2. Deposição química 3. Eletroquímica 4. Paládio 5. Silício 6. Superfícies I. Universidade de São Paulo. Escola Politécnica. Departamento de Engenharia de Sistemas Eletrônicos II. t. 


\begin{abstract}
ALEXANDRE ICHIRO HASHIMOTO
Tecnólogo em Materiais, Processos e Componentes Eletrônicos, Faculdade de Tecnologia de São Paulo - FATEC - SP, 1995.

Mestre em Engenharia Elétrica, pela Escola Politécnica da Universidade de São Paulo LSI/PSI/EPUSP - 1998
\end{abstract}

\title{
ESTUDO DA DEPOSIÇÃO QUÍMICA DE COBALTO EM SUPERFÍCIES DE SILÍCIO PRÉ-ATIVADAS POR PÁLADIO
}

Tese apresentada à Escola Politécnica da Universidade de São Paulo para a obtenção do título de Doutor em Engenharia.

Área de Concentração:

Engenharia Elétrica

Orientador:

Prof. Dr. SEBASTIÃO GOMES DOS SANTOS FILHO 
Dedico esta Tese em especial aos meus Pais, Zenaide Gonçalves Duvra Hashimoto e Francisco Yutaka Hashimoto a eles a minha maior estima por estarem ao meu lado sempre me apoiando com conselhos, segurança, carinho e amor. Obrigado Mãe e Pai.

Também dedico esta Tese a Minha Esposa, Vanessa e aos meus filhos Lucas, Artur e Pedro os quais me apoiaram nos momentos em que muito precisei, é a eles a quem devo meu maior esforço. 


\section{AGRADECIMENTOS}

- Ao Prof. Dr. Sebastião Gomes dos Santos Filho pela sua grande orientação e pelos seus preciosos ensinamentos os quais carregarei, como exemplo, por toda minha vida, pela compreensão, apoio e incentivos que jamais esquecerei; - Obrigado Prof. Sebastião.

- Ao Prof. Dr. Armando A. M. Laganá, Prof. Dr. João A. Martino, Prof. Dr. Nilton Itiro Morimoto, Prof. Dr. Patrick Bernard Verdonck, Dra. Ana Neilde Rodrigues da Silva, Dra. Maria Lúcia Pereira da Silva, Dr. Maurício Massazumi Oka, Prof. Dr. Luís da Silva Zambom e Prof. Ms Renato M. Franzin pelo incentivo moral para a realização desta Tese;

- Aos meus amigos Paulo T. Hoashi, Luciano M. Camillo, Flavio de Sousa, Carlos Vianna, Humber Furlan, Roberto Kenji, Hamilton Fernandes de Moraes Junior, Acácio Luiz Siarkowski e Antonio Pereira do Nascimento Filho pelo apoio e colaborações prestadas;

- Aos amigos do grupo de Engenharia de Superfícies LSI/PEE/EPUSP Willian Aurélio Nogueira, Ronaldo Willian Reis, Leandro Zeidan Toquetti, José Cândido de Souza Filho, Nasser Mahmoud HASSAN, Angelo Eduardo Battistini Marques, Hugo Puertas de Araújo, Cesar Augusto Alves de Souza, Giuliano Gozzi, Alan Rodrigo Navia pelo apoio e compreensão durante a realização do doutorado;

- Aos amigos do LSI/PEE/EPUSP Celina, Márcio, Nelson, Adir, Alexandre, Ana por me ajudarem e apoiarem quando mais precisava;

- Aos amigos do LAMFI, Prof. Dr. Juan Carlos Acquadro, Prof. Dr. Manfredo H. Tabacniks, Marcel e Marcos e por me ajudarem nas medidas de RBS;

- Aos amigos da FATEC-SP que me ajudaram e me incentivaram neste trabalho em especial ao Prof. Victor Sonnenberg;

- À minha esposa Vanessa e meus filhos Lucas e Artur e Pedro pela compreensão e apoio quando sempre precisei;

- Aos meus Pais Francisco e Zenaide os quais me deram apoio para que chegasse até aqui;

- Às minhas Irmãs e cunhados que me apoiaram sempre;

- Aos amigos que ajudaram ao longo deste anos todos me apoiando para a finalização desta Tese, Maisa, Prof. Dr. Edman Altheman, Paulo Feuz, Maria Ursulina (suli), Dr. Custódio Pereira, Prof. Dr. Henrique Altemani, Ana Lindemberg, Marta ;

- E a todos que me ajudaram de forma direta ou indireta na realização deste trabalho e que involuntariamente foram omitidos. 


\section{RESUMO}

Neste trabalho investigamos a deposição química de filmes finos de cobalto sobre superfícies de lâminas de silício, tipo P (100), previamente ativadas com paládio e estudamos alguns mecanismos químicos envolvidos no processo de deposição química de filmes finos de cobalto. Os filmes de cobalto foram caracterizados quanto sua morfologia utilizando técnicas de Microscopia de Força Atômica (AFM) e Espectrometria de Retroespalhamento de Rutherford (RBS).Estudamos dois tipos de banho para deposição química: Receita 1 (2,0M $\left.\mathrm{NH}_{4} \mathrm{Cl}, 0,005 \mathrm{M} \mathrm{CoCl} 2.6 \mathrm{H}_{2} \mathrm{O}, 0,15 \mathrm{M} \mathrm{NaH} \mathrm{PO}_{2} \mathrm{H}_{2} \mathrm{O}\right)$ e Receita $2-(0,14 \mathrm{M}$ $\left.\mathrm{Na}_{3} \mathrm{C}_{6} \mathrm{H}_{5} \mathrm{O}_{7}, 0,65 \mathrm{M}\left(\mathrm{NH}_{4}\right)_{2} \mathrm{SO}_{4}, 0,19 \mathrm{M} \mathrm{CoSO}_{4} .7 \mathrm{H}_{2} \mathrm{O}, 0,28 \mathrm{M} \mathrm{NaH} \mathrm{PO}_{2} \mathrm{H}_{2} \mathrm{O}\right)$ onde o $\mathrm{pH}$ dos banhos foi variado na faixa de 3,7 a 10 através da adição de hidróxido de amônio e a temperatura, na faixa de $65^{\circ} \mathrm{C}$ a $90^{\circ} \mathrm{C}$. Nesta investigação sobre a deposição de cobalto sobre silício tipo $\mathrm{P}$ inicialmente foi observado que os sítios de paládio ficam esparsamente distribuídos sobre toda a superfície da lâmina de silício. A receita 1 não permitiu realizar deposição química sobre silício (100) tipo $\mathrm{P}$ em amplas faixas de $\mathrm{pH}$ e temperatura, com ou sem ativação das superfícies por paládio. Tal fato foi atribuído ao $\mathrm{NH}_{4} \mathrm{Cl}$ que teve o duplo papel de agente complexante e agente tamponante, fato que inviabilizou a realização da deposição química de cobalto. Por outro lado, a mudança do agente complexante para sulfato de amônio e do agente tamponante, para citrato de sódio, permitiu a realização da deposição química de cobalto em faixas de $\mathrm{pH}$ básico $(6-10)$ e temperatura $\left(65^{\circ} \mathrm{C}\right.$ a $\left.90^{\circ} \mathrm{C}\right)$. Surpreendentemente, as maiores taxas de deposição foram obtidas em temperaturas próximas à $80^{\circ} \mathrm{C} \mathrm{e}$ pH próximo a 9,0. Além disso, o aumento da concentração de paládio na superfície, apesar de aumentar a taxa de deposição de cobalto nos instantes iniciais acabou por promover processos de redistribuição de paládio ao longo dos filmes de cobalto depositado. Tal fato foi atribuído a um mecanismo químico concorrente de oxidação tanto do paládio como do cobalto. 


\section{ABSTRACT}

We have investigated in this work the electroless deposition processes of cobalt thin films on silicon wafer surfaces, (100) P type, previously activated with palladium and we have studied some chemical mechanisms by which the electroless deposition of cobalt may occur. The morphology of the cobalt thin films were characterized with the aid of atomic force microscope (AFM) and Rutherford Backscattering spectrometry (RBS). We have studied two types of baths for electroless deposition: Recipe $1\left(2.0 \mathrm{M} \mathrm{NH}{ }_{4} \mathrm{Cl}, 0.005 \mathrm{M} \mathrm{CoCl} .6 \mathrm{H}_{2} \mathrm{O}\right.$, $\left.0.15 \mathrm{M} \mathrm{NaH}{ }_{2} \mathrm{PO}_{2} \mathrm{H}_{2} \mathrm{O}\right)$ and Recipe $2-\left(0.14 \mathrm{M} \mathrm{Na}_{3} \mathrm{C}_{6} \mathrm{H}_{5} \mathrm{O}_{7}, 0.65 \mathrm{M}\left(\mathrm{NH}_{4}\right)_{2} \mathrm{SO}_{4}\right.$, $0.19 \mathrm{M} \mathrm{CoSO} \mathrm{C}_{4} .7 \mathrm{H}_{2} \mathrm{O}, 0.28 \mathrm{M} \mathrm{NaH} \mathrm{PO}_{2} \mathrm{H}_{2} \mathrm{O}$ ) where the $\mathrm{pH}$ of the baths was varied in the range of 3.7 to 10.0 by adding ammonia hydroxide and temperature, in range of $65^{\circ} \mathrm{C}$ to $90^{\circ} \mathrm{C}$. In this investigation about cobalt electroless deposition on (100) P type silicon, at first, it was observed that the palladium sites were sparsely distributed over the silicon wafer surfaces after pre-activation. Unfortunately, recipe 1 was not adequated because cobalt electroless did not occurr for all ranges of tested $\mathrm{pH}$ and temperature and with or without palladium pre-activated. This fact was attributed to the choice of $\mathrm{NH}_{4} \mathrm{Cl}$ which acts as too efficient complexing and tamponant chemical. On the other hand, the change of the complexing agent to $\left(\mathrm{NH}_{4}\right)_{2} \mathrm{SO}_{4}$ and the change of the tamponant agent to $\mathrm{Na}_{3} \mathrm{C}_{6} \mathrm{H}_{5} \mathrm{O}_{7}$ allowed one the cobalt electroless deposition for large ranges of alkaline $\mathrm{pH}(6-10)$ and temperature $\left(65^{\circ} \mathrm{C}-90^{\circ} \mathrm{C}\right)$. Surprisingly, the higher deposition rates were obtained for temperatures around $80{ }^{\circ} \mathrm{C}$ and $\mathrm{pH}$ next to 9.0. Moreover, the increase of surface palladium concentration has allowed to increase the deposition rate at the early stages of the electroless deposition but, in the following, it promoted redistributions of palladium from the $\mathrm{Co} / \mathrm{Si}$ interface to the Co body and oxygen incorporation in the Co film together progressive decrease of the Co-film thickness. This observation was attributed to a palladium and cobalt-oxidation mechanism. 


\section{LISTA DE FIGURAS}

Figura 2.1-1- Processo de pulverização catódica (Sputtering) (Campbell, 2001) __ 18

Figura 2.1-2- Desenho esquemático do equipamento pulverização catódica (Campbell, 2001)__ 18

Figura 2.2-1- Desenho esquemático de uma evaporadora.___ 20

Figura 3.1-1 - Deposição sobre superfície condutora não catalítica, considerando os mecanismos

químicos: a) Com transferência do átomo de hidrogênio; b) Com transferência do hidreto; c) Com

Níquel hidrolisado(HWANG et al., 1995).

Figura 3.1-2-Mecanismo eletroquímico sobre superfície condutora não catalítica, pré-ativada com paládio(HWANG et al., 1995).

Figura 3.2-1- Esquema da curva de potencial versus corrente para o eletrodo de potencial misto onde a curva 2 é a corrente total; a curva 1 é a corrente anódica; e a curva 3 é a corrente catódica (OHNO, 1991).

Figura 3.3-1-Curva de polarização para oxidação anódica do $\mathrm{H}_{2} \mathrm{CO}$ (HCHO - Formaldeído) para

diferentes metais. A linha pontilhada refere-se à densidade corrente atribuída a dissolução anódica dos eletrodos de Cu e Co. (0,1 M HCHO, 0,175 M EDTA 2Na, pH=12,5 e temperatura de $\left.25^{\circ} \mathrm{C}\right)(\mathrm{OHNO}, 1991)$.

Figura 3.3-2- Curva de polarização para oxidação anódica do hipofosfito para diferentes metais. $A$ linha pontilhada refere-se à densidade corrente atribuída a dissolução anódica dos eletrodos de $\mathrm{Ag}$ e $\mathrm{Cu}$. (0,2 $\mathrm{M} \mathrm{NaH}_{2} \mathrm{PO}_{2}, 0,2 \mathrm{M}$ Citrato de Sódio , 0,5 $\mathrm{M} \mathrm{H}_{3} \mathrm{BO}_{3}, \mathrm{pH}=9,0$ e temperatura de $\left.70^{\circ} \mathrm{C}\right)(\mathrm{OHNO}$, 1991).

Figura 3.3-3 - Atividades catalíticas (os potenciais obtidos em $0,1 \mathrm{~mA} \mathrm{~cm}^{2}$ ) para oxidação anódica de diferentes agentes redutores, onde $E_{r}$ são os potenciais de oxidação-redução dos agentes redutores e $\mathrm{H}_{2}$ são os potenciais reversão do Hidrogênio. (a) 0,2 $\mathrm{M} \mathrm{NaH}_{2} \mathrm{PO}_{2}, 0,2 \mathrm{M}$ Citrato de Sódio, 0,5 M $\mathrm{H}_{3} \mathrm{BO}_{3}, \mathrm{pH}=9,0$ e temperatura de $70^{\circ} \mathrm{C}$; (b) 0,1 $\mathrm{M} \mathrm{HCHO}, 0,175 \mathrm{M}$ EDTA 2Na, $\mathrm{pH}=12,5$ e temperatura de $25^{\circ} \mathrm{C}$; (c) 0,03 $\mathrm{M} \mathrm{NaBH}_{4}, 0,175 \mathrm{M}$ EDTA $2 \mathrm{Na}, \mathrm{pH}=12,5$ e temperatura de $25^{\circ} \mathrm{C}$; (d) 2,0g DMAB dm ${ }^{3}$, 0,2 M Citrato de Sódio, 0,5 $\mathrm{M} \mathrm{H}_{3} \mathrm{BO}_{3}, \mathrm{pH}=7,0$ e temperatura de $25^{\circ} \mathrm{C}$; (e) 0,1 $\mathrm{M} \mathrm{N}_{2} \mathrm{H}_{4}, 0,175 \mathrm{M}$ EDTA 2Na, $\mathrm{pH}=12,0$ e temperatura de $25^{\circ} \mathrm{C}$; (OHNO, 1991). 34 Figura 3.5-1 - Gráfico logaritmo do (i $\left.i_{m(O 2)}\right)$ versus $t$ para diferentes valores do raio do eletrodo de micro disco (ALKIRE,2001).

Figura 4.2-1- Espectro de RBS típico de um filme de cobalto sobre Silício ativado por Paládio. __ 49

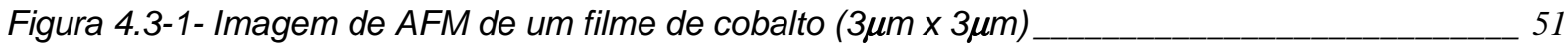

Figura 4.3-2- Imagem AFM de um filme de cobalto mas em uma área de $1 \mu \mathrm{m} \times 1 \mu \mathrm{m}$. em 3D_ 51 Figura 4.4-1 - Concentração de partículas na superfície das lâminas de silício. (ANTTILA et al., 1992).

Figura 4.4-2 - Concentração metálica nas soluções SPM-APM-DHF-HPM (ANTTILA et al., 1992) __ 53 Figura 4.5-1-Gráfico do desvio médio quadrático das alturas ou largura de superfície w(l,t) (HUO \& SCHWARZACHER,2001) Ic é função do tempo de deposição.

Figura 4.5-2- Gráfico do desvio médio quadrático das alturas ou largura de superfície $w(l, t)$ ilustrando o escalamento do tipo normal (HUO \& SCHWARZACHER,2001)

Figura 4.5-3- Gráfico do desvio médio quadrático das alturas ou largura de superfície w(l,t) ilustrando escalamento do tipo anômalo (HUO \& SCHWARZACHER,2001)

Figura 5.6-1 - Representação esquemática do sistema de deposição de cobalto.

Figura 6.1-1 - Espectro de RBS típico; amostra Co2 (receita1: 0,005 M CoCl $+0,15 \mathrm{M} \mathrm{NaH}_{2} \mathrm{PO}_{2}$. $\mathrm{H}_{2} \mathrm{O}$

$+2,0 \mathrm{M} \mathrm{NH}_{4} \mathrm{Cl}, 30 \mathrm{~min}$. à $65^{\circ} \mathrm{C}, \mathrm{pH}=3,7, \mathrm{~T}=22^{\circ} \mathrm{C}$ ).

Figura 6.1-2-Espectro RBS da amostra CuCo1. (receita 0,005 $\mathrm{M} \mathrm{CoCl}_{2}+0,15 \mathrm{M} \mathrm{NaH}_{2} \mathrm{PO}_{2} . \mathrm{H}_{2} \mathrm{O}+2,0$

$\mathrm{M} \mathrm{NH}_{4} \mathrm{Cl}, 4 \mathrm{~min}, \mathrm{pH}=8,2$ e temperatura de aproximadamente $65^{\circ} \mathrm{C}$ ).

Figura 6.1-3-Espectros RBS em escala Log sobrepostos para as amostras Co5 e Co6.____ 73

Figura 6.1-4 - Espectros RBS das amostras Co7 e Co8.__ 74

Figura 6.1-5 - Imagens AFM típicos das amostras Co7 e Co8.

Figura 6.1-6 - Espectro RBS da amostra Co9 (receita 0,19M de CoSO $\mathrm{CH}_{4} \mathrm{O}, 0,28 \mathrm{M}$ de $\mathrm{NaH}_{2} \mathrm{PO}_{2}$.

$\mathrm{H}_{2} \mathrm{O}, 0,14 \mathrm{M}$ de $\mathrm{Na}_{3} \mathrm{C}_{6} \mathrm{H}_{5} \mathrm{O}_{7} . \mathrm{H}_{2} \mathrm{O}, 0,65 \mathrm{M}$ de $\left(\mathrm{NH}_{4}\right)_{2} \mathrm{SO}_{4}$ e $200 \mathrm{ml}$ de $\mathrm{NH}_{4} \mathrm{OH}, 5 \mathrm{~min}, \mathrm{pH}=8,7 \mathrm{e}$ temperatura de $90^{\circ} \mathrm{C}$ ).

Figura 6.1-7 - Espectros RBS das amostras Co10, Co11, Co12 sobrepostos.

Figura 6.1-8 - Imagens AFM (6x6 $\left.\mathrm{m}^{2}\right)$ das amostras: (a) amostra Co10(30s), (b) amostra Co11(1 min) e (d) amostra Co12 (3 min).

Figura 6.1-9 Fotos SEM típicas de superfícies polidas de silício pré-ativadas com solução 0,0005M de

$\mathrm{PdCl}_{2}$ em dHF (40 $\left.\mathrm{H}_{2} \mathrm{O}: 1 \mathrm{HF}(49 \%)\right)$ por: a) $15 \mathrm{~s}$; b) 30s (MARQUES,2003). 
Figura 6.1-10 - Espectros RBS das amostras Co120, Co130, Co140, Co150 e Co160, com tempos de deposição de 20s, 30s, 60s, 120s, e 180s, respectivamente. Foi empregada a receita 2 na temperatura de $80^{\circ} \mathrm{C}$ e $\mathrm{pH}$ variando de 9,4 a 9,8 durante as deposições.

Figura 6.1-11 - Rugosidade RMS em função do tempo de deposição das amostras Co120, Co130, Co140, Co150 e Co160.Utilizando a receita $2\left(\mathrm{Na}_{3} \mathrm{C}_{6} \mathrm{H}_{5} \mathrm{O}_{7} . \mathrm{H}_{2} \mathrm{O}\right.$-(citrato de sódio) 0,14M, $\left(\mathrm{NH}_{4}\right)_{2} \mathrm{SO}_{4}$ $-0,65 \mathrm{M}, \mathrm{CoSO}_{4} .7 \mathrm{H}_{2} \mathrm{O}-0,19 \mathrm{M}, \mathrm{NaH}_{2} \mathrm{PO}_{2} . \mathrm{H}_{2} \mathrm{O}-0,28 \mathrm{M}$, na temperatura de $80^{\circ} \mathrm{C}$ e $\left.\mathrm{pH}=9,4-9,8\right)$.

Figura 6.1-12 - Imagens AFM (1x1 $\left.\mathrm{m}^{2}\right)$ típicos das amostras: (a) Co120-20 s, (b) Co130-30 s, (c) Co140-60 s, (d) Co150 - 120 s e (e) Co150 - $180 \mathrm{~s}$.

Figura 6.1-13 - Largura de superfície $(w(I, t))$ em função do comprimento de escala e do tempo de deposição para a receita $2 \mathrm{em} t=80^{\circ} \mathrm{C}$ e $\mathrm{pH}=\sim 9,4-9,8$ para amostras Co130, Co140 e Co150. _ 82 Figura 6.1-14 -- Espectros RBS das Amostras Co200, Co210, Co220, Co230, Co240, Co250 e Co260 com tempos de deposição de 1, 2, 3, 4 e 5 min na receita 2 com Pd de 0,5 min.

Figura 6.1-15- Gráfico da concentração planar em função do tempo das amostras Co200, Co210,

Co220, Co230, Co240, Co250 e Co260 e receita $2 a \mathrm{Na}_{3} \mathrm{C}_{6} \mathrm{H}_{5} \mathrm{O}_{7} . \mathrm{H}_{2} \mathrm{O}$-(citrato de sódio) 0,14M , $\left(\mathrm{NH}_{4}\right)_{2} \mathrm{SO}_{4}-0,65 \mathrm{M}, \mathrm{CoSO}_{4} .7 \mathrm{H}_{2} \mathrm{O}-0,19 \mathrm{M}, \mathrm{NaH}_{2} \mathrm{PO}_{2} . \mathrm{H}_{2} \mathrm{O}-0,28 \mathrm{M}, 300 \mathrm{ml}$ hidróxido de amônia (38\%) em $400 \mathrm{ml}$ de água)

Figura 6.1-16- Rugosidade RMS em função do tempo de deposição: amostras Co200, Co210, Co220, Co230, Co240, Co250 e Co260 receita $2 \mathrm{a}\left(\mathrm{Na}_{3} \mathrm{C}_{6} \mathrm{H}_{5} \mathrm{O}_{7} . \mathrm{H}_{2} \mathrm{O}\right.$-(citrato de sódio) 0,14M, $\left(\mathrm{NH}_{4}\right)_{2} \mathrm{SO}_{4}-$ $0,65 \mathrm{M}, \mathrm{CoSO}_{4} .7 \mathrm{H}_{2} \mathrm{O}-0,19 \mathrm{M}, \mathrm{NaH}_{2} \mathrm{PO}_{2} . \mathrm{H}_{2} \mathrm{O}-0,28 \mathrm{M}, 300 \mathrm{ml}$ hidróxido de amônia (38\%) em 400ml de água)

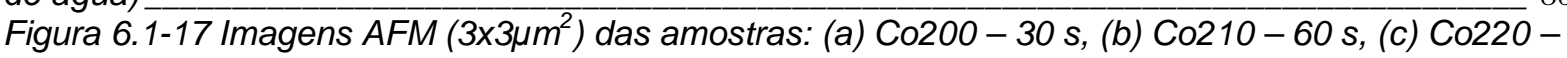
$120 \mathrm{~s}$, (d) Co230-180 s, (e) Co240-240 s (f) Co250-300 se (g) Co260 - $360 \mathrm{~s}$. 87 Figura 6.1-18 - Largura de superfície em função do comprimento de escala e do tempo de deposição para receita 2 a $80^{\circ} \mathrm{C}$ e pH 9,4, para as amostra Co220, Co230 e Co240. 88 Figura 6.1-19 - Largura de superfície em função do comprimento de escala e do tempo de deposição para receita 2 a $80^{\circ} \mathrm{C}$ e $\mathrm{pH} \sim 9,4$, para as amostra Co240, Co250. 


\section{LISTA DE TABELA}

Tabela 3.1-1 - Mecanismos de reação de deposição eletroquímica (HWANG et al., 1995).....

Tabela 3.3-1- Potenciais $E^{*}$ a $0,1 \mathrm{~mA} \mathrm{~cm}^{2}$, energia de ativação $E_{a}$ e fator log $i^{*}$ para oxidação anódica

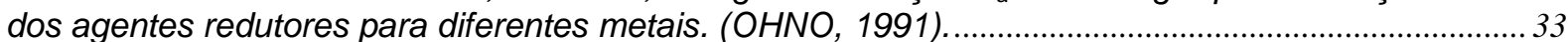

Tabela 3.5-1-Solução de deposição de Co e ligas de Co/Ni (MALLORY et al., 1990)............................ 38 Tabela 3.5-2 - Solução de deposição de Co para Borohidreto de Sódio como agente redutor (MALLORY et al., 1990)

Tabela 3.5-3- Solução de deposição de Co para DMAB como agente redutor (MALLORY et al., 1990)

Tabela 3.5-4 -Solução de deposição de Co contendo DMAB como agente redutor e estabilizadores (MALLORY et al., 1990)

Tabela 3.5-5 - Solução de deposição de Co contendo DMAB como agente redutor e Hipofosfito

(MALLORY et al., 1990)

Tabela 3.5-6- Solução de deposição de Co para Formaldeído como agente redutor (MALLORY et al. 1990).

Tabela 5.7-1- Síntese das amostras fabricadas.

Tabela 6.1-1-Resultados dos espectros de RBS para as amostras Co7, Co8 e Co9

Tabela 6.1-2 - Resultados dos espectros de RBS para as amostras Co10, Col1 e Col2.....

Tabela 6.1-3 - Resultados dos espectros de RBS e AFM para as amostras Co120, Co130, Co 140, Co 150 e Co 160 .

Tabela 6.1-4- Resultados dos espectros de RBS e AFM para as amostras Co200, Co210, Co220,

Co230, Co240, Co250 e Co 260 


\section{LISTA DE ABREVIATURAS}

AFM Atomic Force Microscopy (Microscopia de Força Atômica)

APM Ammonium Peroxide Mixture

Cat Catalisado

Cl's Circuitos Integrados

DC "Direct current” corrente contínua

DHF Diluted Hydrofluoric Solution

DMA Dimetilâmina Borana

EDT "Ethylene Diamine Tetraacetic Acid" (ácido etilenodiamino A tetracético)

GSI Giga Scale Integration

HF Hydrofluoric Acid (Solution)

HPM Hydrofluoric Peroxide Mixture

MOI 5-Metil-2-Oxazolidinona

MOS Metal-Óxido-Semicondutor

Ox Agente Oxidante

RBS Rutherford Backscattering Spectrometry (espectrometria de retroespalhamento de Rutherford)

Red Agente Redutor

RF Radio Freqüência

RHE Eletrodo de hidrogênio reversível

RMS "Root Mean Square" (Valor médio quadrático)

SC-1 Standard Cleaning 1

SC-2 Standard Cleaning 2

SPM Sulfur Peroxide Mixture

UHP Ultra High Pure

VLSI Very Large Scale Integration

XRD X - Ray Diffraction (Difração de Raios X) 


\section{LISTA DE SÍMBOLOS}

\begin{tabular}{ll}
$\mathrm{A}$ & Ampéres \\
$\left(\varepsilon_{\mathrm{in}}\right)$ & Seção de choque de freamento durante a entrada \\
$\left(\varepsilon_{\text {out }}\right)$ & Seção de choque de freamento durante a saída \\
{$[\varepsilon]$} & Fator de freamento \\
$\Delta \mathrm{S}_{\text {sist }}$ & Variação da entropia do sistema \\
$3 \mathrm{D}$ & Três dimensões \\
$\mathrm{A}_{\mathrm{CoR}}$ & Área total sob o sinal de cobalto de um filme espesso de \\
$\beta$ & referência, \\
$\beta_{\text {local }}$ & Expoente de crescimento temporal \\
$\mathrm{d}_{\mathrm{Co}}$ & Densidade atômica do cobalto \\
$\mathrm{D}_{\mathrm{Co}}$ & Densidade do cobalto \\
$\Delta \mathrm{E}$ & Variação de Energia \\
$\Delta \mathrm{G}$ & Energia livre de Gibbs \\
$\Delta \mathrm{Q}_{\mathrm{sist}}$ & Troca de calor entre o sistema e sua vizinhança \\
$\Delta \mathrm{X}$ & Variação de posição \\
$\Delta \mathrm{Y}_{\mathrm{i}}$ & Enésimo deslocamento generalizado \\
$\mathrm{e}^{-}$ & Carga do elétron \\
$\mathrm{E}^{*}$ & Potencial para oxidação anódica dos agentes redutores \\
$\mathrm{E}_{0}$ & Energia do feixe incidente \\
$\mathrm{e}_{1}$ & Carga eletrônica \\
$\mathrm{E}_{\mathrm{a}}$ & Energia de ativação \\
$\mathrm{E}_{\mathrm{im}}$ & Potencial de imersão \\
$\mathrm{E}_{\mathrm{oc}}$ & Potencial de circuito aberto \\
$\mathrm{E}_{\mathrm{pl}}$ & Potencial misto \\
$\mathrm{E}_{\mathrm{pm}}$ & Potencial misto de estado estacionário \\
$\mathrm{E}_{\mathrm{r}}$ & Potenciais de oxiredução dos agentes redutores \\
$\mathrm{F}_{\mathrm{gi}}$ & Enésima força generalizada \\
$\mathrm{H}$ & expoente de Hurst \\
$\mathrm{i}$ & Corrente \\
$\mathrm{i}_{\mathrm{a}}$ & Corrente anódica \\
$\mathrm{i}_{\mathrm{c}}$ & Corrente catódica \\
$\mathrm{I}_{\mathrm{m}}\left(\mathrm{O}_{2}\right)$ & Corrente de eletro-redução do $\mathrm{O}_{2}$ \\
$\mathrm{i}_{\mathrm{n}}$ & Corrente total \\
$\mathrm{i}_{\mathrm{pl}}$ & Corrente de deposição \\
$\mathrm{K}_{\mathrm{M}}$ & Fator cinemático \\
$l$ & Comprimento de escala \\
$\mathrm{L}$ & Ligante \\
& \\
\hline
\end{tabular}




\begin{tabular}{|c|c|}
\hline$l_{c}$ & Comprimento de escala crítico \\
\hline M & Metal \\
\hline$M_{1}$ & Massa atômica da partícula do material a ser analisado \\
\hline$M_{2}$ & Massa atômica da partícula incidente \\
\hline $\mathrm{M}_{\mathrm{Co}}$ & Massa atômica do cobalto \\
\hline$M^{\circ}$ & Metal em estado de oxidação igual a zero \\
\hline $\mathrm{N}$ & Número de elétrons trocados em um processo de oxirredução \\
\hline $\mathrm{N}$ & Número de pontos contidos na área analisada \\
\hline$N_{\text {avg }}$ & Número de Avogadro \\
\hline $\mathrm{N}_{\mathrm{d}}$ & Concentração planar total de átomos \\
\hline $\mathrm{N}_{\mathrm{dR}}$ & $\begin{array}{l}\text { Concentração planar total de cobalto do filme espesso de } \\
\text { referência }\end{array}$ \\
\hline $\mathrm{N}_{\mathrm{v}}$ & Densidade volumétrica de átomos no alvo \\
\hline $\mathrm{pH}$ & Logaritmo do inverso da concentração \\
\hline $\mathrm{Q}_{\mathrm{Co}}$ & Carga total integrada na análise RBS \\
\hline$Q_{\text {CoR }}$ & $\begin{array}{l}\text { Carga total integrada na análise RBS para o filme de cobalto } \\
\text { espesso de referência }\end{array}$ \\
\hline $\mathrm{R}_{\mathrm{m}}$ & Rugosidade média \\
\hline $\mathrm{R}_{\mathrm{v}-\mathrm{p}}$ & Rugosidade vale-pico \\
\hline $\mathrm{T}$ & Tempo \\
\hline$t_{C o}$ & Espessura de cobalto \\
\hline $\mathrm{T}_{\mathrm{viz}}$ & Temperatura da vizinhança \\
\hline $\mathrm{W}(\mathrm{l}, \mathrm{t})$ & $\begin{array}{l}\text { Desvio médio quadrático das alturas conhecido como largura } \\
\text { de superfície associado ao comprimento de escala " } l \text { " no } \\
\text { instante "t" }\end{array}$ \\
\hline Z & Altura média \\
\hline $\bar{z}$ & Média das alturas \\
\hline $\mathrm{Z}_{1}$ & Número atômico da partícula incidente \\
\hline $\mathrm{Z}_{2}$ & Número atômico da partícula do alvo (amostra) \\
\hline $\mathrm{z}_{\mathrm{c}}$ & $\begin{array}{l}\text { Expoente dinâmico conhecido como escalamento dinâmico de } \\
\text { Family-Vicsek }\end{array}$ \\
\hline$Z_{\max }$ & Altura máxima \\
\hline$Z_{\min }$ & Altura mínima \\
\hline$Z_{n}$ & Altura em relação a uma referência de nível inferior mínimo \\
\hline$\theta_{\mathrm{e}}$ & Ângulo de espalhamento \\
\hline$\theta_{s}$ & Ângulo de espalhamento após a colisão \\
\hline$\sigma_{\text {choque }}$ & Seção de choque diferencial \\
\hline & Feixe de partículas alfa \\
\hline
\end{tabular}


Sumário

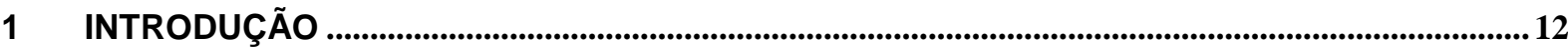

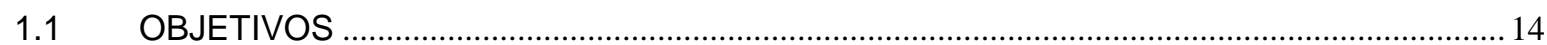

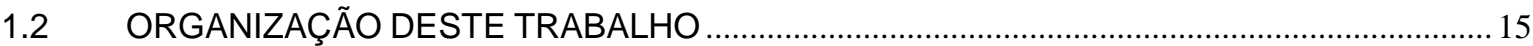

2 TÉCNICAS DE DEPOSIÇÃO DE FILMES FINOS............................................................................ 17

2.1 DEPOSIÇÃO POR PULVERIZAÇÃO CATÓDICA (SPUTTERING) ….................................... 17

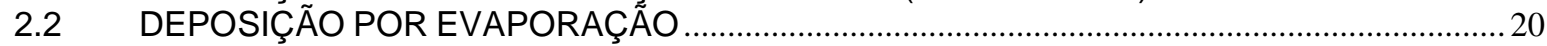

3 DEPOSIÇÃO QUÍMICA ............................................................................................................................... 22

3.1 MECANISMOS DE DEPOSIÇÃO QUÍMICA ……..................................................................2 23

3.2 TEORIA DO POTENCIAL MISTO (OHNO, 1991; ALKIRE ET AL. 2001; HUO, 2001) ............28

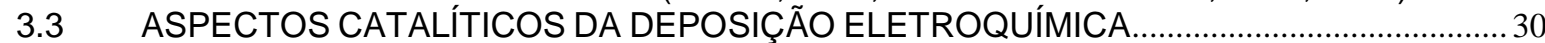

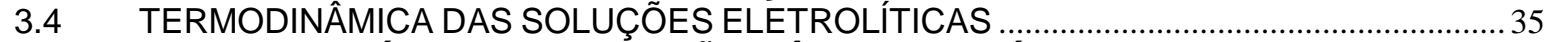

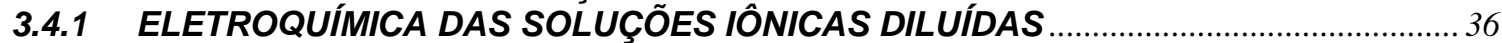

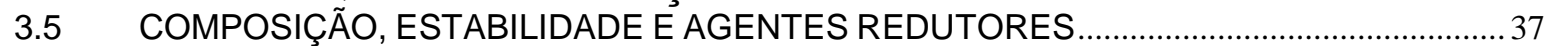

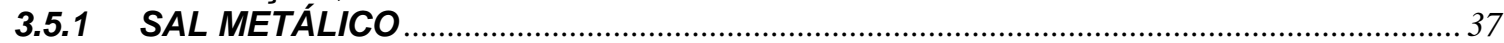

3.5.2 AGENTES REDUTORES

3.5.2.1 HIDRAZINA (MALLORY ET AL., 1990) ......................................................................... 38

3.5.2.2 BOROHIDRETO DE SÓDIO (MALLORY ET AL., 1990)........................................................38

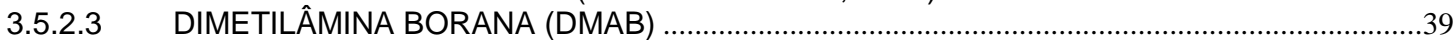

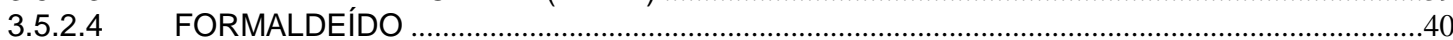

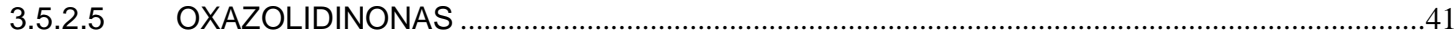

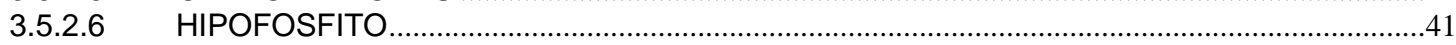

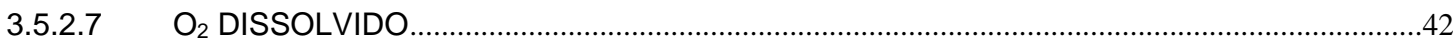

4 TÉCNICAS DE ANÁLISE DE SUPERFÍCIES DE LÂMINAS DE SILÍCIO.......................................45

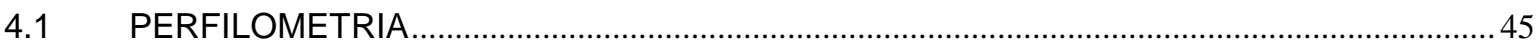

4.2 RBS (ESPECTROSCOPIA DE RETROESPALHAMENTO DE RUTHERFORD) …..............46

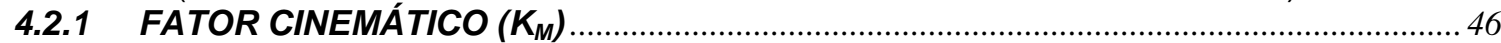

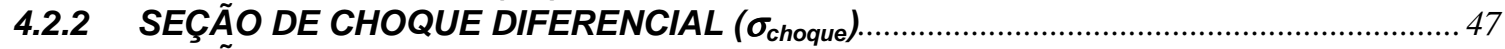

4.2.3 SEÇÃO DE CHOQUE DE FREAMENTO, PERDA DE ENERGIA E FATOR DE

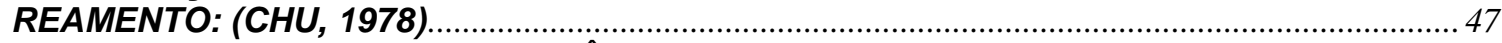

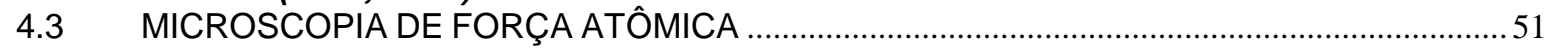

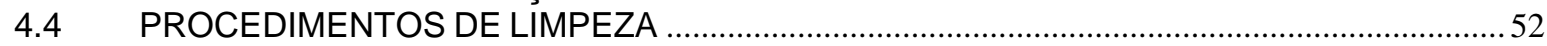

4.5 ESTUDO DA EVOLUÇÃO DA RUGOSIDADE NO CRESCIMENTO DE FILMES FINOS ....54

4.5.1 - PARÂMETROS PARA A QUANTIFICAÇÃO DE RUGOSIDADE (HUO, 2001) ........... 54

4.5.2 - ESTUDO DO ESCALAMENTO DINÂMICO DA RUGOSIDADE DE SUPERFÍCIE..... 56

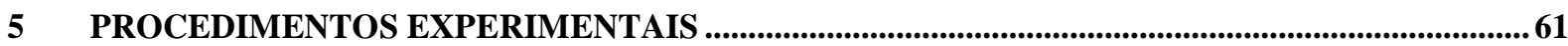

5.1 PREPARAÇÃO DO SUBSTRATO UTILIZADO PARA DEPOSIÇÃO DO FILME ....................61

5.1.1 TIPO DE SUBSTRATO

5.1.2 PREPARAÇÃO DO SUBSTRATO

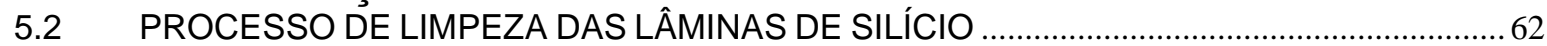

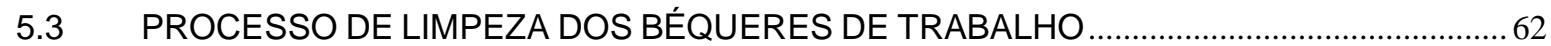

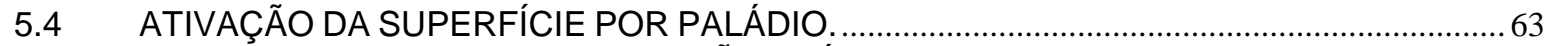

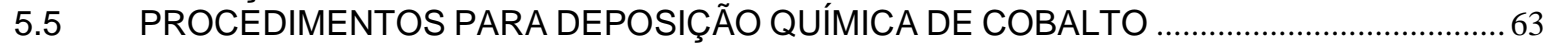

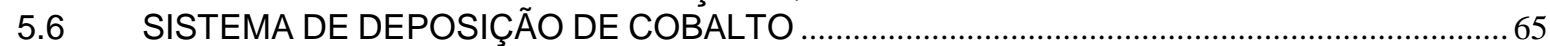

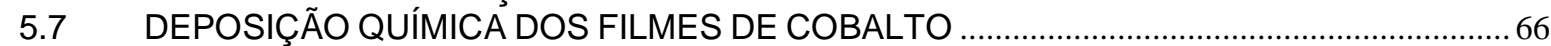

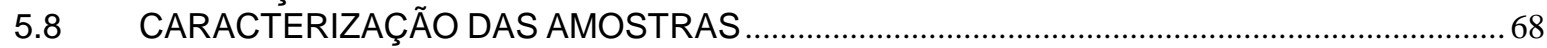

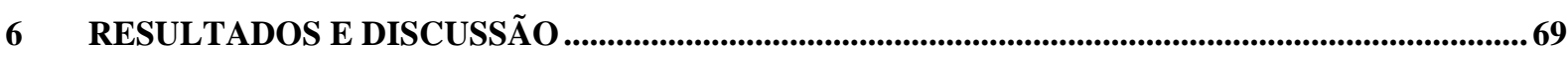

6.1 DEPOSIÇÃO QUÍMICA DE COBALTO

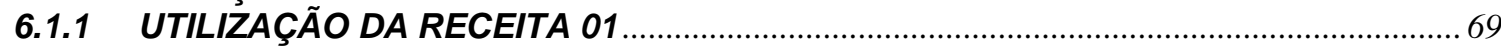

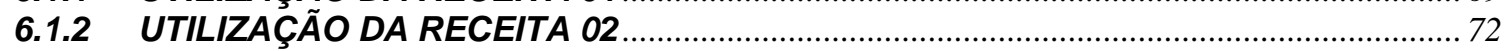

7 CONCLUSÕES E PERSPECTIVAS FUTURAS ............................................................................... 89

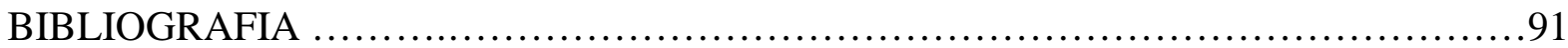




\section{INTRODUÇÃO}

Os avanços da tecnologia de fabricação de circuitos integrados MOS e o surgimento de novas tecnologias nas áreas de dispositivos eletrônicos têm despertado pesquisas em diversas áreas incluindo a de novos materiais com características compatíveis com os processos de microeletrônica. Com isto, surge a preocupação de se encontrar métodos mais eficientes e mais baratos na obtenção de filmes finos metálicos compatíveis com as etapas de fabricação em microeletrônica.

Por outro lado, existe um aumento crescente do estudo de obtenção de filmes finos por deposição química (SANTOS, 1996, ALKIRE, 2001, NARAYANAN, 2003, VASKELIS, 2006, RUDNIK, 2007, DADVAND, 2007). Por exemplo, a deposição de filmes finos de cobre pode ocorrer em uma solução de limpeza química, na etapa final de imersão em solução diluída de ácido fluorídrico (HF) (SANTOS FILHO,1996). Observa-se na literatura que se existir contaminação residual de íons de cobre em solução diluída de HF, ocorrerá à deposição química de cobre sobre as lâminas de silício através de reações de deslocamento. Por intermédio dos mecanismos de deposição química espontânea, o processo para a realização da deposição seletiva na fabricação de Cl's pode também ser empregado (TING, 1989a, 1989b; SHACHAM-DIAMAND, 2007; RUDNIK, 2007; OSAKA, 2002, 2007).

Instituições como IBM Corp. e a Motorola Inc utilizam filmes finos de cobre eletrodepositados para fabricar linhas de interconexão em Cl's desde 1998 (ANDRICACOS et al 1998,1999 e ; O'SULLIVAN et al.,1998; DUHIN,2007). Com isto, estas empresas conseguiram que seus microprocessadores passassem a ter melhor desempenho pelo fato do cobre apresentar características elétricas melhores do que o alumínio que era empregado anteriormente (KIM et al JAGANNATHAN et al.,1993; GAUDIELLO et al.,1993; ANDRICACOS 1998). 
Um outro filme de grande interesse e que pode ser obtido através da técnica de deposição química é a liga binária cobalto-fósforo. Esta liga tem boas características magnéticas e também é muito empregada como cobertura de proteção em superfícies de cobre (MALLORY et al., 1990). Ligas como CoO tem sido estudada por apresentar características anti-ferromagnética além de características elétricas interessantes no campo de contatos elétricos bem como em células de energia solar (ENTANI,2004; EZE,1998). Ligas ternárias com excelentes características magnéticas (CowP, CoNiP, CoFeP e CoZnP) têm sido empregadas como barreiras, coberturas para proteção mecânica, química, promotoras de aderência, dentre outras aplicações (MALLORY et al., 1990 e DULAL,2007). Portanto, baseado na literatura, pode-se afirmar que os processos de deposição química de filmes finos estão sendo hoje cada vez mais estudados e pesquisados.

No entanto, apesar das diversas pesquisas existentes, nenhum estudo sobre deposição química (electroless) de cobalto sobre silício foi feito até o presente momento. Aplicações importantes associadas ao cobalto sobre silício incluem fabricação de junções tipo Schottky (AHMETOGLU,2007) e base metálica de transistores bipolares (DELATORRE,2006) no âmbito da spintrônica. 


\subsection{OBJETIVOS}

Dada a importância do processo de deposição química de cobalto sobre silício, os nossos objetivos específicos foram:

- Estudo da deposição de filmes finos de cobalto por meio de diferentes soluções de deposição química utilizando hipofosfito de sódio como agente redutor.

- Estudo do modelo de deposição autocatalítica (electroless) do filme fino de cobalto sobre as superfícies de silício tipo $\mathrm{P}$ pré-ativadas com paládio.

- Análise da morfologia e da rugosidade dos filmes de cobalto obtidos por deposição química sobre silício. 


\subsection{ORGANIZAÇÃO DESTE TRABALHO}

Neste primeiro capítulo apresentamos até o presente momento a introdução e objetivos. Os capítulos seguintes estão organizados como segue.

\section{Capitulo 2. Técnicas de Deposição de filmes finos}

Neste capitulo apresentaremos uma rápida revisão bibliográfica sobre as técnicas de deposição de filmes finos por pulverização catódica (Sputtering) e Evaporação.

\section{Capitulo 3. Deposição Química}

Neste capítulo serão abordados os mecanismos de deposição química de filmes finos incluindo os modelos atualmente propostos para a deposição química de filmes metálicos sobre superfícies catalíticas.

\section{Capitulo 4. Técnicas de Análise de superfícies de lâminas de Silício}

Serão apresentadas as técnicas de AFM e RBS para caracterização de superfícies bem como uma descrição de ambas as análises. Abordaremos também a análise do escalamento dinâmico da rugosidade das superfícies dos filmes finos visando quantificar a dependência da rugosidade RMS com o tempo de deposição e determinar o tipo de escalamento. 


\section{Capitulo 5. Procedimentos Experimentais}

Serão mostrados, neste capítulo, os procedimentos empregados para obtenção de filmes finos de cobalto (receitas de deposição) bem como os procedimentos de análise.

\section{Capitulo 6. Resultados e Discussão}

Neste capítulo serão apresentados os resultados das deposições químicas de cobalto analisadas por RBS e AFM. Apresentaremos também uma discussão detalhada desses resultados.

\section{Capitulo 7. Conclusões e perspectivas futuras}

Serão apresentadas neste capítulo as principais conclusões sobre as deposições químicas de filmes finos de cobalto. Também, serão apresentadas as perspectivas para futuros trabalhos sobre a deposição de filmes finos. 


\section{TÉCNICAS DE DEPOSIÇÃO DE FILMES FINOS}

Atualmente, existem várias técnicas de deposição de filmes finos as quais são de grande importância na fabricação dos diversos dispositivos e nas diversas tecnologias de microeletrônica. Normalmente, o que se busca no estudo e na implementação destas técnicas é atingir melhores características tais como: melhor uniformidade, boa reprodutividade, alta adesão, alta taxa de deposição, baixa rugosidade e baixo custo (SANTOS FILHO, 1996). Portanto, tem-se feito um grande esforço na área de microeletrônica para se obter o melhor compromisso possível de forma a satisfazer o critério de máxima qualidade. Dentre as técnicas de deposição existentes, neste capítulo abordaremos as técnicas de deposição por pulverização catódica (Sputtering), evaporação, e finalmente, falaremos sobre a deposição eletroquímica espontânea, ilustrando de maneira simplificada como o processo de deposição química tende a ser mais simples e de baixo custo, por não se utilizar vácuo ou estruturas mais sofisticadas produzindo filmes finos de boa qualidade.

\subsection{DEPOSIÇÃO POR PULVERIZAÇÃO CATÓDICA (SPUTTERING)}

A técnica de pulverização catódica (sputtering) foi desenvolvida a mais de 130 anos atrás por W.R.Grove (SCHUEGRAFT,1988) e consiste basicamente na ejeção dos átomos ou moléculas da superfície de um material chamado de "alvo" por meio de uma incidência de partículas de alta energia, que transferem "momentum" para estes átomos de superfície (Figura 2.1-1). Os átomos da superfície do alvo, após terem sido arrancados, caminham até atingir uma superfície desejada aonde irão se depositar. Este processo deve ser realizado dentro de uma câmara em vácuo (Figura 2.1-2). 


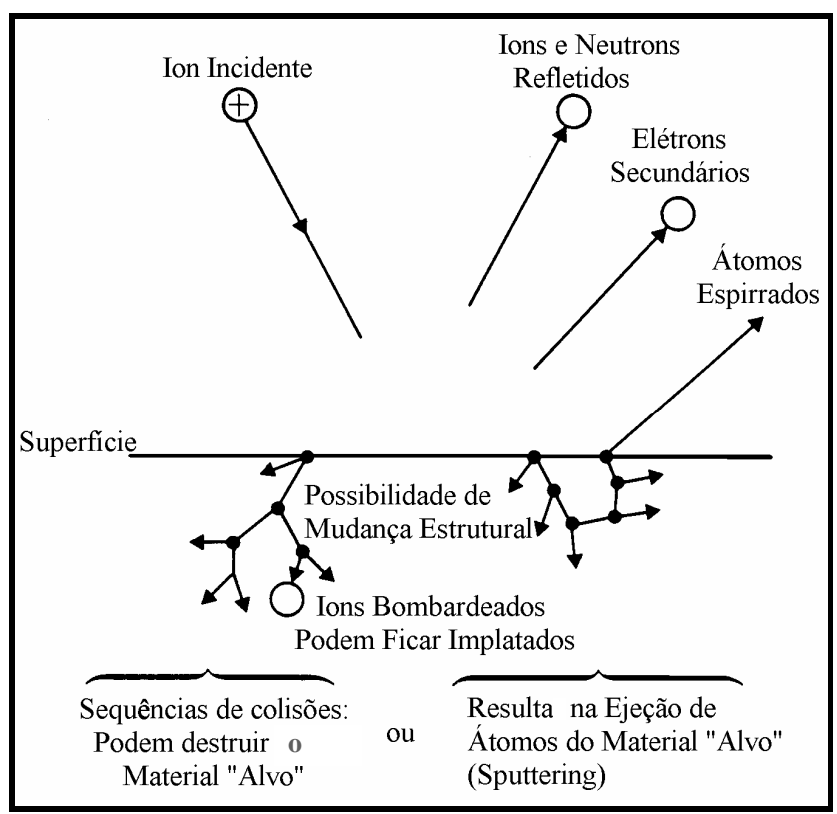

Figura 2.1-1- Processo de pulverização catódica (Sputtering) (Campbell, 2001)

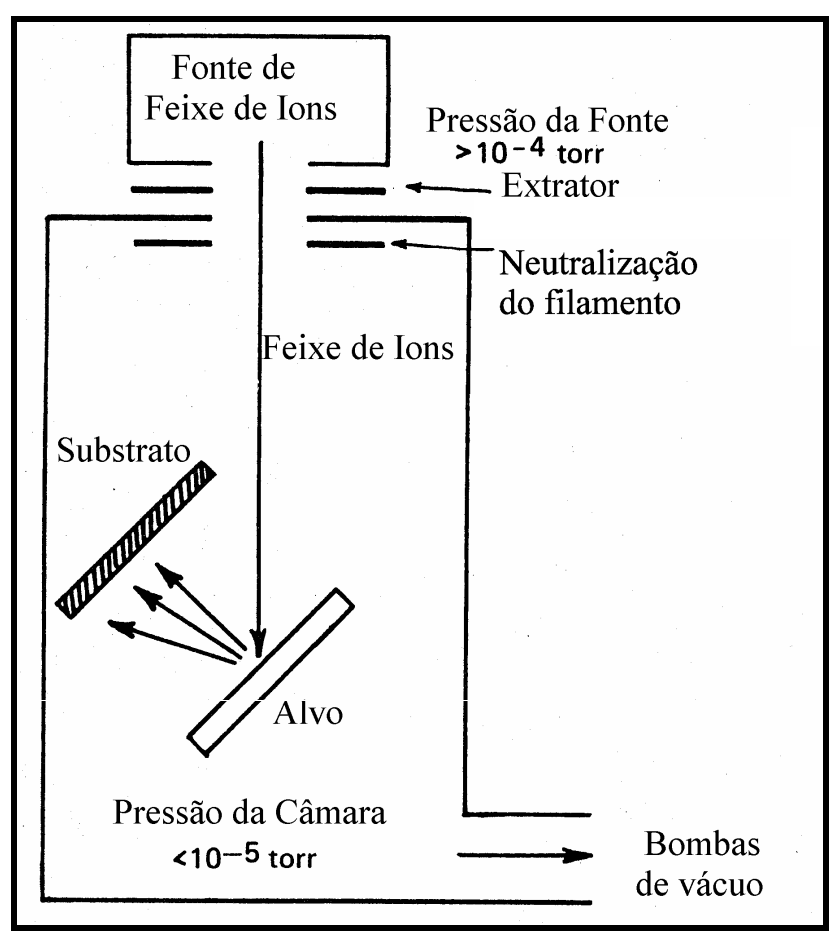

Figura 2.1-2- Desenho esquemático do equipamento pulverização catódica (Campbell, 2001) 
As partículas de alta energia normalmente são geradas dentro de um plasma em condições de pressão e regime elétrico específicos. Este plasma é composto por elétrons e íons positivos, em igual número, sendo então estes íons positivos as partículas de alta energia que irão incidir sobre a superfície do material "alvo" (Figura 2.1-2).

Existem dois processos básicos de deposição por pulverização catódica: DC ou RF sendo que a diferença de um processo para o outro, é o tipo de tensão aplicada entre os eletrodos (DC: corrente contínua ou RF: rádio freqüência).

As vantagens que se tem em optar por fazer uma deposição por pulverização catódica são: a possibilidade de se fazer limpeza "in-situ" da superfície antes de depositar qualquer filme, obtenção de filmes finos de espessuras atômicas, controle da topografia ou da rugosidade da superfície, entre outros.

Por estas e outras vantagens muitos autores tem estudado os filmes finos obtidos por pulverização catódica, como é o caso de Adams et. al. (ADAMS, 1995) que estudaram filmes muito finos (espessura menor que $80 \mathrm{~nm}$ ) de molibdênio obtido via Magnetron ${ }^{1}$ sobre silício com óxido nativo.

Eles observaram uma tensão mecânica de compressão da ordem de $10^{10}$ dinas $/ \mathrm{cm}^{2}$ a qual com o aumento da espessura relaxava e até passava para estado de tensão mecânica de tração.

Estudaram, também, a evolução da microestrutura dos filmes de molibdênio e constataram que o tamanho de grão era função da espessura, sendo que inicialmente sua profundidade aumentava rapidamente nos estágios iniciais de crescimento, mas passava a diminuir quando o filme atingia uma espessura superior a $80 \mathrm{~nm}$.

Portanto, as características finais dos filmes finos dependem fortemente das características da deposição: uma delas é a espessura conforme dito anteriormente (SCHUEGRAFT, 1988).

\footnotetext{
${ }^{1}$ Magnetron é um processo de pulverização catódica (sputtering) que utiliza um campo magnético adicional que resulta em um aumento da taxa de deposição devido ao aumento de fluxo de íons que chegam ao alvo.
} 


\subsection{DEPOSIÇÃO POR EVAPORAÇÃO}

A deposição por evaporação é um processo muito utilizado para a deposição de camadas metálicas de contatos nos circuitos integrados, por ser uma técnica rápida, limpa (vácuo da ordem $<10^{-6}$ torr) e de certo modo simples. Esta técnica é uma das mais estudadas e compreendidas na literatura.

Consiste basicamente em se fazer fluir uma corrente elétrica $(A)$ em um cadinho de tungstênio o qual se aquecerá por efeito joule e promoverá a evaporação de uma determinada massa de metal sólido, previamente colocada sobre o mesmo. Após evaporar-se, o material sólido se depositará nas lâminas colocadas a uma determinada altura e distância do cadinho sendo que todo este aparato deverá estar em vácuo.

A Figura 2.2-1 mostra esquematicamente um equipamento de evaporação de filmes finos.

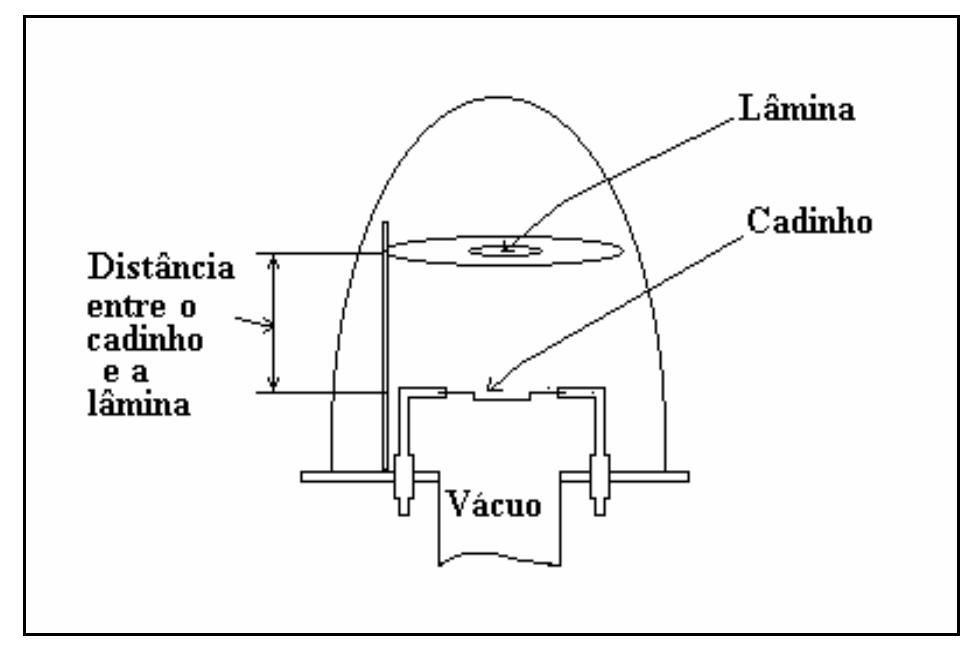

Figura 2.2-1- Desenho esquemático de uma evaporadora.

Muitos trabalhos foram realizados para se estudar os filmes obtidos pela técnica de deposição por evaporação. H.F. Ely et. al. (ELY, 1973), por exemplo, estudaram a metalização por alumínio evaporado em vácuo aplicado a circuitos integrados monolíticos. 
No trabalho de H.F. Ely et. al. (ELY, 1973), foi feito um estudo da influência da temperatura do substrato durante a deposição e constataram que esta temperatura não alterava a espessura do filme depositado, mas sim a granulação do filme, ou seja, quanto maior fosse à temperatura do substrato maior seria a granulação do filme.

Também, concluíram que os filmes depositados de alumínio por evaporação possuíam uma boa aderência sobre substratos de silício e sobre óxido de silício o que justifica a aplicação em larga escala deste material em contatos com junções e em linhas de interconexão. 


\section{DEPOSIÇÃO QUÍMICA}

Os primeiros a se interessarem pela deposição química de cobalto foram Brenner e Ridell (Brenner et al., 1946; MALLORY et al., 1990; ALKIRE et al., 2001) que utilizaram hipofosfito de sódio, cloreto de cobalto, citrato de sódio e cloreto de amônia e ajustaram o pH entre 9 e $10 \mathrm{com}$ a adição de hidróxido de amônia utilizando substrato de vidro. Relataram que a deposição com esta solução era impraticável em meio ácido. Estes autores também reportaram que a adição de íons como $\mathrm{Cd}^{+2}, \mathrm{Zn}^{+2}, \mathrm{Mg}^{+2}$ e $\mathrm{Fe}^{+2}$ resultavam em uma diminuição da taxa de deposição da mesma forma que a adição de íons de $\mathrm{CN}^{-}$e SCN'(MALLORY et al., 1990).

Para o caso de deposição química de cobalto, um dos elementos mais importantes da solução de deposição é o agente redutor (hipofosfito de sódio), pois é ele quem faz com que os íons de cobalto se reduzam a "cobalto zero", ou seja, os íons de cobalto $\mathrm{Co}^{+2}$ passam para seu estado normal Co sobre a superfície na qual irá depositar. As características dos filmes de cobalto obtidos variam de acordo com o agente redutor utilizado.

Por exemplo, filmes opacos e brilhantes podem ser obtidos utilizando sulfato de hidrazina como agente redutor nas concentrações de 1,2 $\mathrm{M}$ e 1,8M, respectivamente. Filmes brilhantes também podem ser obtidos utilizando dimetilamino-borana em meios ácidos (MALLORY et al., 1990). Além destes agentes redutores também temos amino-boranas, borohidretos e cobalto-boranos que também são largamente utilizados para a deposição de filmes de cobalto (MALLORY et al., 1990).

Filmes de cobalto depositados eletroquímicamente podem ser empregados como uma proteção efetiva contra a corrosão do aço. Além disso, o filme de cobalto pode ter boas características magnéticas, ser muito resistente ao desgaste e ter boa condutividade elétrica ou térmica (MALLORY et al., 1990).

As pesquisas de deposição eletroquímica estão aumentando por possuir vantagens por ser um processo mais simples e barato comparando-se com processos de deposição que utiliza vácuo e processos seletivos de deposição 
(O'SULLIVAN, 1998). Outra característica que tem se encontrado com a deposição eletroquímica é a possibilidade de aplicação no estado da arte em nanotecnologia (ALKIRE et al. 2001): nanofios de cobalto.

\subsection{MECANISMOS DE DEPOSIÇÃO QUÍMICA}

Os princípios básicos da deposição química podem ser descritos pelas reações abaixo, onde os íons metálicos se reduzem ao adquirirem elétrons depositando-se nos sítios ativos (ALKIRE, 2001).

$$
\begin{aligned}
& \operatorname{Re} d \rightarrow O x+n e^{-} \\
& M^{n+}+n e^{-} \rightarrow M \downarrow
\end{aligned}
$$

Reunido todas temos:

$$
\operatorname{Re} d+M^{n+} \stackrel{\text { superficie_catalitica }}{\longrightarrow} O x+M \downarrow
$$

Onde:

Red - é o agente redutor;

Ox - é o agente oxidante;

Desta forma, temos elétrons originados da oxidação heterogênea do agente redutor, equação (1), na região catalítica ativa da superficie onde se reduzem o ion metátilco a átomos de metal os quais se depositam na superfície, equação(2). 
Segundo a literatura temos três formas de nomenclatura para caracterizar variantes da deposição eletroquímica descritas a seguir (HASSAN,2002).

- Deposição autocatalítica (electroless)

- A fonte de elétrons é um agente redutor componente da solução.

- Deposição por deslocamento galvânico

- Existe um consumo do substrato que fornece elétrons para a deposição.

- Eletrodeposição

- Existe uma fonte externa de elétrons.

Os mecanismos de deposição química foram extensivamente estudados por diversos autores (SANTOS FILHO, 1996, ALKIRE, 2001) e quatro principais mecanismos de reações químicas foram propostos para descrever o processo de redução utilizando hipofosfito de sódio em meios alcalinos ou ácidos.

O primeiro deles foi proposto por Brenner e Ridel (1944) o qual diz que a redução do metal ocorre através do hidrogênio atômico (veja Tabela 3.1-1).

O segundo mecanismo sugerido por Hersch (1955) é o da transferência de um íon hidreto.

O terceiro é um mecanismo eletroquímico $(\mathrm{OHNO}, 1991)$ onde a deposição do níquel ocorre por meio de um processo eletrolítico junto à superfície catalítica (Figura 3.1-1).

O quarto mecanismo ocorre com átomos de metal hidrolisado com íons de hidroxila (Figura 3.1-2) (HWANG et al., 1995). 
Todos estes mecanismos são suportados por vários outros autores, no entanto, ainda não se tem um resultado totalmente conclusivo (OHNO, 1991; HWANG et al., 1995). A deposição química de filmes de cobalto em substratos isolantes normalmente começa com o crescimento de ilhas e estruturas aglomeradas seguido pelo crescimento lateral que acaba por formar um filme contínuo. O processo de deposição química em substratos condutores não catalíticos aparenta ter o mesmo comportamento como no caso de substratos isolantes sem o surgimento de novos núcleos o que sugerem um mecanismo puramente químico (mecanismos 1,2 e 4 na Tabela 3.1-1 e Figura 3.1-1). 
Tabela 3.1-1 - Mecanismos de reação de deposição eletroquímica (HWANG et al., 1995)

1.Mecanismo do hidrogênio atômico

$$
\begin{aligned}
& \mathrm{H}_{2} \mathrm{PO}_{2}^{-} \stackrel{\text { cat. }}{\longrightarrow} \mathrm{PO}_{2}^{-}+2 \mathrm{H} \text { (cat.) } \\
& \mathrm{PO}_{2}^{-}+\mathrm{H}_{2} \mathrm{O} \rightarrow \mathrm{HPO}_{3}^{2-}+\mathrm{H}^{+} \\
& M^{2+}+2 H(\text { cat. }) \rightarrow M^{0}+2 H^{+} \\
& \mathrm{H}_{2} \mathrm{PO}_{2}^{-}+\mathrm{H}(\text { cat. }) \rightarrow \mathrm{P}^{0}+\mathrm{H}_{2} \mathrm{O}+\mathrm{OH}^{-} \\
& 2 H(\text { cat. }) \rightarrow H_{2} \uparrow
\end{aligned}
$$

2.Mecanismo do íon hidreto

$$
\begin{aligned}
& \mathrm{H}_{2} \mathrm{PO}_{2}^{-}+\mathrm{H}_{2} \mathrm{O}\left.\rightarrow \mathrm{HPO}_{3}^{2-}+2 \mathrm{H}^{+}+\mathrm{H}^{-} \text {(ácido }\right) \\
& \mathrm{H}_{2} \mathrm{PO}_{2}^{-}+2 \mathrm{OH}^{-} \rightarrow \mathrm{HPO}_{3}^{2-}+\mathrm{H}_{2} \mathrm{O}+\mathrm{H}^{-}(\text {básico }) \\
& \mathrm{M}^{2+}+2 \mathrm{H}^{-} \rightarrow\left[\mathrm{M}^{0}+2 \mathrm{H}\right] \rightarrow \mathrm{M}^{0}+\mathrm{H}_{2} \uparrow \\
& \mathrm{H}^{+}+\mathrm{H}^{-} \rightarrow \mathrm{H}_{2} \uparrow(\text { ácido }) \\
& \mathrm{H}_{2} \mathrm{O}+\mathrm{H}^{-} \rightarrow \mathrm{H}_{2} \uparrow+\mathrm{OH}^{-} \text {(básico) }
\end{aligned}
$$

3.Mecanismo eletroquímico

$$
\begin{gathered}
\mathrm{H}_{2} \mathrm{PO}_{2}^{-}+\mathrm{H}_{2} \mathrm{O} \rightarrow \mathrm{H}_{2} \mathrm{PO}_{3}^{-}+2 \mathrm{H}^{+}+2 e^{-} \\
\mathrm{M}^{2+}+2 e^{-} \rightarrow \mathrm{M}^{0} \\
2 \mathrm{H}^{+}+2 e^{-} \rightarrow \mathrm{H}_{2} \uparrow \\
\mathrm{H}_{2} \mathrm{PO}_{2}^{-}+e^{-} \rightarrow \mathrm{P}^{0}+2 \mathrm{OH}^{-}
\end{gathered}
$$

4.Mecanismo das hidroxilas

$$
\begin{aligned}
& \mathrm{M}(\mathrm{OH})_{2}+\mathrm{H}_{2} \mathrm{PO}_{2}^{-} \rightarrow \mathrm{MOH}+\mathrm{H}_{2} \mathrm{PO}_{3}^{-}+\mathrm{H} \\
& \mathrm{MOH}+\mathrm{H}_{2} \mathrm{PO}_{2}^{-} \rightarrow \mathrm{M}^{0}+\mathrm{H}_{2} \mathrm{PO}_{3}^{-}+\mathrm{H} \\
& \mathrm{M}+\mathrm{H}_{2} \mathrm{PO}_{2}^{-} \rightarrow \mathrm{P}^{0}+\mathrm{MOH}+\mathrm{OH}^{-} \\
& \mathrm{MOH}+\mathrm{H}_{2} \mathrm{O} \rightarrow \mathrm{M}(\mathrm{OH})_{2}+\mathrm{H} \\
& \mathrm{H}+\mathrm{H} \rightarrow \mathrm{H}_{2} \uparrow
\end{aligned}
$$


A distinção entre mecanismo químico (1,2 ou 4 na tabela 3.1-1) ou eletroquímico (3 na tabela 3.1-1) pode ser constatada sobre superfícies condutoras não catalíticas pré-ativadas quando a deposição ocorrer uniformemente em toda a superfície independente do número de núcleos iniciais (3) ou não (1, 2 ou 4). Isto porque na deposição eletroquímica flui elétrons tanto pelo sítio como pelo substrato condutor (veja figura 3.1-2)

A deposição química de cobalto sobre uma superfície ativada de grafite pirolítica $^{2}$ altamente orientada que é condutora e não catalítico é um exemplo que segue o mecanismo eletroquímico de deposição (veja Figura 3.1-2)

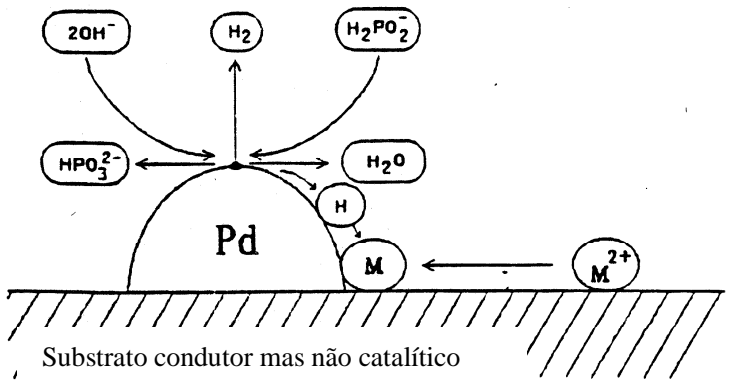

(a)

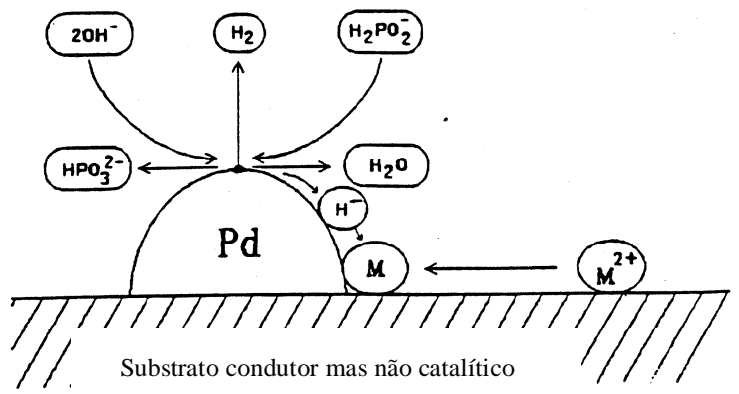

(b)

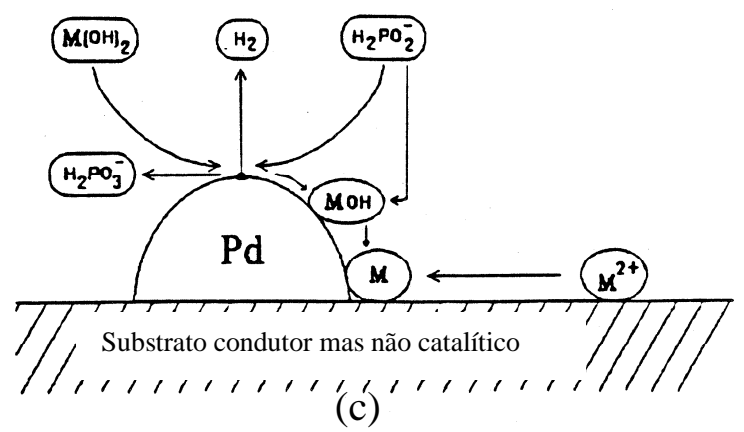

Figura 3.1-1 - Deposição sobre superfície condutora não catalítica, considerando os mecanismos químicos: a) Com transferência do átomo de hidrogênio; b) Com transferência do hidreto; c) Com Níquel hidrolisado(HWANG et al., 1995).

\footnotetext{
${ }^{2}$ Grafite Pirolítica - material feito em carbono é dado este nome devido ao processo de fabricação que se utiliza de altas temperaturas e em ambiente de vácuo.
} 


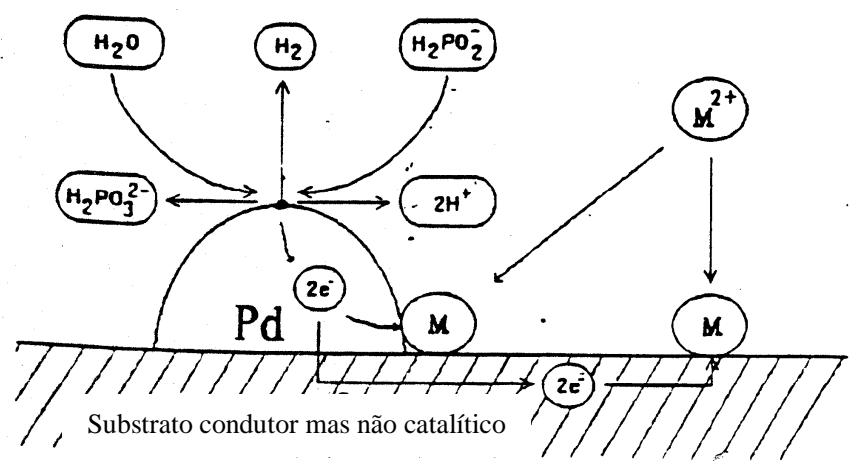

Figura 3.1-2-Mecanismo eletroquímico sobre superfície condutora não catalítica, pré-ativada com paládio(HWANG et al., 1995).

\subsection{TEORIA DO POTENCIAL MISTO (OHNO, 1991; ALKIRE ET AL. 2001; HUO, 2001)}

A deposição química também pode ser explicada pela teoria do potencial misto que tem como base a combinação da deposição catódica do metal e da oxidação anódica do redutor no potencial de imersão $E_{\text {im }}(O H N O, 1991)$. As equações químicas são escritas a seguir $(\mathrm{OHNO}, 1991)$.

- Equação de reação Catódica(OHNO,1991):

$$
M L_{m}^{n+1}+n e^{-} \rightarrow M+m L
$$

- Equação de reação Anódica(OHNO,1991)

$$
\operatorname{Re} d \rightarrow O x+n e^{-}
$$

onde:

$\mathrm{L}=$ ligante,

Red $=$ agente redutor,

Ox = agente oxidante,

$\mathrm{n}=$ número de elétrons,

m- número de ligantes. 
A descrição quantitativa do sistema de deposição química é possível com bases na curva de pontecial versus corrente tanto para reação total como para a reação parcial como mostra a Figura 3.2-1(OHNO,1991). A curva 2 pontilhada mostra a curva de potencial-corrente para a reação total. O eixo $\mathrm{E}$ corresponde ao potencial e no ponto onde a corrente é igual a zero chamamos de potencial misto $E_{p l}(O H N O, 1991)$. Já nas curvas 1 e 3, temos potencial-corrente para as reações anódica $\left(i_{a}\right)$ e catódica $\left(i_{c}\right)$ respectivamente $(\mathrm{OHNO}, 1991)$. Então de acordo com a teoria do potencial misto, o ponto da corrente $i$ é o resultado da soma algébrica das duas corrente parciais $\mathrm{i}_{\mathrm{a}}$ e $\mathrm{i}_{\mathrm{c}}$ :

$$
i=i_{a}+i_{c}
$$

Quando $i_{a}$ é igual a $i_{c}$, temos o potencial misto $E_{p l}$ que corresponde a corrente de deposição química $i_{p l}(\mathrm{OHNO}, 1991)$ ou:

$$
i_{p l}=i_{a}=i_{c}
$$

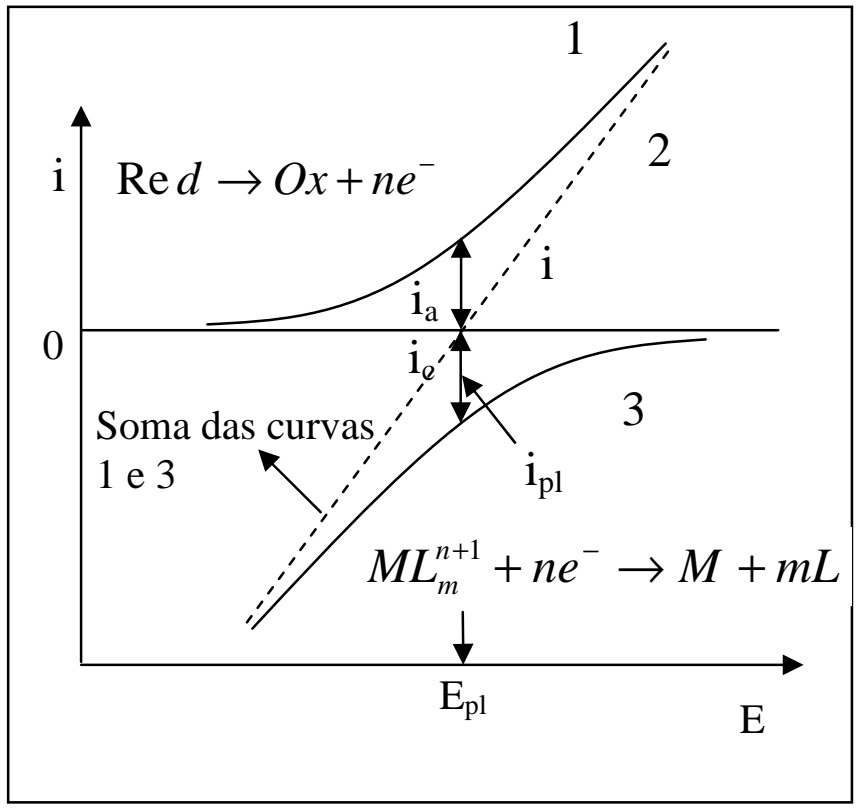

Figura 3.2-1- Esquema da curva de potencial versus corrente para o eletrodo de potencial misto onde a curva 2 é a corrente total; a curva 1 é a corrente anódica; e a curva 3 é a corrente catódica (OHNO,1991). 
A partir deste ponto as reações representadas pelas equações (4) e (5) ocorrem simultaneamente na superfície catalítica ou nos sítios ativos (sítios anódicos e catódicos do mesmo substrato fazendo um curto circuito gerando um fluxo de elétrons) (HUO, 2001), desta forma tem-se a condição de um estado estacionário e esta situação caracteriza-se de potencial misto do estado estacionário $\left(\mathrm{E}_{\mathrm{pm}}\right)$.

De acordo com HUO et. Al (HUO, 2001) a teoria do potencial misto não descreve com exatidão os mecanismos de reação autocatalítica de diversos metais, pois em alguns casos existe a formação de óxido sobre o substrato de deposição, ou ocorre a reação do agente redutor com o metal que está complexado. Desta forma, a taxa de reação catódica parcial é modificada sendo necessário um estudo mais aprofundado (HUO, 2001).

\subsection{ASPECTOS CATALÍTICOS DA DEPOSIÇÃO ELETROQUÍMICA}

A idéia aqui será de apresentar os aspectos catalíticos que favorecem o processo de deposição.

Segundo O'Sullivan, E.J. (O'SULLIVAN, 2001) a reação crítica do processo de deposição eletroquímica do ponto de vista da catálise é a reação de oxidação e a habilidade do agente redutor em promover esta oxidação.

É importante destacar, que aparentemente nenhum metal pode ser reduzido por todos os agentes redutores no processo de deposição eletroquímica, por exemplo, a redução do cobre é melhor obtida através da oxidação do agente redutor $\mathrm{H}_{2} \mathrm{CO}$ e é ineficiente para o caso da oxidação do hipofosfito. Já o $\mathrm{Ni}$ e o Co são fracamente catalisados pelo $\mathrm{H}_{2} \mathrm{CO}$ e são reduzidos por todos os outros agentes redutores. O Paládio é um excelente catalisador para a deposição de metais porque promove inclusive a ação do agente redutor (O'SULLIVAN, 2001).

Ohno et al. (1991) em seu trabalho obtiveram o gráfico mostrado na Figura 3.3-1, onde se observa as curvas de polarização da oxidação do $\mathrm{H}_{2} \mathrm{CO}$ para vários eletrodos metálicos onde a atividade catalítica para o Co e o $\mathrm{Ni}$ é quase 
insignificante comparado com outros eletrodos para oxidação do formaldeído. Este gráfico foi obtido a partir de uma solução contendo EDTA, mantida a $25^{\circ} \mathrm{C}$ com $\mathrm{pH}=12,5$ e potencial menor que $-0,8 \mathrm{~V}$ para o eletrodo de calomelano ${ }^{3}$ saturado.

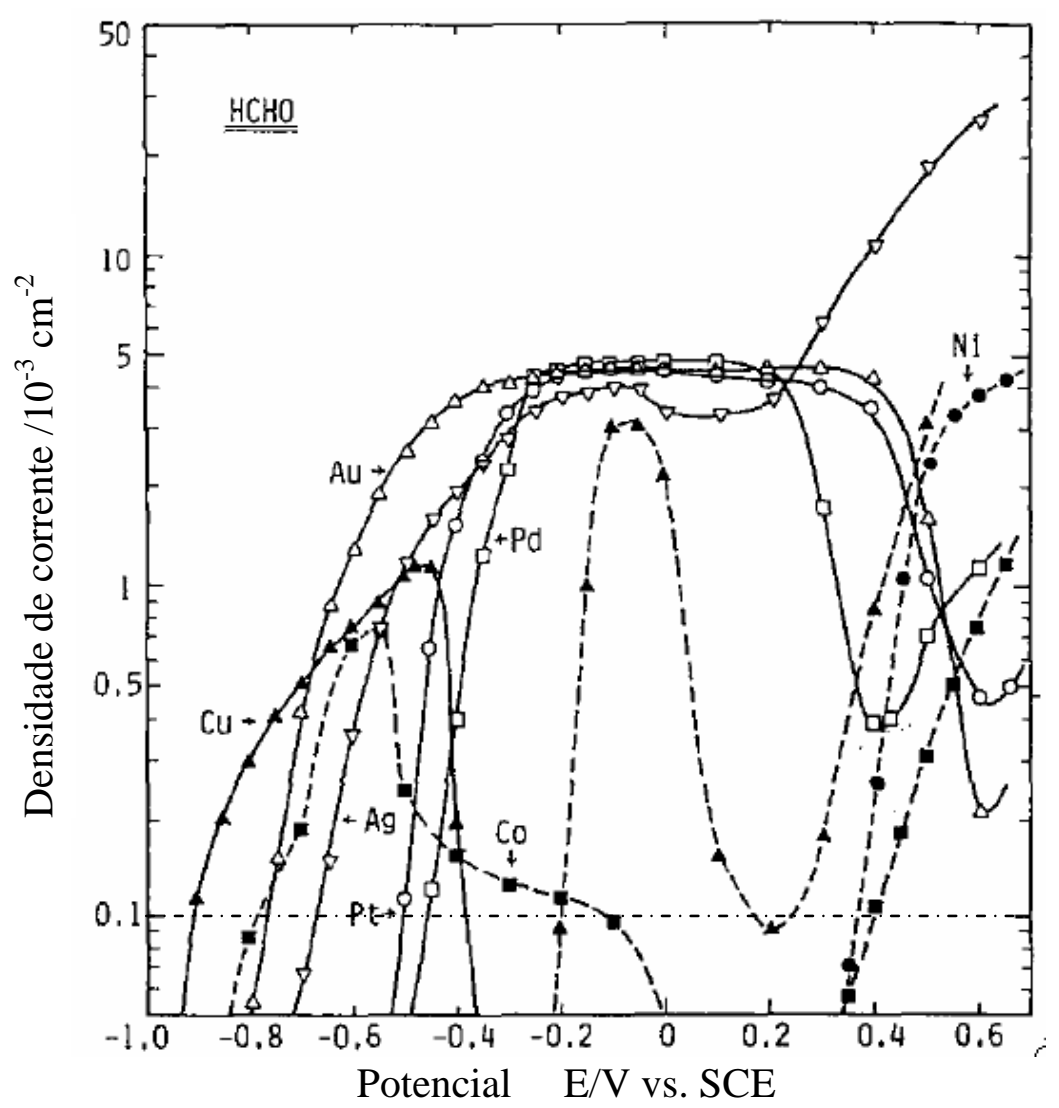

Figura 3.3-1-Curva de polarização para oxidação anódica do $\mathrm{H}_{2} \mathrm{CO}(\mathrm{HCHO}-$ Formaldeído) para diferentes metais. A linha pontilhada refere-se à densidade corrente atribuída a dissolução anódica dos eletrodos de $\mathrm{Cu}$ e Co. $(0,1 \mathrm{M} \mathrm{HCHO}$, $0,175 \mathrm{M}$ EDTA $2 \mathrm{Na}, \mathrm{pH}=12,5$ e temperatura de $\left.25^{\circ} \mathrm{C}\right)(\mathrm{OHNO}, 1991)$.

Outro gráfico obtido por Ohno et al. $(O h n o, 1991)$ pode ser observado na Figura 3.3-2 onde se observa as curvas de polarização da oxidação anódica do $\mathrm{NaH}_{2} \mathrm{PO}_{2}$ para diferentes metais onde a atividade catalítica para o Co e o Ni passa a ser mais eficiente comparado com o gráfico mostrado na Figura 3.3-1 onde se utiliza $\mathrm{H}_{2} \mathrm{CO}$ como agente redutor. Este gráfico foi obtido a partir de uma solução contendo $\mathrm{NaH}_{2} \mathrm{PO}_{2}$, mantida e $70^{\circ} \mathrm{C}$ com pH=9,0.

\footnotetext{
${ }^{3}$ Calomelano: eletrodo de referência SCE do tipo $\mathrm{Hg} / \mathrm{Hg}_{2} \mathrm{Cl}_{2}$.
} 


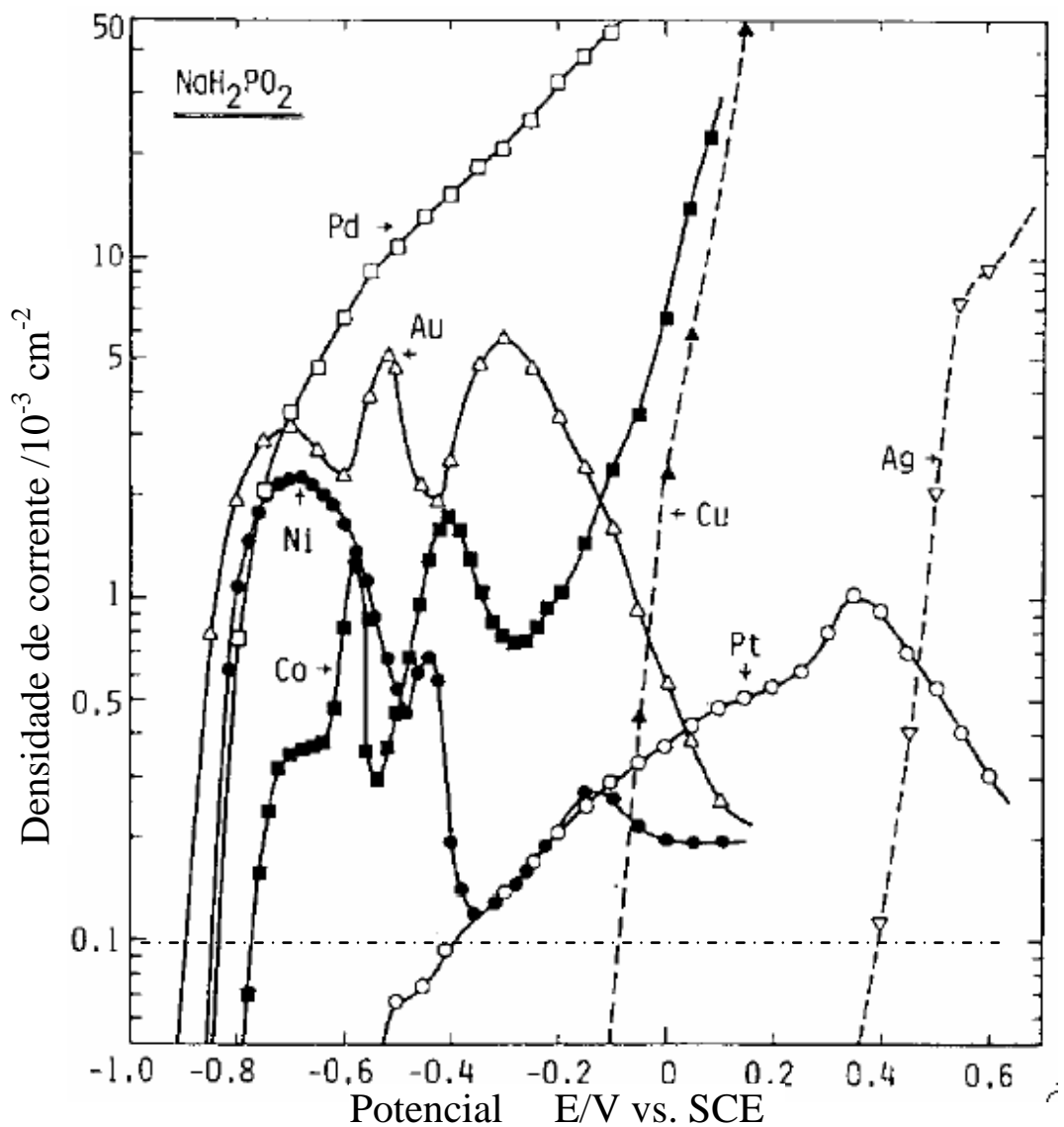

Figura 3.3-2- Curva de polarização para oxidação anódica do hipofosfito para diferentes metais. A linha pontilhada refere-se à densidade corrente atribuída a dissolução anódica dos eletrodos de $\mathrm{Ag}$ e $\mathrm{Cu}$. $\left(0,2 \mathrm{M} \mathrm{NaH}_{2} \mathrm{PO}_{2}, 0,2 \mathrm{M}\right.$ Citrato de Sódio , 0,5 $\mathrm{M} \mathrm{H}_{3} \mathrm{BO}_{3}$, $\mathrm{pH}=9,0$ e temperatura de $\left.70^{\circ} \mathrm{C}\right)(\mathrm{OHNO}, 1991)$.

Desta forma, Ohno et al. (1991) montaram uma tabela (tabela 3.3-1) que pode ser observada a seguir, onde notamos os potenciais dos metais para cada tipo de agente redutor. 
Tabela 3.3-1- Potenciais $E^{*}$ a $0,1 \mathrm{~mA} \mathrm{~cm}{ }^{2}$, energia de ativação $E_{a}$ e fator $\log i^{*}$ para oxidação anódica dos agentes redutores para diferentes metais. (OHNO, 1991).

\begin{tabular}{|c|c|c|c|c|c|}
\hline Agente redutor & Metal & $\begin{array}{c}\mathrm{E}^{*} \\
(\mathrm{~V}(\mathrm{SCE}))\end{array}$ & $\begin{array}{c}\mathrm{E}_{\mathrm{a}} \\
\left(\mathrm{kJ} \mathrm{mol}^{-1}\right)\end{array}$ & $\begin{array}{c}\log i^{*} \\
\left(10^{-3} \mathrm{Acm}^{2}\right)\end{array}$ & $\begin{array}{l}\text { Potencial de } \\
\text { referência } \\
\text { (V (SCE)) }\end{array}$ \\
\hline \multirow{5}{*}{$\mathrm{NaH}_{2} \mathrm{PO}_{2}$} & $\mathrm{Au}$ & $-0,982$ & 33 & 5,7 & $-0,80$ \\
\hline & $\mathrm{Ni}$ & $-0,935$ & 46 & 9,2 & $-0,80$ \\
\hline & $\mathrm{Pd}$ & $-0,910$ & 54 & 8,9 & $-0,80$ \\
\hline & Co & 0,854 & 88 & 11 & $-0,80$ \\
\hline & $\mathrm{Pt}$ & $-0,300$ & 59 & 8,8 & 0,20 \\
\hline \multirow[t]{7}{*}{$\mathrm{HCHO}$} & $\mathrm{Cu}$ & $-0,906$ & 50 & 8,5 & $-0,70$ \\
\hline & $\mathrm{Au}$ & $-0,770$ & 29 & 4,7 & $-0,70$ \\
\hline & $\mathrm{Ag}$ & $-0,675$ & 29 & 4,3 & $-0,65$ \\
\hline & $\mathrm{Pt}$ & $-0,508$ & 38 & 6,1 & $-0,50$ \\
\hline & $P d$ & $-0,464$ & 24 & 4,4 & $-0,35$ \\
\hline & $\mathrm{Ni}$ & 0,366 & 46 & 7,3 & 0,40 \\
\hline & Co & 0,450 & 31 & 4,8 & 0,45 \\
\hline \multirow{7}{*}{$\mathrm{NaBH}_{4}$} & $\mathrm{Ni}$ & $-1,190$ & 40 & 7,2 & $-0,95$ \\
\hline & Co & $-1,180$ & 40 & 8,2 & $-0,95$ \\
\hline & $\mathrm{Pd}$ & $-1,136$ & 54 & 10 & $-0,95$ \\
\hline & $\mathrm{Pt}$ & $-0,983$ & 46 & 8,4 & $-0,95$ \\
\hline & $A u$ & $-0,850$ & 39 & 7,4 & $-0,70$ \\
\hline & $\mathrm{Ag}$ & $-0,832$ & 46 & 7,4 & $-0,70$ \\
\hline & $\mathrm{Cu}$ & $-0,761$ & 46 & 7,3 & $-0,70$ \\
\hline \multirow[t]{6}{*}{ DMAB } & $\mathrm{Ni}$ & $-0,866$ & 35 & 6,2 & $-0,55$ \\
\hline & Co & $-0,832$ & 37 & 6,3 & $-0,55$ \\
\hline & $\mathrm{Pd}$ & $-0,766$ & 41 & 7,1 & $-0,55$ \\
\hline & $\mathrm{Au}$ & $-0,650$ & 42 & 6,8 & $-0,55$ \\
\hline & $\mathrm{Pt}$ & $-0,633$ & 14 & 1,6 & $-0,55$ \\
\hline & $\mathrm{Ag}$ & $-0,565$ & 50 & 8 & $-0,55$ \\
\hline \multirow[t]{7}{*}{$\mathrm{NH}_{2} \mathrm{NH}_{2}$} & Co & $-0,940$ & 31 & 5,7 & $-0,75$ \\
\hline & $\mathrm{Ni}$ & $-0,871$ & 33 & 5,5 & $-0,75$ \\
\hline & $\mathrm{Pt}$ & $-0,800$ & 17 & 3 & $-0,75$ \\
\hline & $\mathrm{Pd}$ & $-0,797$ & 38 & 6,1 & $-0,75$ \\
\hline & $\mathrm{Cu}$ & $-0,556$ & 33 & 5,3 & $-0,50$ \\
\hline & $\mathrm{Ag}$ & $-0,460$ & 42 & 6,3 & $-0,50$ \\
\hline & $\mathrm{Au}$ & $-0,413$ & 59 & 8,1 & $-0,50$ \\
\hline
\end{tabular}

Da Tabela 3.3-1 obtém-se os diagramas da Figura 3.3-3, onde se observa a atividade catalítica dos metais, para diferentes redutores em relação aos potenciais de oxirredução dos agentes redutores (Er), onde o curso da atividade catalítica aumenta, indo do auto para o baixo potencial $(\mathrm{OHNO}, 1991)$. 
(a)

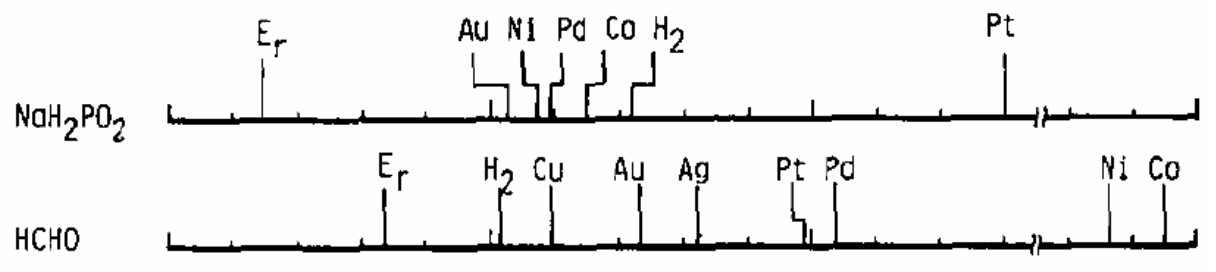

(c) $\mathrm{NOBH}_{4}$

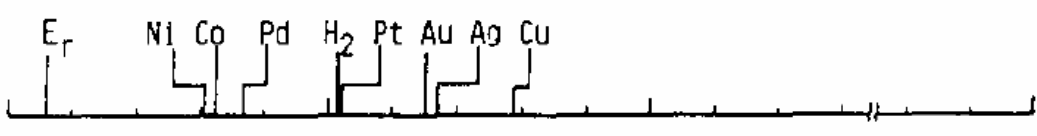

(d) DMAB

(e) $\mathrm{NH}_{2} \mathrm{NH}_{2}$
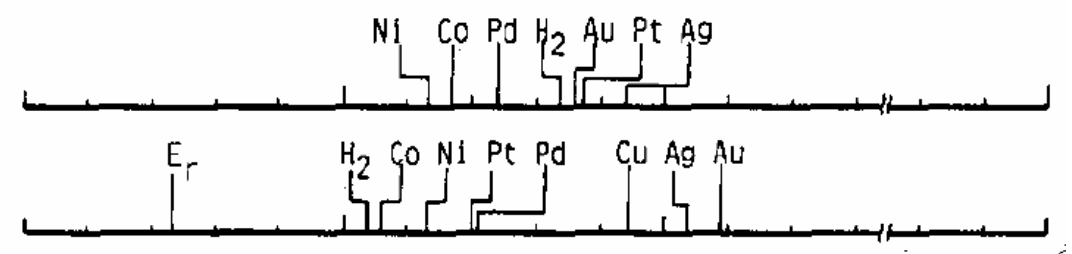

Figura 3.3-3 - Atividades catalíticas ( os potenciais obtidos em $0,1 \mathrm{~mA} \mathrm{~cm}{ }^{2}$ ) para oxidação anódica de diferentes agentes redutores, onde $E_{r}$ são os potenciais de oxidação-redução dos agentes redutores e $\mathrm{H}_{2}$ são os potenciais reversão do Hidrogênio. (a) 0,2 $\mathrm{M} \mathrm{NaH}{ }_{2} \mathrm{PO}_{2}, 0,2 \mathrm{M}$ Citrato de Sódio, 0,5 $\mathrm{M} \mathrm{H}_{3} \mathrm{BO}_{3}, \mathrm{pH}=9,0$ e temperatura de $70^{\circ} \mathrm{C}$; (b) $0,1 \mathrm{M} \mathrm{HCHO}, 0,175 \mathrm{M}$ EDTA $2 \mathrm{Na}, \mathrm{pH}=12,5$ e temperatura de $25^{\circ} \mathrm{C}$; (c) $0,03 \mathrm{M} \mathrm{NaBH}_{4}, 0,175 \mathrm{M}$ EDTA $2 \mathrm{Na}, \mathrm{pH}=12,5$ e temperatura de $25^{\circ} \mathrm{C}$; (d) 2,0g DMAB dm ${ }^{-3}, 0,2 \mathrm{M}$ Citrato de Sódio, $0,5 \mathrm{M} \mathrm{H}_{3} \mathrm{BO}_{3}, \mathrm{pH}=7,0$ e temperatura de $25^{\circ} \mathrm{C}$; (e) $0,1 \mathrm{M} \mathrm{N}_{2} \mathrm{H}_{4}, 0,175 \mathrm{M}$ EDTA $2 \mathrm{Na}, \mathrm{pH}=12,0$ e temperatura de $25^{\circ} \mathrm{C}$; (OHNO, 1991). 


\subsection{TERMODINÂMICA DAS SOLUÇÕES ELETROLÍTICAS}

Santos, S.G.F.em seu trabalho intitulado "Oxidação térmica Rápida do Silício: influência dos Procedimentos de limpeza química e dos perfis temporais de temperatura na qualidade dos óxidos de porta MOS" descreveu as condições gerais de espontaneidade e de equilíbrio termodinâmico onde uma transformação de estado irreversível pode ocorrer dentro de um dado sistema separado do resto do universo por uma vizinhança. E sendo esta uma transformação irreversível, pode ser descrita pela desigualdade de Clausius através da equação geral 3.8 (SANTOS FILHO, 1996):

$$
\Delta S_{s i s t}>\frac{\delta Q_{s i s t}}{T_{v i z}}
$$

onde $\Delta S_{\text {sist }}$ é a variação de entropia do sistema, $\Delta Q_{\text {sist }}$ corresponde à troca de calor entre o sistema e sua vizinhança e $T_{\text {viz }}$ é a temperatura da vizinhança (SANTOS FILHO, 1996).

A equação 3.8 da desigualdade de Clausius estabelece que a variação da entropia dentro do sistema deve ser maior que a troca de calor entre o sistema e sua vizinhança normalizada em relação à temperatura da vizinhança para que uma transformação ocorra de forma irreversível (SANTOS FILHO, 1996).

A partir da equação 3.8 e das equações do primeiro principio da termodinâmica e do trabalho (e as considerações necessárias, descritas na integra na tese de doutorado de Santos S.G.F. (1996)), chega-se na condição de irreversibilidade ou espontaneidade, equação 3.9.

$$
\Delta G+\sum_{i} F_{g_{i}} \cdot \Delta Y_{I}<0
$$

onde $\Delta G$ é a energia livre de Gibbs, $F_{g i}$ é a enésima força generalizada e $\Delta Y$ é o enésimo deslocamento generalizado (SANTOS FILHO, 1996). No entanto, uma transformação de estado reversível é definida na condição de equilibro 
passando então a desigualdade de Clausius a ser uma igualdade (SANTOS FILHO, 1996) dada pela equação 3.10 .

$$
\Delta S_{s i s t}=\frac{\delta Q_{s i s t}}{T_{v i z}}
$$

Desta forma, na condição de equilíbrio termodinâmico, a temperatura da vizinhança é igual à temperatura do sistema, resultando na equação de equilíbrio termodinâmico (SANTOS FILHO, 1996) conforme equação 3.11.

$$
\Delta G+\sum_{i} F_{g_{i}} \cdot \Delta Y_{I}=0
$$

\subsubsection{ELETROQUÍMICA DAS SOLUÇÕES IÔNICAS DILUÍDAS}

Através da desigualdade de Clausius, Santos (1996) em sua tese de doutorado chegou à equação que relaciona a energia de Gibbs com as concentrações dos solutos para soluções diluídas ideais, a partir daí, pode-se prever se uma dada reação química poderá ocorrer de forma espontânea ou não (SANTOS FILHO, 1996).

Santos (1996) estava interessado em descrever um sistema específico que era o de uma lâmina imersa em solução de ácido fraco do tipo DHF (diluted hydrofluodric solution). Nesta situação, entre o eletrodo (lâmina de silício) e o eletrólito (solução DHF) pode ocorrer uma reação de oxidação junto da superfície da lâmina de silício com subseqüente liberação de elétrons, os quais se agregam aos metais dissolvidos em solução DHF na forma catiônica $\left(\mathrm{M}^{2+}\right)$ resultando em metais no estado de oxidação igual a zero $\left(\mathrm{M}^{0}\right)$. A reação química completa então será dada pela soma da reação de oxidação do silício com a reação de redução dos metais. Esta reação é denominada de reação de oxidação-redução ou RedOx 
(SANTOS FILHO, 1996), onde ocorre a transferência de elétrons da reação de oxidação $\left(\mathrm{Si}^{0}=\mathrm{Si}^{4+}+4 \mathrm{e}\right)$ para a reação de redução $\left(\mathrm{M}^{2+}+2 \mathrm{e}=\mathrm{M}^{0}\right)$ (SANTOS FILHO, 1996).

A partir deste ponto, então, Santos(1996), relacionou a constante de equilíbrio com os potenciais associados ao sistema eletrodo/eletrólito (lâmina de silício (solução DHF) o que permitiu prever quando um determinado tipo de metal dissolvido na solução irá ou não se depositar espontaneamente sobre a superfície da lâmina de silício.

\subsection{COMPOSIÇÃO, ESTABILIDADE E AGENTES REDUTORES}

\subsubsection{SAL METÁLICO}

O sal metálico é o responsável pela geração dos íons metálicos na solução de deposição que irão se depositar na superfície desejada por meio da redução destes íns na forma metálica, sendo que para o caso de íons de cobalto se utiliza $\mathrm{CoCl}_{2} .6 \mathrm{H}_{2} \mathrm{O}$ ou $\mathrm{CoSO}_{4.7} \mathrm{H}_{2} \mathrm{O}$ (MALLORY et al., 1990, HASSAN,2002).

\subsubsection{AGENTES REDUTORES}

Segundo a literatura (MALLORY et al., 1990) os agentes redutores são responsáveis por realizar redução do metal sobre a superfície desejada. O hipofosfito como agente redutor tem sido utilizado para a deposição de metais e ligas metálicas devido ao seu baixo custo (MALLORY et al., 1990).

Um dos maiores problemas é que alguns dos agentes redutores tendem a se decomporem extinguindo o processo de deposição. (MALLORY et al., 1990). Mas em alguns casos, os filmes obtidos se apresentam com boas qualidades, por exemplo, para os processos de obtenção de filmes magnéticos de baixa coercitividade. Desta forma o processo eletroquímico se tem mostrado como um 
processo mais econômico (MALLORY et al., 1990), alguns dos agentes redutores mais utilizados podem ser observados na Figura 3.3-3.

De acordo com a literatura (MALLORY et al., 1990) os filmes de cobalto obtidos para cada um dos agentes redutores mostrados na Figura 3.3-3. A seguir apresentaremos algumas receitas clássicas para os principais agentes redutores: hidrazina, borohidreto de sódio, dimetilamina borana, formaldeído, oxazodilinonas e hipofosfito.

\subsubsection{HIDRAZINA (MALLORY ET AL., 1990)}

O filme se deposita em Co puro sem acontecer a codeposição de parte do agente redutor, a liga $\mathrm{Co} / \mathrm{Ni}$ também pode ser depositada por esta solução (Tabela 3.5-1). (MALLORY et al., 1990)

Tabela 3.5-1-Solução de deposição de Co e ligas de Co/Ni (MALLORY et al., 1990)

\begin{tabular}{|c|c|c|}
\hline & \multicolumn{2}{c|}{ Solução } \\
\hline Componentes & Co & Co+Ni \\
\hline $\mathrm{Na}$ tartrate & $0,4 \mathrm{M}$ & $0,4 \mathrm{M}$ \\
\hline $\mathrm{N}_{2} \mathrm{H}_{2} \cdot \mathrm{HCl}$ & $1,0 \mathrm{M}$ & $1,0 \mathrm{M}$ \\
\hline Tiuréia & $2 \sim 4 p p m$ & $3 p p m$ \\
\hline $\mathrm{Co}$ & $0,05 \sim 0,08 \mathrm{M}$ & - \\
\hline $\mathrm{Co}+\mathrm{Ni}$ & - & $0,05 \mathrm{M}$ \\
\hline $\mathrm{pH}(\mathrm{NaOH})$ & 12,0 & 12,0 \\
\hline Temperatura $\left({ }^{\circ} \mathrm{C}\right)$ & 90 & 90 \\
\hline
\end{tabular}

\subsubsection{BOROHIDRETO DE SÓDIO (MALLORY ET AL., 1990).}

Normalmente esta deposição ocorre sobre superfícies ativadas por Pd e 0 filme de Co-B é depositado, no entanto, enquanto a taxa de deposição muda com a temperatura e com a concentração de reagentes. Observa-se nesse caso que a composição do filme amorfo depositado não muda. A ordem da reação encontrada foi zero para $\mathrm{OH}^{-}$e $\mathrm{BH}_{4}$ e pode ser obtido através da solução descrita na Tabela 3.5-2 (MALLORY et al., 1990) 
Tabela 3.5-2 - Solução de deposição de Co para Borohidreto de Sódio como agente redutor (MALLORY et al., 1990)

\begin{tabular}{|c|c|}
\hline Componente & Concentração \\
\hline $\mathrm{CoCl}_{2} \cdot 6 \mathrm{H}_{2} \mathrm{O}$ & $0,0126 \sim 0,0315 \mathrm{M}$ \\
\hline $\mathrm{Na}_{3}$ citrato $2 \mathrm{H}_{2} \mathrm{O}$ & $0,0126 \mathrm{M}$ \\
\hline $\mathrm{NaBH}_{4}$ & $0,0031 \sim 0,0142 \mathrm{M}$ \\
\hline $\mathrm{pH}(\mathrm{NaOH})$ & $10.2 \sim 11.3$ \\
\hline Temperatura $\left({ }^{\circ} \mathrm{C}\right)$ & $13 \sim 28$ \\
\hline
\end{tabular}

\subsubsection{DIMETILÂMINA BORANA (DMAB)}

Quando o agente redutor é a dimetilamina borana, obtém-se ligas de Co$\mathrm{Ni}$ em temperatura ambiente (Tabela 3.5-3). O tempo de vida útil da solução é de aproximadamente $30 \mathrm{~min}$. (MALLORY et al., 1990) para receita indicada na tabela 3.5-3

Tabela 3.5-3- Solução de deposição de Co para DMAB como agente redutor (MALLORY et al., 1990)

\begin{tabular}{|c|c|}
\hline Componente & Concentração \\
\hline $\mathrm{Co}$ & $25 \mathrm{~g} / \mathrm{L} \mathrm{MCl} \cdot 6 \mathrm{H}_{2} \mathrm{O}$ \\
\hline $\mathrm{Co}+\mathrm{Ni}$ & $10 \sim 50$ por cento \\
\hline $\mathrm{Na}_{4} \mathrm{P}_{2} \mathrm{O}_{7} .10 \mathrm{H}_{2} \mathrm{O}$ & $50 \mathrm{~g} / \mathrm{L}$ \\
\hline $\mathrm{DMAB}$ & $10 \mathrm{~g} / \mathrm{L}$ \\
\hline $\mathrm{pH}(\mathrm{NaOH})$ & 10.5 \\
\hline
\end{tabular}

A Piridina, ácido cítrico e $\mathrm{CrCl}_{3}$ estabilizam a solução com DMAB (Tabela 3.5-4), sendo que estes inibidores não codepositam como os metais pesados e componentes a base de sulfato. A introdução de hipofosfito juntamente com 0 DMAB pode inibir a deposição sobre certas circunstâncias (MALLORY et al., 1990). 
Tabela 3.5-4 -Solução de deposição de Co contendo DMAB como agente redutor e estabilizadores (MALLORY et al., 1990)

\begin{tabular}{|c|c|}
\hline Componente & Concentração \\
\hline CoSO $_{4}$ & $0,2 \mathrm{M}$ \\
\hline Ácido glicolico & $0,0003 \mathrm{M}$ \\
\hline Ácido lático & $0,00016 \mathrm{M}$ \\
\hline Ácido Sucinico & $0,055 \mathrm{M}$ \\
\hline$\left(\mathrm{CH}_{3} \mathrm{CH}_{2}\right)_{2} \mathrm{NH}_{\text {B }} \mathrm{BH}_{4}$ & $4 \mathrm{M}$ \\
\hline Piridina & $0,0063 \mathrm{M}$ \\
\hline $\mathrm{CrCl}_{3}$ & $0,009 \mathrm{M}$ \\
\hline Ácido cítrico & $0,014 \mathrm{M}$ \\
\hline $\mathrm{pH}$ & $6.0 \sim 6.5$ \\
\hline Temperatura $\left({ }^{\circ} \mathrm{C}\right)$ & $70 \sim 80$ \\
\hline
\end{tabular}

De acordo com a literatura (MALLORY et al., 1990), se for introduzido hipofosfito em ambiente ácido, o processo de deposição pode se tornar mais lento (Tabela 3.5-5 A).

Tabela 3.5-5 - Solução de deposição de Co contendo DMAB como agente redutor e Hipofosfito (MALLORY et al., 1990)

\begin{tabular}{|c|c|c|c|}
\hline Componente & A & B & C \\
\hline $\mathrm{CoSO}_{4} .7 \mathrm{H}_{2} \mathrm{~g} / \mathrm{L}$ & 25 & 30 & 30 \\
\hline $\mathrm{DMAB} \mathrm{g} / \mathrm{L}$ & 4 & 4 & - \\
\hline $\mathrm{NaH}_{2} \mathrm{PO}_{2} . \mathrm{H}_{2} \mathrm{O} \mathrm{g} / \mathrm{L}$ & - & - & 20 \\
\hline $\mathrm{Na}_{2}$ sucinado & 25 & - & - \\
\hline $\mathrm{Na}_{3}$ citrato $.2 \mathrm{H}_{2} \mathrm{O}$ & - & 80 & 80 \\
\hline $\mathrm{NH}_{4} \mathrm{Cl}$ & - & 60 & 60 \\
\hline $\mathrm{NH}_{4} \mathrm{OH}$ & - & 60 & 60 \\
\hline $\mathrm{pH}$ & 5.0 & 9.0 & 9.0 \\
\hline Temperatura $\left({ }^{\circ} \mathrm{C}\right)$ & 70 & 80 & 80 \\
\hline
\end{tabular}

\subsubsection{FORMALDEÍDO}

Concentrações altas de $\mathrm{OH}^{-}$na solução de deposição (Tabela 3.5-6) formam o complexo solúvel de $\left[\mathrm{Co}(\mathrm{OH})_{4}\right]^{-2}$ não tendo a necessidade de complexos orgânicos para a redução do Co. O processo de deposição é acompanhado pela evolução do Hidrogênio. $O$ controle da taxa de deposição é mais bem controlado com a variação da concentração de Co. Em adição a redução do cobalto o formaldeído segue a reação de Cannizarro sendo que a cinética e a perda de reagentes se torna rápida a altas concentrações (MALLORY et al., 1990). 
Tabela 3.5-6- Solução de deposição de Co para Formaldeído como agente redutor (MALLORY et al., 1990)

\begin{tabular}{|c|c|}
\hline Componente & Concentração \\
\hline $\mathrm{CoCl}_{2}$ & $0,002 \sim 0,010 \mathrm{M}$ \\
\hline $\mathrm{HCHO}$ & $0,1 \sim 0,2 \mathrm{M}$ \\
\hline $\mathrm{NaOH}$ & $7 \sim 9 \mathrm{M}$ \\
\hline Temperatura $\left({ }^{\circ} \mathrm{C}\right)$ & 30 \\
\hline
\end{tabular}

\subsubsection{OXAZOLIDINONAS}

Com a mistura de 5-metil-2-oxazolidinona [MOI] com sal orgânico de cobalto consegue-se depositar camadas de cobalto em diferentes tipos de substratos. Tipicamente a mistura de cinco (5) partes de acetilacetona de cobalto em 100 partes de $\mathrm{MOI}$ seguido por um recozimento por 2 horas a $230-250^{\circ} \mathrm{C}$ produz um filme contínuo e condutivo de cobalto, sendo que o limite da espessura depende somente da quantidade da mistura colocada sobre a superfície. (MALLORY et al., 1990)

\subsubsection{HIPOFOSFITO}

No estudo do comportamento dos aditivos na deposição de Co e Ni, Tafel reportou a co-deposição do fósforo com o cobalto. Neste estudo conseguiu-se obter o coeficiente de transferência e um gráfico que permitia calcular o número de elétrons envolvidos na deposição do fósforo.

Durante o processo de deposição do cobalto raramente se necessita de estabilizadores, mas isto não é sempre verdade para a deposição de ligas (MALLORY et al., 1990). O fósforo se deposita junto com o cobalto em pequenas quantidades, acima de um $1 \%$ de toda a concentração. A tiuréia é bem conhecida por ser uma inibidora, mas para concentrações acima de $5,8 \times 10^{-6} \mathrm{M}$, se transforma em acelerador. O hidrogênio envolvido é incorporado na deposição do Co. A imidazona tem sido proposta como um estabilizante da solução que não se incorpora no filme depositado. (MALLORY et al., 1990) 
Também é observado que $\circ \mathrm{Co}^{+3}, \circ$ qual está presente na solução de deposição de Co devido à oxidação do $\mathrm{Co}^{+2}$ pelo ar, age como estabilizador. A taxa de deposição em soluções com hipofosfito, particularmente em ambientes ácidos, é inibida pelas espécies $\mathrm{Co}^{+3} \mathrm{e} \mathrm{Co}^{+2}$. (MALLORY et al., 1990)

\subsubsection{7 $\mathrm{O}_{2}$ DISSOLVIDO}

Segundo O'Sullivan, E.J. (ALKIRE, 2001) normalmente nas soluções de deposição eletroquímica o oxigênio dissolvido pode ser encontrado em concentrações da ordem de $10^{-4} \mathrm{~mol} \mathrm{dm}^{-3}$ na temperatura ambiente. Com a adição de estabilizadores na solução de deposição eletroquímica, as moléculas de $\mathrm{O}_{2}$ tendem a se adsorver fracamente nas superfícies catalíticas ativas. Da mesma forma que a superfície metálica reduz metais ela também reduz o oxigênio dissolvido por meio de reações que envolvam 2 ou 4 elétrons afetando assim 0 potencial misto, pois a superfície passa a ficar coberto pelo oxigênio dissolvido. A equação da reação de redução do Oxigênio dissolvido de 4 elétrons é dada pela equação 3.12 .

$$
\mathrm{O}_{2}+2 \mathrm{H}_{2} \mathrm{O}+4 e \stackrel{\text { sup.catalitica }}{\longrightarrow} \mathrm{OH}^{-}
$$

Muitas das reações de deposições eletroquímicas têm a reação de redução acontecendo em um sobrepotencial na região controlada pela difusão, desta forma, os efeitos relacionados como dimensão e a distribuição do tipo de deposição tende a ser parecida tanto para estabilizadores como com oxigênio dissolvido (ALKIRE, 2001).

Para grandes áreas de deposição os efeitos do oxigênio dissolvido na cinética de deposição tende a ser uniforme sobre todo o substrato exceto nas bordas. No entanto, no caso de efeitos de difusão não planar na cinética de deposição, é preciso se considerar as espessuras que forem menores que a espessura da camada de difusão do $\mathrm{O}_{2}$, pois a magnitude destes efeitos será determinada pela hidrodinâmica e temperatura (ALKIRE, 2001). 
Os efeitos da reação de redução do $\mathrm{O}_{2}$ não é somente um estado estável da cinética de deposição, mas também o inicio da deposição, chamada de tempo de indução.

No começo do processo de deposição o potencial do circuito aberto $\left(\mathrm{E}_{\mathrm{oc}}\right)$ de cada substrato uniformemente e cataliticamente ativo (ou a partícula catalítica sobre 0 isolante) estará elevado o suficiente para ocorrer a deposição eletroquímica. Isto é uma conseqüência da superfície catalítica ativa estar coberta por espécies como $\mathrm{O}$ ou $\mathrm{OH}$ que acabam por mascarar as atividades catalíticas da superfície. $\mathrm{O}$ valor de $\mathrm{E}_{\mathrm{oc}}$ esperado está na faixa de $+0,5 \mathrm{~V}$ a $+0,7 \mathrm{~V}$ em relação ao eletrodo de hidrogênio reversível (RHE) para a superfície de paládio (ALKIRE, 2001).

Normalmente este potencial pode ser anódico ou positivo com relação ao valor do potencial misto $\left(E_{m}\right)$ da reação eletroquímica (Figura 3.3-2 item 3.2). Fazendo a remoção das espécies de óxido da superfície catalítica, a deposição catalítica pode iniciar ou não, dependendo da relação entre a cinéticas das reações dos íons metálicos com a reação de redução do $\mathrm{O}_{2}$ e a oxidação do agente redutor. Uma vez atingido um valor de $E_{m}$ apropriado à deposição do metal irá acontecer (ALKIRE, 2001).

Segundo O'Sullivan, E.J. (ALKIRE, 2001), a oxidação do redutor ocorre sobre o controle cinético pelo menos sobre uma região acima do potencial de interesse da deposição eletroquímica. Isto indica que a cinética ou mais especialmente o equivalente à densidade de corrente parcial para este reação deveria ser a mesma para qualquer característica catalítica ativa. Por outro lado, é conhecido que a reação de redução do $\mathrm{O}_{2}$ pode acontecer sobre a condição de controle de difusão a poucos centésimos de milivolts do potencial catódico do valor de potencial do circuito aberto $\left(E_{o c}\right)$ mesmo para uma pequena reação catalítica. Isto é verdade para catálise inicial do Pd utilizado para deposição eletroquímica e isto pode ser válido para amostras recentemente depositadas eletroquímicamente de Ni-P, Co-P e Cu. Assim, a redução do $\mathrm{O}_{2}$ se torna controlada pela difusão quando uma das dimensões excede a espessura da camada de difusão do $\mathrm{O}_{2}$. $\mathrm{O}$ transporte do $\mathrm{O}_{2}$ acontece sobre as condições de difusão planar (exceto para condições de borda) (ALKIRE, 2001). 
Por outro lado, as situações para características menores que a espessura da camada de difusão pode ser descrita fazendo analogia com o eletrodo de micro disco (ALKIRE, 2001). O máximo da densidade de corrente para eletro-redução do $\mathrm{O}_{2}\left(\mathrm{i}_{\mathrm{m}\left(\mathrm{O}_{2}\right)}\right)$ pode ser observado no gráfico abaixo (Figura 3.5-1) em relação ao raio do eletrodo de micro-disco, $r$ :

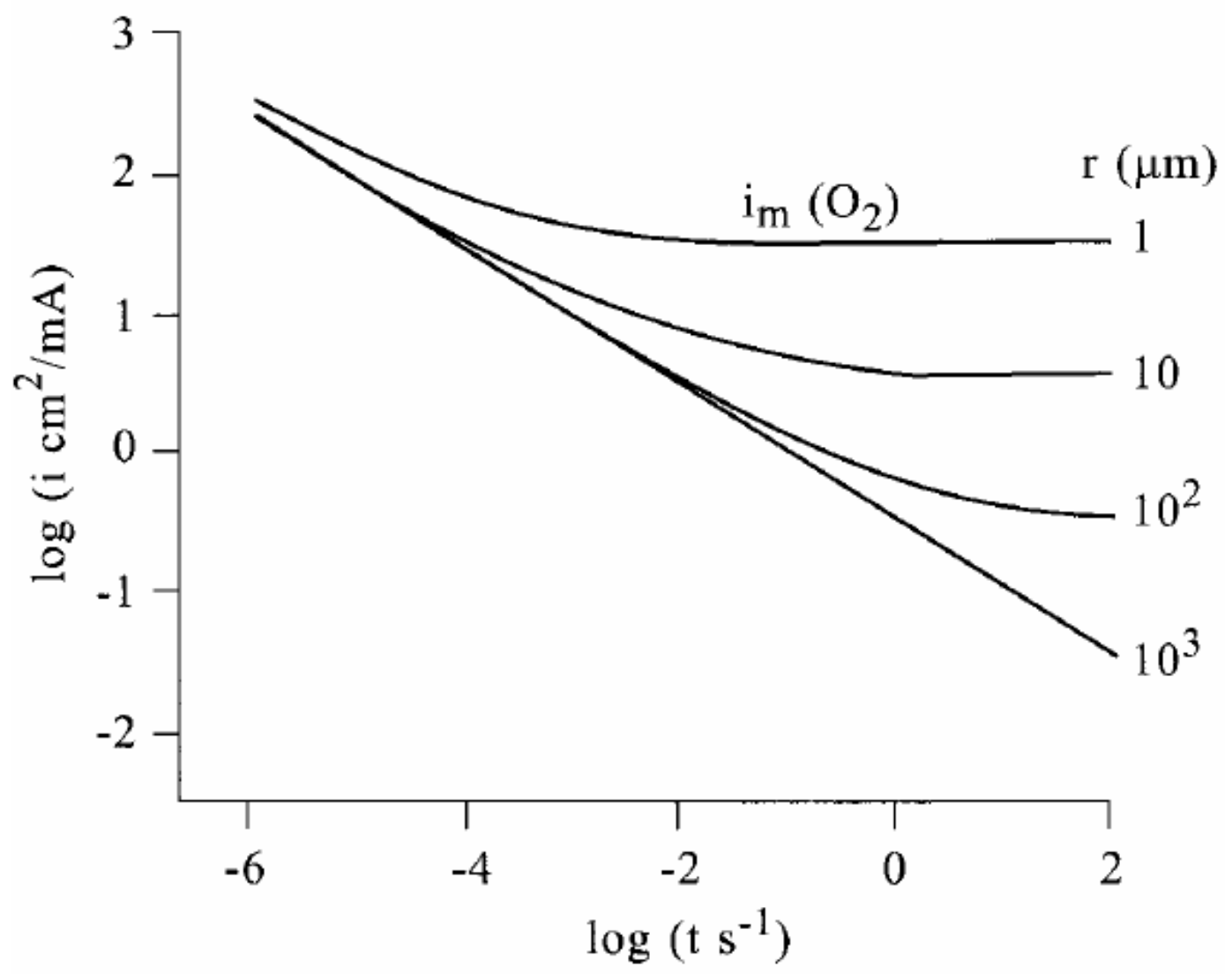

Figura 3.5-1 - Gráfico logaritmo do (i $\left.\mathbf{i}_{\mathrm{m}(\mathrm{O} 2)}\right)$ versus $\mathrm{t}$ para diferentes valores do raio do eletrodo de micro disco (ALKIRE,2001).

Na Figura 3.5-1, pode-se observar várias curvas de $\left(\mathrm{i}_{\mathrm{m}\left(\mathrm{O}_{2}\right)}\right)$ versus log de $\mathrm{t}$ (onde t é o tempo), onde para grandes valores de $\mathrm{r}$, o transporte do $\mathrm{O}_{2}$ para a superfície segue um comportamento de perfil linear para tempos finitos sem agitação. No caso de pequenos valores de r, no entanto, na condição de difusão estável aplicada há tempos pequenos tem um perfil de natureza não linear devido ao processo de difusão. Dessa forma, a densidade de corrente parcial para a redução do $\mathrm{O}_{2}$ na deposição eletroquímica deverá tender a ser governada pelos fatores cinéticos para pequenas regiões enquanto que para regiões maiores será determinada pela espessura da camada de difusão (ALKIRE, 2001). 


\title{
4 TÉCNICAS DE ANÁLISE DE SUPERFÍCIES DE LÂMINAS DE SILÍCIO
}

\begin{abstract}
Neste capítulo, abordaremos de forma simples e resumida as técnicas de análise utilizadas para a caracterização dos filmes finos depositados para 0 desenvolvimento deste trabalho. Estas técnicas são de grande importância no estudo das características físicas e morfológicas dos filmes finos obtidos pelos processos de deposição eletroquímica espontânea.
\end{abstract}

Descreveremos aqui as seguintes técnicas de análise:

- Perfilometria (medida de altura de degrau);

- RBS (Espectroscopia de Retroespalhamento de Rutherford);

- AFM (Microscopia de Força Atômica);

\subsection{PERFILOMETRIA}

Através da análise por perfilometria, pode-se obter um perfil topográfico bidimensional das superfícies em análise e também, podem-se medir a partir destes mesmos perfis as alturas de degrau. O equipamento de perfilometria converte e amplifica sinais provenientes de uma ponta bem fina que percorre a amostra e sobre a qual está aplicada uma força pré-determinada $(\sim 1 \mathrm{nN})$ de acordo com o tipo material do qual se deseja levantar o perfil topográfico. O "subir" e "descer" da ponta induz sinais elétricos que são enviados, por exemplo, a uma tela de TV que mostra um gráfico do perfil do filme [SOU97]. 


\subsection{RBS (ESPECTROSCOPIA DE RETROESPALHAMENTO DE RUTHERFORD)}

RBS (RUTHERFORD BACKSCATTERING SPECTROMETRY) tem por princípio a incidência de partículas Alfa $\left({ }^{4} \mathrm{He}^{+}\right)$em uma amostra (em vácuo em uma pressão da ordem de $10^{-6}$ torr) com uma energia inicial bem determinada $E_{0}$, seguido de um retroespalhamento destas partículas Alfa, com uma energia $\mathrm{K}_{M} \mathrm{E}_{0}$, as quais serão coletadas por um detector que amplificará e converterá em sinais elétricos transmitindo-os para um microcomputador o qual, por sua, vez fornecerá um espectro (CHU, 1978).

Existem cinco parâmetros básicos de grande importância para a técnica de RBS, o fator cinemático, seção de choque diferencial, seção choque de freamento, fator de freamento e a perda de energia ( $\mathrm{CHU}, 1978)$.

\subsubsection{FATOR CINEMÁTICO $\left(\mathrm{K}_{\mathrm{M}}\right)$}

O fator cinemático $\left(\mathrm{K}_{\mathrm{M}}\right)$ é um fator de perda de energia de uma partícula quando a mesma colide com outra. Uma partícula de massa $M_{1}$ se movendo com uma determinada velocidade, ao colidir com uma partícula de massa $\mathrm{M}_{2}$ parada, perde parte de sua energia cinética para a partícula de massa $\mathrm{M}_{2}$. Assumindo a colisão como uma colisão elástica (sem perda de energia durante a transferência) entre as duas partículas pode-se, dizer que o Fator Cinemático, ou seja, a razão das energias do projétil entre "o depois" e "o antes" da colisão é dado pela equação 4.1 (CHU, 1978):

$$
K_{M}=\left[\frac{\left(M_{2}^{2}-M_{1}^{2} \cdot \operatorname{sen}^{2} \theta_{e}\right)^{\frac{1}{2}}+M_{1} \cdot \cos \theta_{e}}{M_{2}+M_{1}}\right]^{2}
$$

onde $\theta_{\mathrm{e}}$ é o ângulo de espalhamento, $M_{1}$ e $M_{2}$ são as massas das partículas incidentes e do material a ser analisado, respectivamente. 


\subsubsection{SEÇÃO DE CHOQUE DIFERENCIAL ( $\left.\sigma_{\text {choque }}\right)$}

A seção de choque diferencial é a probabilidade de existir a colisão entre duas partículas levando a ocorrência do espalhamento. Considerando o modelo já citado no item anterior, existe uma ligação direta entre a energia incidente $\mathrm{E}_{0} \mathrm{com}$ a energia $E_{1}=K_{M} E_{0}$ de espalhamento da partícula em um angulo " $\theta_{s}$ " após a colisão elástica. No entanto, a probabilidade de ocorrer este choque pode ser expressa pela integral da equação 4.2 (CHU, 1978):

$$
\frac{d \sigma_{\text {choque }}}{d x}=\left[\frac{Z_{1} \cdot Z_{2} \cdot e_{1}^{2}}{4 \cdot E_{0} \cdot \operatorname{sen}^{2}\left(\frac{\theta_{s}}{2}\right)}\right]^{2}
$$

Onde:

$\sigma_{\text {choque }}$ : é a seção de choque diferencial;

$Z_{1}$ : número atômico da partícula incidente;

$Z_{2}$ : número atômico da partícula do alvo (amostra);

$\theta_{s}$ : ângulo suplementar entre o feixe incidente e o detetor;

E1: é a carga eletrônica e

$E_{0}$ : é a energia do feixe incidente.

\subsubsection{SEÇÃO DE CHOQUE DE FREAMENTO, PERDA DE ENERGIA E FATOR DE REAMENTO: (CHU, 1978)}

Além da seção de choque diferencial ( $\left.\sigma_{\text {choque }}\right)$, define-se também a seção de choque de freamento $(\varepsilon)$ associado à perda de energia de uma dada partícula dentro da amostra. Esta perda de energia corresponde ao fato de se ter uma partícula se movendo ao longo do material "alvo" com uma energia que decai de $\mathrm{E}_{0}$ a um valor "E" antes que ocorra a colisão. Esta perda de energia é definida como sendo dada por (CHU, 1978): 


$$
\frac{d E}{d x}(E) \equiv \lim \frac{\Delta E}{\Delta X} \quad \operatorname{com} \Delta \mathrm{X} \rightarrow 0
$$

Esta perda de energia de uma partícula movendo-se ao longo do material deve-se a interação com as nuvens de elétrons dos átomos do material ou a colisões de pequenos ângulos com o núcleo dos átomos da rede. Portanto, a seção de choque de freamento $(\varepsilon)$ pode ser dada pela seguinte equação 4.4 (CHU, 1978).

$$
\mathcal{E} \equiv \frac{1}{N_{v}} \cdot \frac{d E}{d x}
$$

onde $N_{v}$ é a densidade volumétrica de átomos no alvo, e por convenção, $\varepsilon$ é dado pela seguinte unidade: elétron.Volts.centímetro quadrado por átomo $\left(\mathrm{eV} \mathrm{cm}{ }^{2}\right)$.

O fator de freamento [E], por sua vez, pode ser obtido através das seções de choque de freamento durante a entrada $\left(\varepsilon_{\text {in }}\right)$ e durante a saída $\left(\varepsilon_{\text {out }}\right)$ do feixe conforme a equação 4.5 (CHU, 1978).

$$
[\mathcal{\varepsilon}]=\left.K_{M} \cdot \varepsilon_{\text {in }}\right|_{E=E_{o}}+\left.\frac{1}{\cos \theta_{e}} \cdot \varepsilon_{\text {out }}\right|_{E=K_{M} \cdot E_{o}}
$$

onde o feixe de partículas " $\alpha$ " incide segundo a direção normal e o feixe refletido apresenta ângulo de espalhamento $\theta_{\mathrm{e}}$.

Através dos fatores previamente definidos podemos extrair uma série de parâmetros dos espectros de RBS. Por exemplo, através do espectro mostrado na Figura 4.2-1 podemos chegar a obter a concentração planar total de átomos de cobalto por centímetro quadrado $\left(\mathrm{N}_{\mathrm{d}}\right)$ e sua respectiva espessura ( $\left.\mathrm{t}_{\mathrm{co}}\right)$ a partir do sinal de cobalto. 


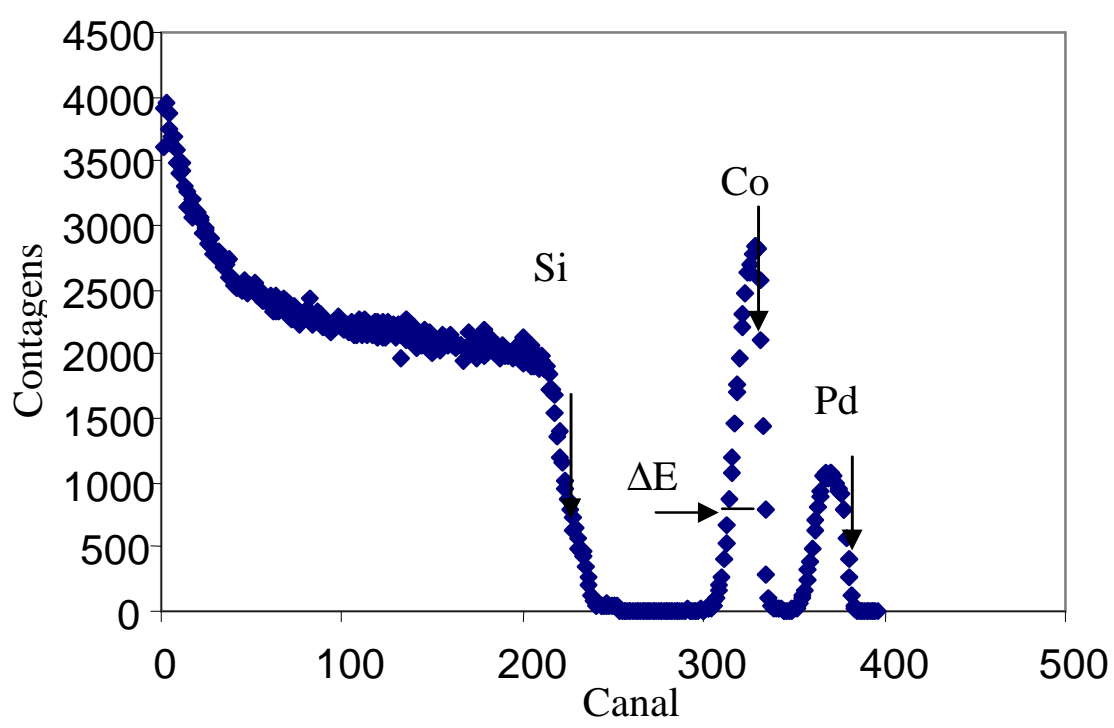

Figura 4.2-1- Espectro de RBS típico de um filme de cobalto sobre Silício ativado por Paládio.

O espectro da Figura 4.2-1 foi obtido através de um equipamento com as seguintes características: $E_{0}=2,4 \mathrm{MeV}$; carga integrada $20 \mu \mathrm{C}$; ângulo de espalhamento de $10^{\circ} ; 5 \mathrm{KeV} / \mathrm{canal}$.

Do espectro mostrado na Figura 4.2-1 verifica-se que o sinal de cobalto vai do canal 341 até o canal 357 e, desta forma, temos uma largura em energia $\Delta \mathrm{E}=80 \mathrm{KeV}$. Com a largura em energia e $\mathrm{o}$ fator de freamento, podemos determinar a concentração planar total de cobalto através da equação 4.6 ( $\mathrm{CHU}$, 1978).

$$
N_{d}=\frac{\Delta E}{[\varepsilon]}=N_{d_{R}}
$$

onde,

$\mathrm{N}_{\mathrm{d}}$ : concentração planar total

$M_{C_{0}}=58,93 \quad$ (massa atômica do cobalto)(Callister Jr, W.C -2000).

$[\varepsilon]=123,1 \cdot 10^{-15} \mathrm{eVcm}^{2}(\mathrm{CHU}, 1978)$ 
portanto,

$$
N_{d}=\frac{80}{123,1 \cdot 10^{-15}}=0,65 \cdot 10^{18} \mathrm{At} / \mathrm{cm}^{2}
$$

A espessura, por sua vez, será dada por (CHU, 1978):

$$
t_{C o}=\frac{N_{d}}{d_{C o}}
$$

Onde $\mathrm{d}_{\mathrm{co}}$ é a densidade atômica do cobalto.

Se considerar a densidade do cobalto tabelada $\left(D_{C_{0}}=8,9 \mathrm{~g} / \mathrm{cm}^{3}\right.$ para material de "bulk") tem-se (SANTOS FILHO,1996):

$$
d_{C o}=\frac{N_{a v g} \cdot D_{C o}}{M_{C o}}
$$

onde $\mathrm{N}_{\mathrm{avg}}$ é o número de Avogadro. Portanto:

$d_{C_{0}}=0,91 \cdot 10^{23} \mathrm{At} / \mathrm{cm}^{3}$

e assim, substituindo os valores na expressão 19 temos:

$\mathrm{t}_{\mathrm{Co}}=0,71 \cdot 10^{-5} \mathrm{~cm}$ ou $71,0 \mathrm{~nm}$.

A obtenção da concentração planar total de cobalto $\left(\mathrm{N}_{\mathrm{d}}\right)$, utilizando a expressão 18 , só é possível para filmes espessos onde " $\Delta \mathrm{E}$ " pode ser obtido facilmente conforme indicado na (largura na meia altura).

No caso de filmes finos onde " $\Delta E$ " não pode ser estimado adequadamente (o sinal de cobalto não apresenta patamar definido), a concentração planar total de cobalto deve ser obtido através da área do sinal de cobalto de acordo com a seguinte expressão (SANTOS FILHO, 1996):

$$
N_{d}=\frac{A_{C o} \cdot Q_{C o_{R}} \cdot N_{d_{R}}}{A_{C o_{R}} \cdot Q_{C o}}
$$

onde $A_{C_{0}}$ é a área total sob o sinal de cobalto do filme fino, $Q_{C_{o}}$ é a carga total integrada na análise RBS para o filme fino de cobalto, $A_{C o R}$ é a área total sob o sinal de cobalto de um filme espesso de referência, $Q_{C o R}$ é a carga total integrada 
na análise RBS para o filme de cobalto espesso de referência e $N_{d R}$ é a concentração planar total de cobalto do filme espesso de referência obtida através da expressão 18.

\subsection{MICROSCOPIA DE FORÇA ATÔMICA}

No microscópio de força atômica, uma ponta muito fina e pequena está apoiada sobre a superfície do material a ser analisado e sobre esta ponta, que se desloca na direção horizontal, está aplicada uma força constante. A deflexão vertical da ponta é convertida num sinal eletrônico que mais tarde será colocado na forma de um gráfico 3D conforme os exemplos mostrados na Figura 4.3-1 e Figura 4.3-2. Através de um tratamento adequado de imagens pode-se magnificar o relevo superficial da amostra e com isto pode-se analisar a granulometria do material e principalmente fazer um estudo da rugosidade de forma quantitativa.

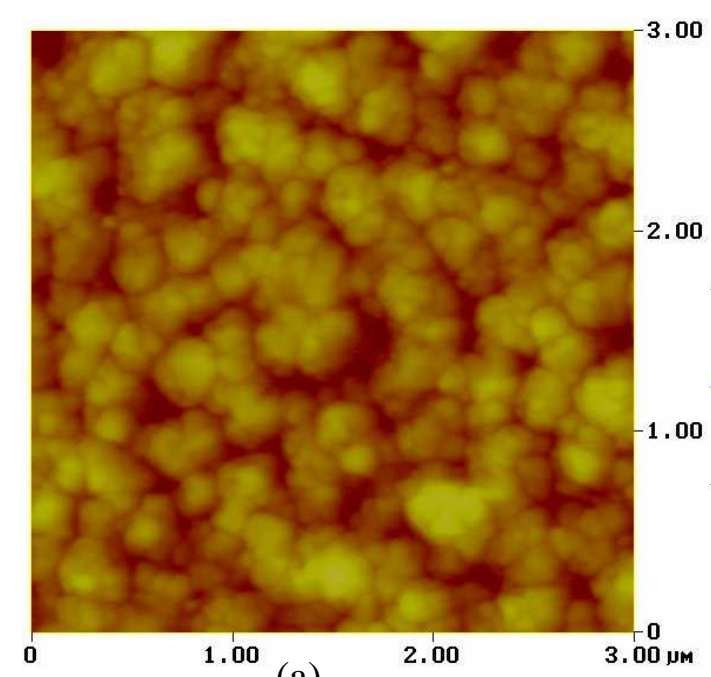

(a)

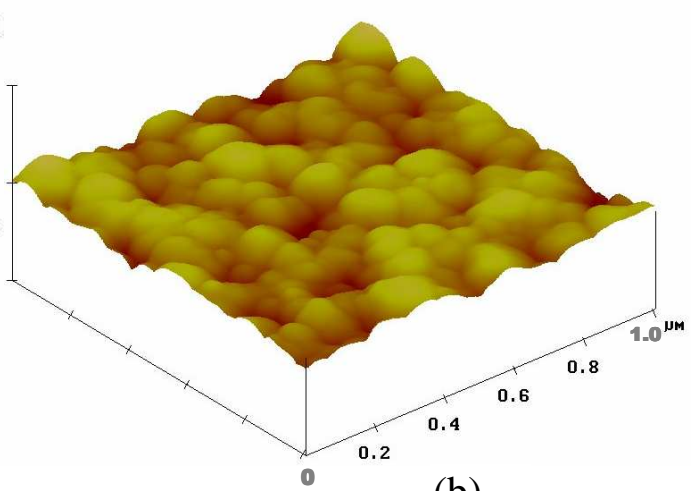

(b)

Figura 4.3-1- Imagem de AFM de um Figura 4.3-2- Imagem AFM de um filme de cobalto $(3 \mu \mathrm{m} \times 3 \mu \mathrm{m})$ filme de cobalto mas em uma área de $1 \mu \mathrm{m} \times 1 \mu \mathrm{m}$. em 3D 


\subsection{PROCEDIMENTOS DE LIMPEZA}

Sabe-se da literatura que os procedimentos de limpeza química inicial das lâminas de silício são de grande importância, pois é nesta etapa em que se eliminam a maior parte da contaminação sobre a superfície das amostras ou sobre o óxido de superfície. Relatos mostram que existe uma relação entre as características elétricas e a contaminação metálica, por exemplo, o campo elétrico de ruptura do óxido de porta e a carga total no óxido são afetados significativamente com uma contaminação metálica da ordem de $10^{11}$ átomos $/ \mathrm{cm}^{2}$. Por outro lado, a contaminação com átomos de Fe acarreta a degradação do tempo de vida dos portadores minoritários e aumenta a corrente de fuga em transistores MOS (MIZOKAMl et al. 1994).

Anttila et.al. (ANTTILA et al., 1992) realizaram um estudo sobre os efeitos das soluções químicas na contaminação metálica das lâminas de silício. Em seu trabalho foram testadas soluções químicas de vários fornecedores com relação aos níveis de contaminantes deixados sobre as lâminas de silício depois da limpeza química das mesmas. Foram utilizadas soluções químicas de $\mathrm{HCl}$ e $\mathrm{NH}_{4} \mathrm{OH}$ de três fornecedores e $\mathrm{H}_{2} \mathrm{O}_{2}$ de quatro fornecedores distintos.

Concluíram que a solução APM $\left(\mathrm{NH}_{4} \mathrm{OH}: \mathrm{H}_{2} \mathrm{O}_{2}: \mathrm{H}_{2} \mathrm{O}, 1: 1: 570^{\circ} \mathrm{C} 10 \mathrm{~min}\right.$.) conseguia resultados melhores para particulados na superfície das lâminas de silício (Figura 4.4-1),enquanto que o ferro, zinco e alumínio se depositavam muito mais fácil (Figura 4.4-1). Uma possível redução destes contaminantes seria obtida com a utilização de solução APM com pureza maior, um menor tempo de fervura e uma melhor combinação entre a temperatura e a razão das misturas da solução, especificamente, o hidróxido de amônio. 


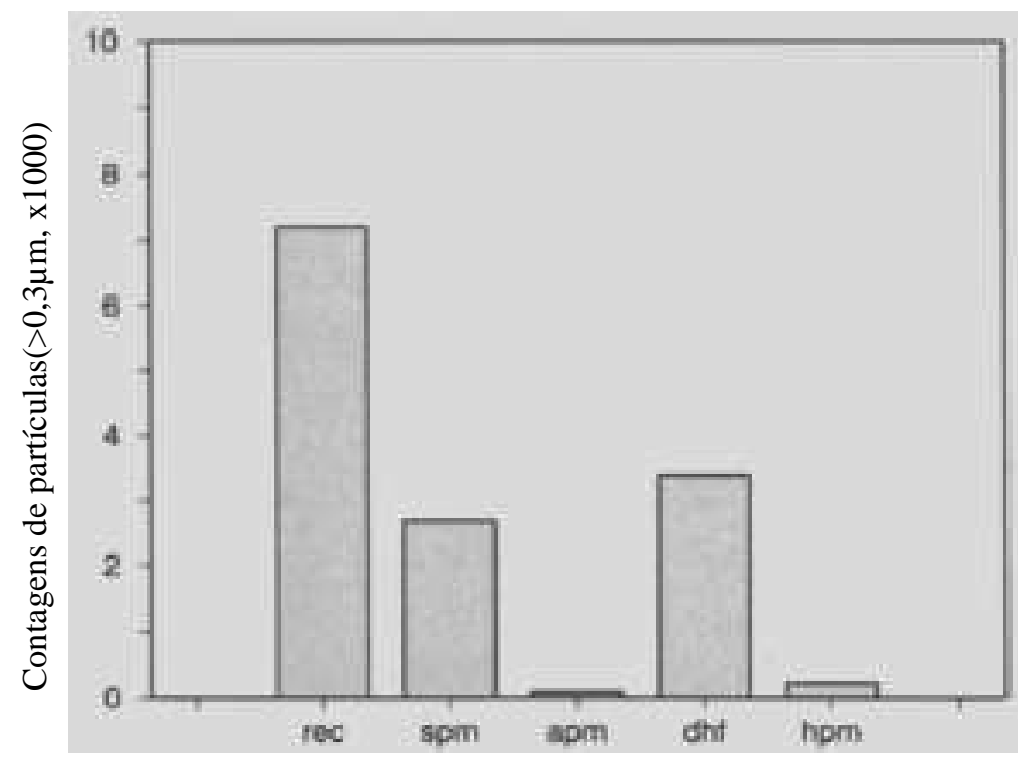

Figura 4.4-1 - Concentração de partículas na superfície das lâminas de silício. (ANTTILA et al., 1992).

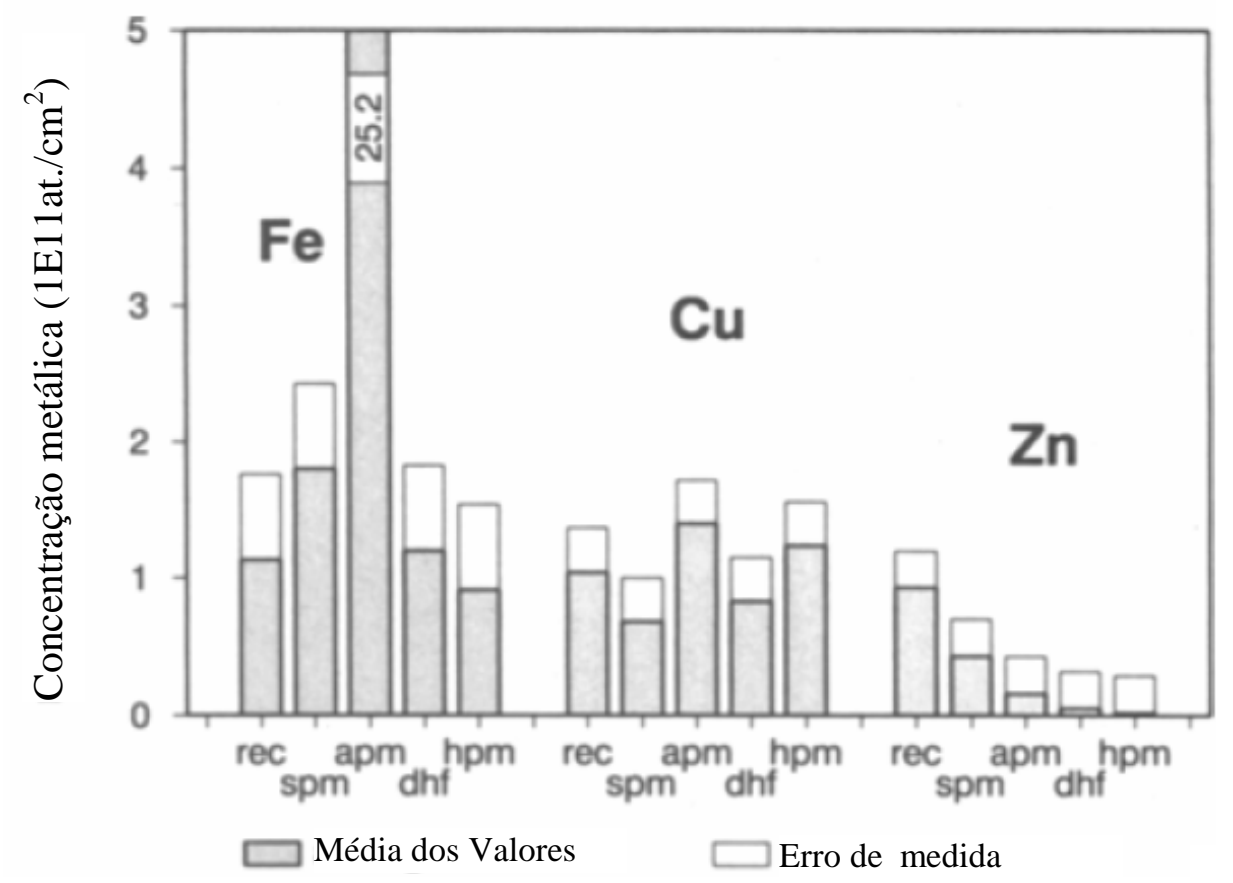

Figura 4.4-2 - Concentração metálica nas soluções SPM-APM-DHF-HPM (ANTTILA et al., 1992) 
No caso da solução HPM ( $\mathrm{HCl}: \mathrm{H}_{2} \mathrm{O}_{2}: \mathrm{H}_{2} \mathrm{O}, 1: 1: 570^{\circ} \mathrm{C} 10$ min.) observou-se que os níveis de contaminantes metálicos eram baixos (Figura 4.4-2) e independentes dos fornecedores. Constatou-se também que o peróxido de hidrogênio em soluções alcalinas se decompõe muito rápido sendo isto o principal causador das contaminações metálicas.

Através deste estudo, pode-se observar que apesar da concentração elevada de partículas nas lâminas recebidas, os íons de ferro e cobre passam a ficar mais elevados depois dos processos de limpeza completa e os íons de zinco baixaram. Porém ao se observar as concentrações de ferro e cobre das lâminas recebidas, a concentração de zinco inicial é menor que ambas.

\subsection{ESTUDO DA EVOLUÇÃO DA RUGOSIDADE NO CRESCIMENTO DE FILMES FINOS}

O estudo da evolução da rugosidade no crescimento dos filmes finos com o tempo é de extrema importância para se compreender e prever a morfologia da superfície, Segundo Huo et. Al.. (HUO, 2001), a rugosidade de superfície pode afetar a taxa de deposição de filmes finos, influenciar na rugosidade do filme depositado, na resistividade, dificultar no processo de escalamento de dispositivos em microeletrônica, espalhamento de elétrons em interfaces de $\mathrm{Si} / \mathrm{SiO}_{2}$ e também nas características elétricas como em contatos entre siliceto/silício (HUO, 2001).

\subsection{1 - PARÂMETROS PARA A QUANTIFICAÇÃO DE RUGOSIDADE (HUO, 2001)}

Os quantificadores da rugosidade são (HUO, 2001):

$\begin{array}{ll}- & \text { Altura média }(\mathrm{z}) \\ \text { - } & \text { Rugosidade média }\left(\mathrm{R}_{\mathrm{m}}\right) \\ \text { - } & \text { Rugosidade } \mathrm{RMS}\left(\mathrm{R}_{\mathrm{rms}}\right)\end{array}$


- $\quad$ Rugosidade vale-pico $\left(\mathrm{R}_{\mathrm{v}-\mathrm{p}}\right)$

onde a Altura média (z) é a média das alturas em relação a uma referência de nível inferior mínimo dentro de uma área analisada, e é descrita pela relação 4.10 (HUO, 2001).

$$
\bar{z}=\frac{\sum_{n=1}^{N} z_{n}}{N}
$$

onde,

- $Z_{n}$ é a altura em relação a uma referência de nível inferior mínimo

- $\quad \mathrm{N}$ é o número de pontos contidos na área analisada.

A Rugosidade média $\left(R_{m}\right)$ é o desvio médio das alturas em relação a uma altura média na área analisada dada pela relação 4.11 (HUO, 2001).

$$
R_{m}=\sum_{n=1}^{N} \frac{\left|z_{n}-\bar{z}\right|}{N}
$$

onde,

- $\quad \bar{z}$ é a média das alturas.

A rugosidade RMS $\left(R_{r m s}\right)$ é fornecida pelo cálculo do desvio padrão das alturas (equação 4.12) (HUO, 2001).

$$
R_{R M S}=\sqrt{\frac{\sum_{n=1}^{N}\left(z_{n}-\bar{z}\right)^{2}}{N}}
$$


A rugosidade vale-pico $\left(R_{v-p}\right)$ é distância máxima vale-pico na área analisada dada pela relação 4.13 (HUO, 2001).

$$
R_{v-p}=z_{\text {max }}-z_{\text {min }}
$$

onde,

- $\quad z_{\max }$ é o ponto mais alto;

- $z_{\text {mim }}$ é o ponto mais baixo, se o nível de referência for inferior mínimo, temos $Z_{\text {mim }}=0$ (HUO, 2001).

\subsection{2 - ESTUDO DO ESCALAMENTO DINÂMICO DA RUGOSIDADE DE SUPERFÍCIE}

Segundo Huo (2001) o microscópio de força atômico (AFM) é uma ferramenta útil para estudar o escalamento dinâmico da rugosidade de superfície para vários metais. O AFM gera uma imagem $3 \mathrm{D}$, que pode ser observada na Figura 4.3-2, e por meio desta imagem pode-se gerar um arquivo ASCII que contem a distribuição de alturas associadas à área analisada. Desta forma pode-se obter o valor do desvio médio quadrático da distribuição de alturas em uma área quadrada de lado "l" segundo a equação 4.14 .

$$
w(l, t)=\sqrt{\left\langle(z-\bar{z})^{2}\right\rangle}=\sqrt{\frac{\sum_{n=1}^{N}\left(z n^{-}\right)^{2}}{N}}=R_{R M S}
$$

onde,

- $\mathrm{W}(\mathrm{l}, \mathrm{t})$-é o desvio médio quadrático das alturas conhecido como largura de superfície associada ao comprimento de escala "l" no instante " $t$ "; 
- "l" - é comprimento de escala;

- z - é a altura da superfície em relação a um nível de referência;

- $\quad \bar{z}$ - é a média das alturas;

- "t" - é o tempo.

Com os valores de $w$ de cada região de uma imagem de AFM, pode ser gerado um gráfico em função do comprimento de escala "l" (Figura 4.5-1)

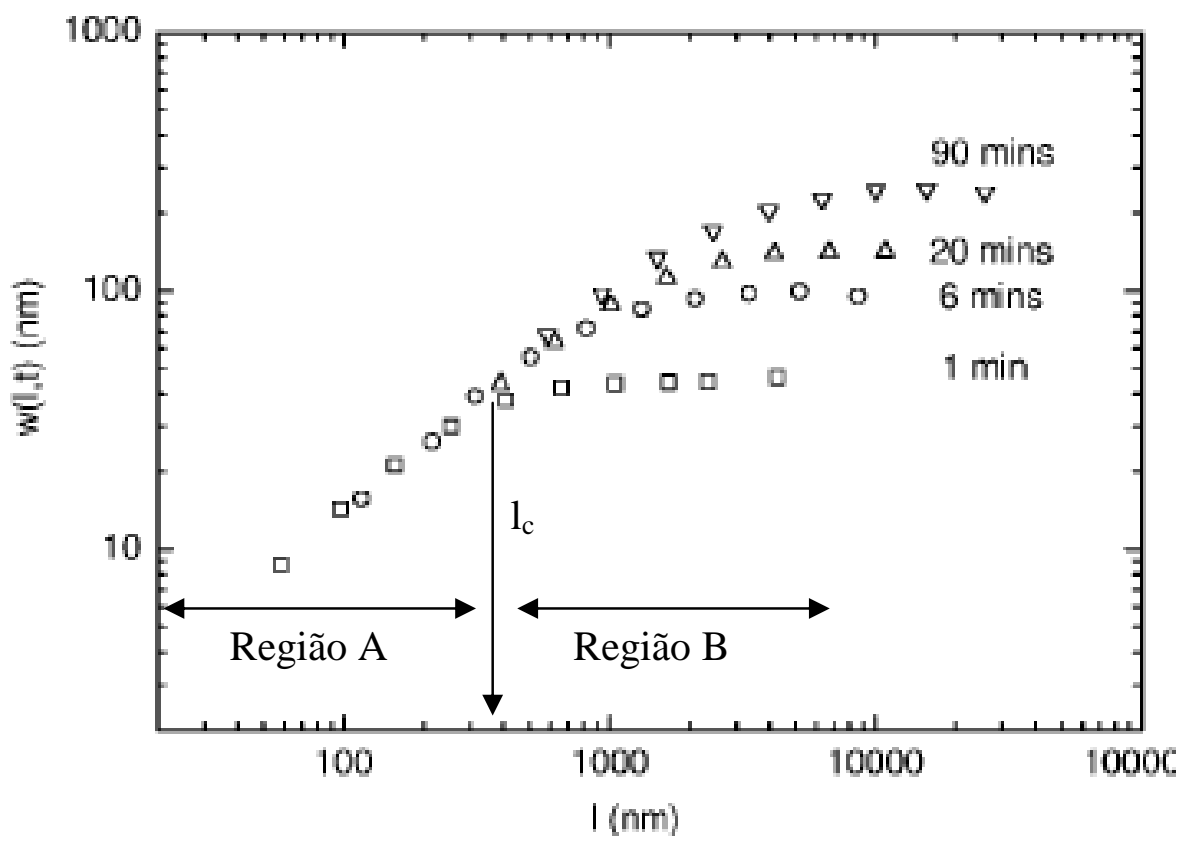

Figura 4.5-1-Gráfico do desvio médio quadrático das alturas ou largura de superfície $\mathrm{w}(\mathrm{l}, \mathrm{t})$ (HUO \& SCHWARZACHER,2001) $\mathrm{I}_{\mathrm{c}}$ é função do tempo de deposição.

Segundo Huo (2001), pode-se observar na Figura 4.5-1 duas regiões:

- região A - Valores de w aumentam em função de " $l$ ", abaixo de " $l c$ ";

- região $\mathrm{B}$ - saturação de $\mathrm{w}$, onde w se mantém constante ao aumentar os valores de "l", acima de "l";

- "ll" - é o comprimento de escala crítico e separa as duas regiões. 
Na região A, os valores de w são constantes com o aumento de "t", e w é proporcional a "l" elevado à potência de H, conforme relação 4.15 (HUO, 2001).

$$
w(l) \propto l^{H} \quad \text { para " } l "<<" l_{c} "
$$

onde,

- H é o expoente de Hurst, indica como a rugosidade aumenta com o comprimento de escala e pode ser extraído pelo cálculo da inclinação da reta do gráfico de w em função de "l" na região A (HUO, 2001).

$\mathrm{Na}$ região $\mathrm{B}$, os valores de $\mathrm{w}$ aumentam com o aumento do tempo de deposição "t" e w é proporcional a "t" elevado à potência de $\beta$, conforme equação 4.16 (HUO, 2001):

$$
w(l) \propto t^{\beta} \quad \text { para "l" }>>l_{c} "
$$

onde,

- $\beta$ é o expoente de crescimento temporal, indica como a rugosidade evolui com o tempo de deposição ou espessura do filme depositado e pode ser extraído pelo cálculo da inclinação da reta do gráfico de w em função de "t" ou da espessura média do filme depositado para w da região B (HUO, 2001).

Segundo Huo (2001) quando a deposição se inicia em uma superfície lisa, w é normalmente independente do tempo de deposição "t" para comprimento de escala pequenos ("l" $<<$ " $l_{c}$ "), e é independente de "l" para "l" >> " $l_{c}$ ". Quando "l" = " $l$ " tem-se a máxima extensão de correlação lateral, " $l_{c} " \propto t^{1 / z_{c}}$ onde $z_{c}$ é o expoente dinâmico e deve ser igual a $H / \beta$, conhecido como escalamento dinâmico de Family-Vicsek . (HUO, 2001) representado na equação 4.17.

$$
w(l, t)=l^{H} \cdot f\left(t / l^{z_{c}}\right)
$$


A função de escalamento $f(x)$ é constante para $x>>1$, e varia com $x^{\beta}$ para $X<<1$. Segundo Huo (2001), existem dois tipos de escalamento:

- tipo normal - (Figura 4.5-2) os valores de w são constantes com o aumento do tempo de deposição "t" e o comprimento de escala segue as equações 4.16 e 4.17 (HUO, 2001);

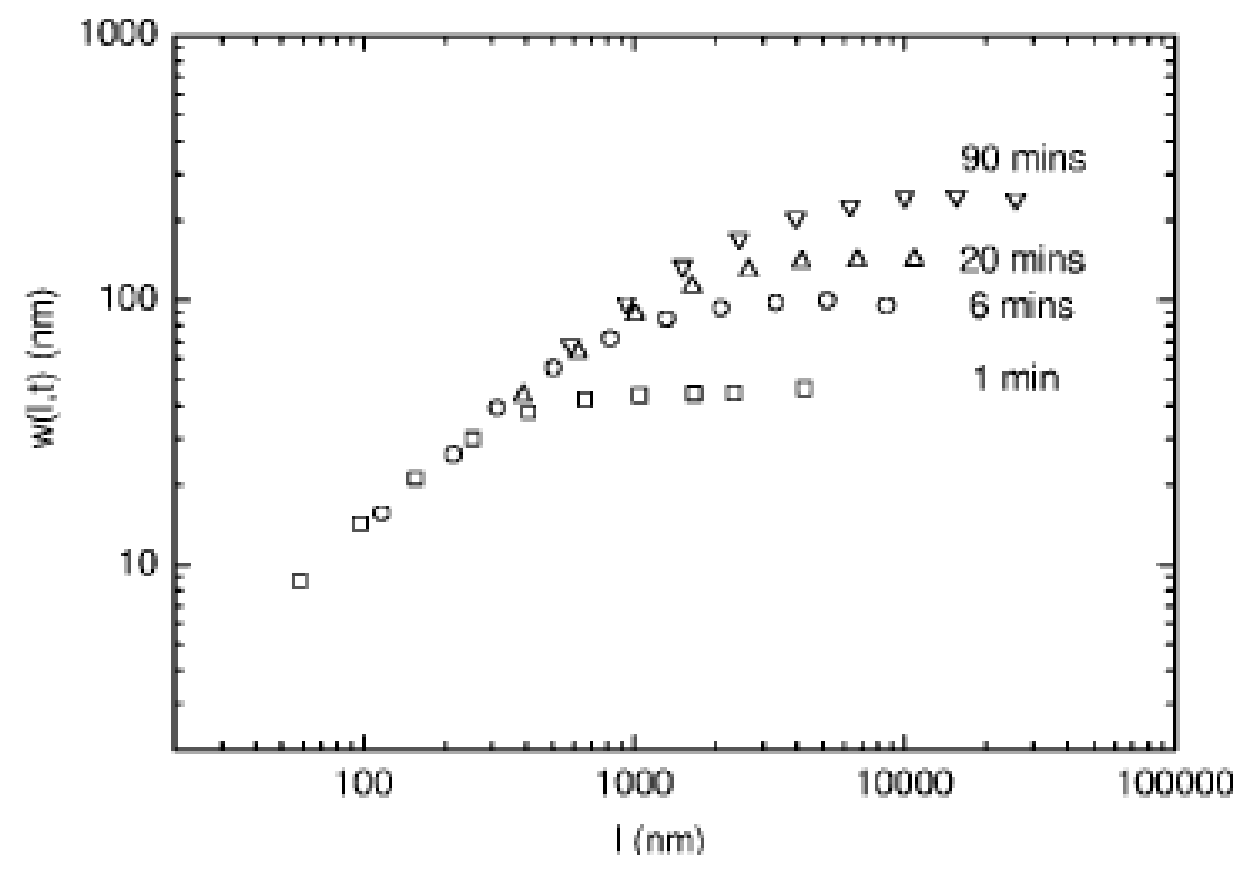

Figura 4.5-2- Gráfico do desvio médio quadrático das alturas ou largura de superfície $w(l, t)$ ilustrando 0 escalamento do tipo normal (HUO \& SCHWARZACHER,2001)

- tipo anômalo - (Figura 4.5-3) os valores de w abaixo do comprimento de escala crítico " $l_{c}$ " aumenta com o tempo de deposição "t", fazendo que evoluam os valores da rugosidade, na região onde "l" $<<$ " $l_{c}$ ", com 0 tempo de deposição ou com a espessura do filme depositado. Nesse caso, w escala com "l" na potência $\mathrm{H}$ e "t", com $\beta_{\text {local }}$ (equação 4.18) (HUO, 2001).

$$
w(l, t) \propto l^{H} t^{\beta_{\text {local }}} \quad \text { para "l" }<<l_{c} "
$$

onde $\beta_{\text {local }}$ é o expoente de crescimento temporal local e caracteriza como valores da rugosidade evoluem com o tempo de deposição ou com a espessura do filme 
na região onde "l" < " $l$ ". Para a região $B(" l$ " >> " $l$ "), w escala com "t" elevado à potência $\beta+\beta_{\text {local }}$ (equação 4.19)(HUO, 2001):

$$
w(l, t) \propto l^{H} t^{\beta+\beta_{\text {local }}} \quad \text { para "l" }<<" l_{c} "
$$

o Expoente $\beta_{\text {local }}$ pode ser obtido pelo cálculo da inclinação da reta do gráfico de w em função do tempo de deposição (HUO, 2001). Se o valor do expoente $\beta_{\text {local }}$ neste gráfico for diferente de zero, tem-se o escalamento anômalo (HUO, 2001) descrito pela equação 4.20.

$$
w(l, t)=l^{H} \cdot t^{\beta_{\text {local }}} f\left(t / l^{z_{c}}\right)
$$

Segundo Huo (2001), no escalamento anômalo, w é dependente de "t" para "l" pequeno ("l" $<<$ " $l$ "), ou seja, a lei de potência é dependente de "l" e "t". A lei de potência é dependente de "t" para " $l$ " grande ("l" >> " $l_{c}$ ") w escala com $t$ " na região onde "l" >> " $l_{c}$ " e o ponto de intersecção continua a escalar com $t / z_{c}$.

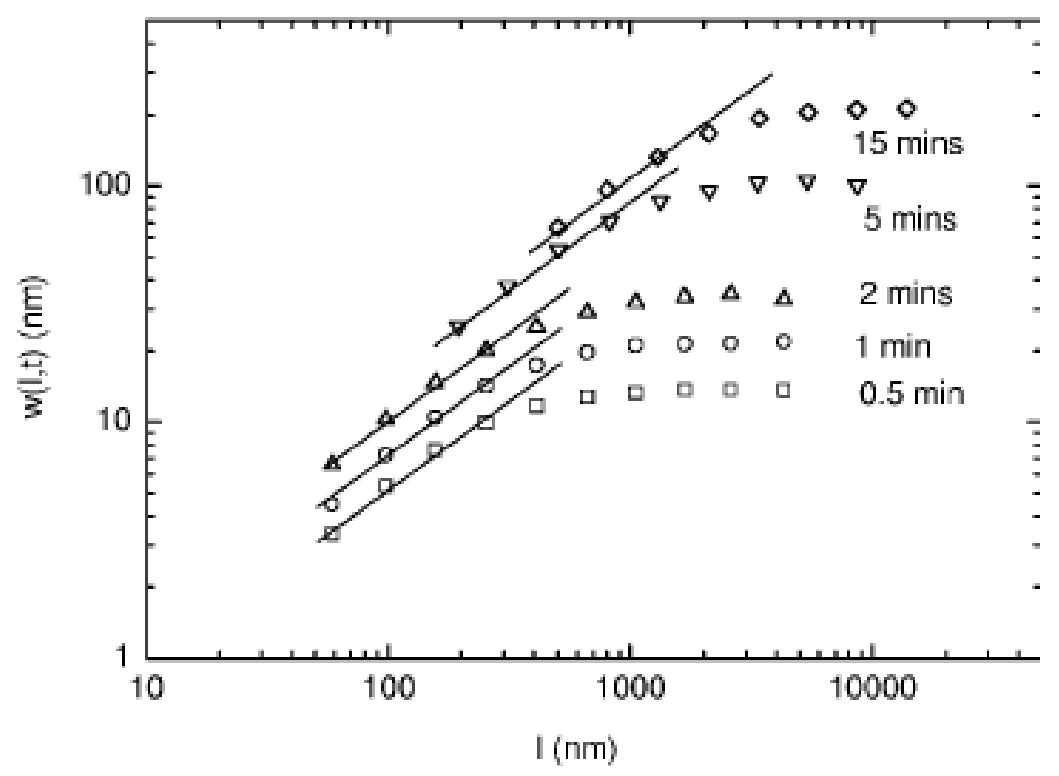

Figura 4.5-3- Gráfico do desvio médio quadrático das alturas ou largura de superfície $w(\mathrm{l}, \mathrm{t})$ ilustrando escalamento do tipo anômalo (HUO \& SCHWARZACHER,2001) 


\section{PROCEDIMENTOS EXPERIMENTAIS}

Abordaremos neste capítulo os procedimentos experimentais empregados na preparação dos filmes finos de cobalto depositados sobre a superfície de silício (100) tipo P ativada com paládio, as técnicas utilizadas na caracterização dos filmes obtidos e os procedimentos para obtenção dos parâmetros de rugosidade.

\subsection{PREPARAÇÃO DO SUBSTRATO UTILIZADO PARA DEPOSIÇÃO DO FILME}

Apresentaremos as características do substrato e o processo de ativação da superfície como etapas preliminares antes da deposição química de cobalto. Este é o primeiro estudo sobre esse tipo de deposição química (electroless) utilizando substratos de silício (100). Na literatura nada foi encontrado até a escrita da tese. A maioria dos estudos refere-se à eletrodeposição sobre às superfícies metálicas (OSAKA, 2007; LIU, 2004) e substratos de carbono (ROBERTIS, 2005).

\subsubsection{TIPO DE SUBSTRATO}

Todas as amostras utilizadas nos experimentos foram de lâminas de silício (Si) de 2 ou 3 polegadas de diâmetro, orientação (100), tipo P (dopadas com boro), resistividade na faixa de 1 a $10 \Omega \mathrm{cm}$. 


\subsubsection{PREPARAÇÃO DO SUBSTRATO}

Nesta pesquisa, os substratos foram retirados direto da caixa na capela eletroquímica e clivadas dentro da capela em duas metades no caso de lâminas de 2 polegadas e quatro no caso de lâminas de 4 polegadas.

As amostras de silício geradas receberam um jato de nitrogênio para eliminar as partículas de silício originadas pela clivagem.

\subsection{PROCESSO DE LIMPEZA DAS LÂMINAS DE SILÍ́CIO}

De acordo com especificação do fabricante das lâminas de silício adquiridas (WAFERNET), as concentrações de contaminantes metálicos são inferiores a $1 \times 10^{11} \mathrm{~cm}^{-2}$, valor esse compatível com as limpezas tipo RCA (SANTOS FILHO, 1996).

Desta forma optou-se pela utilização direta das lâminas de $\mathrm{Si}$, pois as concentrações iniciais de impurezas eram suficientemente baixas de forma a não influenciar nos processos subseqüentes de pré-ativação das lâminas de silício.

\subsection{PROCESSO DE LIMPEZA DOS BÉQUERES DE TRABALHO}

A limpeza dos béqueres foi realizada utilizando-se o seguinte processo:

- 5 min de enxágüe em água deionizada $(18 \mathrm{M} \Omega \mathrm{cm})$

- Fervura por 10 min em uma solução de hidróxido de amônia (4 $\mathrm{H}_{2} \mathrm{O}: 1 \mathrm{H}_{2} \mathrm{O}_{2}: 1 \mathrm{NH}_{4} \mathrm{OH}(38 \%)$ ), na temperatura de $70{ }^{\circ} \mathrm{C}$

- $5 \mathrm{~min}$ de enxágüe em água deionizada $(18 \mathrm{M} \Omega \mathrm{cm})$ 


\subsection{ATIVAÇÃO DA SUPERFÍCIE POR PALÁDIO.}

Como mencionado no item 3.1 (Figura 3.3-1), a introdução de sítios de paládio em uma superfície age como catalisador para a deposição química de metais e não é necessário recobrir toda a superfície no caso da mesma ser condutora (DUBIN,1992) este efeito já foi suficientemente explicado no capitulo 3. Baseado em trabalhos anteriores realizados no âmbito do nosso grupo (MARQUES, 2003), a ativação da superfície de silício foi realizada por meio das seguintes etapas:

- Preparou-se uma solução de $40 \mathrm{H}_{2} \mathrm{O}+1 \mathrm{HF}(49 \%)$

- Adicionou-se 0,1g/l de $\mathrm{PdCl}_{2}(0,0005 \mathrm{M})$

- Foi feita a imersão das amostras por $15 \mathrm{~s}$ ou $30 \mathrm{~s}$.

- Enxágüe em água deionizada por $30 \mathrm{~s}$

De acordo com Marques (2003) a imersão durante 15s e 30s resulta em sítios dispersos com concentrações planares de $3,0 \times 10^{+19} \mathrm{~cm}^{-2}$ e $5,8 \times 10^{+19} \mathrm{~cm}^{-2}$ respectivamente.

\subsection{PROCEDIMENTOS PARA DEPOSIÇÃO QUÍMICA DE COBALTO}

$\mathrm{Na}$ deposição química de cobalto foram utilizadas duas receitas reportadas por Mallory (1990) Kiflawi (1983) e Baylis (1977): uma baseada na utilização de cloreto de cobalto (receita 1) e a outra baseada na utilização de sulfato de cobalto (receita 2). Estas receitas foram empregadas pela primeira vez sobre superfícies de silício. Foram variados a temperatura e o $\mathrm{pH}$ de ambas visando estudar e caracterizar tamanhos de grão, rugosidade superficial, concentração planar, espessura e mecanismos deposição sobre o silício. As receitas empregadas foram as seguintes:

\section{Receita 1:}

1. $\mathrm{NH}_{4} \mathrm{Cl}-2,0 \mathrm{M}$

2. $\mathrm{CoCl}_{2} \cdot 6 \mathrm{H}_{2} \mathrm{O}-0,005 \mathrm{M}$

3. $\mathrm{NaH}_{2} \mathrm{PO}_{2} \mathrm{H}_{2} \mathrm{O}$ (hipofosfito de Sódio)- 0,15M 
Nesta receita o hipofosfito de sódio atua como agente redutor, e o cloreto de cobalto como fonte de íons de cobalto e $\circ \mathrm{NH}_{4} \mathrm{Cl}$ atua como agente complexante ou ligante de forma a impedir a precipitação do cobalto. Além disso, o $\mathrm{NH}_{4} \mathrm{Cl}$ também tem a função de atuar como agente tamponante para estabilização do $\mathrm{pH}$ (MALLORY, 1990). A temperatura foi variada na faixa de 22 à $65^{\circ} \mathrm{C} \mathrm{e} \mathrm{o} \mathrm{pH}$ da solução foi variado na faixa de 3,7 a 8,7 através da adição de hidróxido de amônio (38\%). Este tipo de banho desestabiliza-se já para temperaturas maiores que 65 C MALLORY, 1990)

\section{Receita 2}

1. $\mathrm{Na}_{3} \mathrm{C}_{6} \mathrm{H}_{5} \mathrm{O}_{7}$ (citrato de sódio) $0,14 \mathrm{M}$

2. $\left(\mathrm{NH}_{4}\right)_{2} \mathrm{SO}_{4}-0,65 \mathrm{M}$

3. $\mathrm{CoSO}_{4} .7 \mathrm{H}_{2} \mathrm{O}-0,19 \mathrm{M}$

4. $\mathrm{NaH}_{2} \mathrm{PO}_{2} \mathrm{H}_{2} \mathrm{O}$ (hipofosfito de Sódio)- $0,28 \mathrm{M}$

Nesta receita, também utilizamos o hipofosfito de sódio que atua como agente redutor, o citrato de sódio, como agente tamponante na estabilização do $\mathrm{pH}$ e o $\left(\mathrm{NH}_{4}\right)_{2} \mathrm{SO}_{4}$ atua como agente complexante ou ligante de forma a impedir a precipitação do Cobalto (MALLORY, 1990). Por outro lado, foi empregado como fonte de íons metálicos, o sulfato de cobalto. A temperatura foi variada na faixa de 75 a $90{ }^{\circ} \mathrm{C}$ e o pH da solução foi variado de 4,8 a 11,5 através da adição de quantidades adequadas de hidróxido de amônio (38\%). 


\subsection{SISTEMA DE DEPOSIÇÃO DE COBALTO}

O sistema de deposição de cobalto empregado consistiu de uma placa de aquecimento para béqueres (hot plate), um béquer para a solução de deposição de cobalto, um termômetro e uma pinça de teflon para segurar a amostra. Na Figura 5.6-1 temos um esquema do sistema de deposição.

Os componentes da solução foram adicionado um a um na seqüência indicada nas receitas 1 e 2 sendo que cada componente foi completamente dissolvido antes de se adicionar o próximo. Após assegurar visualmente a homogeneidade da solução, foram realizadas as deposições químicas de cobalto.

A barra magnética indicada na Figura 5.6-1, foi mantida em baixa rotação $\left(1 \mathrm{~s}^{-1}\right)$ a fim de prevenir a formação de precipitados e evitar depleção de espécies sobre as amostras (SANTOS FILHO,1996). O pH das soluções foi medido com a ajuda de um phmetro modelo pHM210 fabricado pela Radiometer.

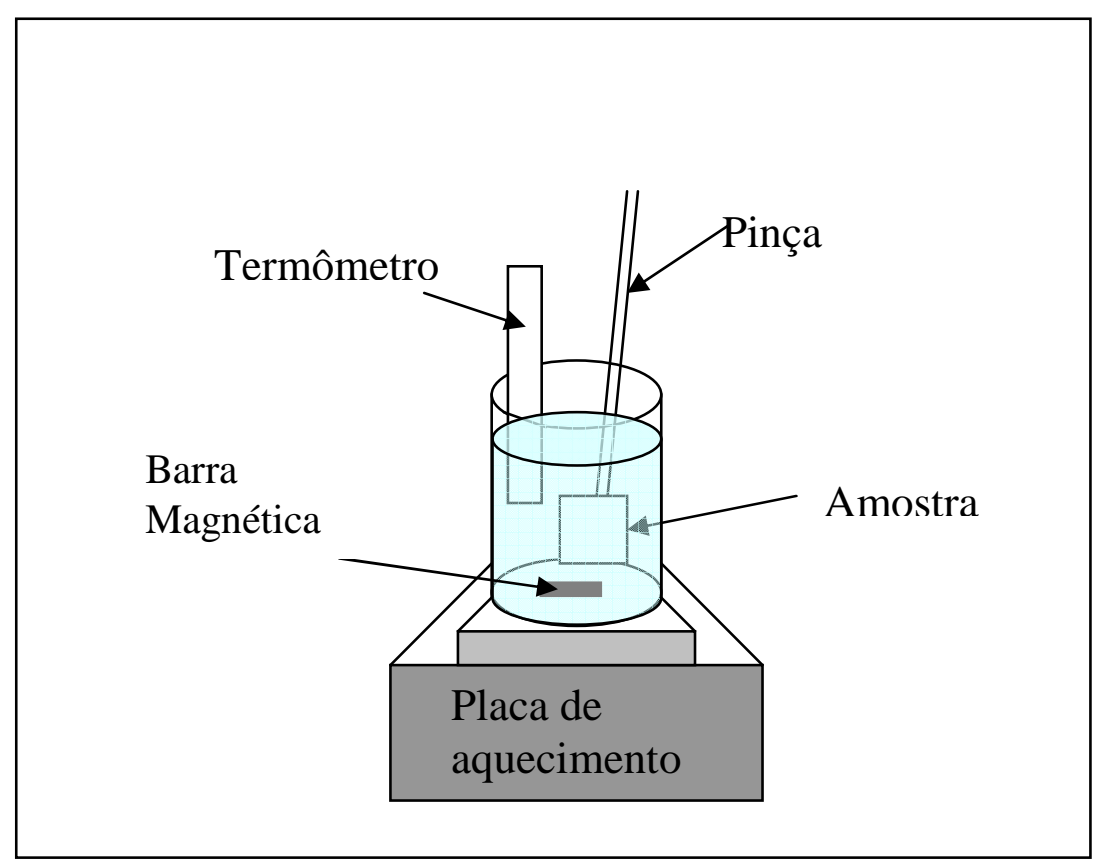
cobalto.

Figura 5.6-1 - Representação esquemática do sistema de deposição de 


\subsection{DEPOSIÇÃO QUÍMICA DOS FILMES DE COBALTO}

abaixo:

As deposições químicas foram realizadas seguindo o procedimento descrito

a) Limpeza do béquer de deposição em uma solução $4 \quad \mathrm{H}_{2} \mathrm{O}: 1 \quad \mathrm{H}_{2} \mathrm{O}_{2}(28 \%)$ : $1 \mathrm{NH}_{4} \mathrm{OH}(38 \%)$

b) Preparação da solução de ativação (item 5.4)

c) Preparação da solução de deposição (Receita 1 ou 2)

d) Clivagem das lâminas (item 5.1.2)

e) "dip" na solução de ativação (item 5.4)

f) Enxágüe em água deionizada (30 s)

g) Imersão na solução de deposição de cobalto para tempos variando na faixa de $30 \mathrm{~s}$ a $30 \mathrm{~min}$

h) Enxágüe em água deionizada e

i) Secagem da amostra com jato de nitrogênio ultrapuro.

A tabela 5.7-1 apresenta uma síntese das amostras preparadas utilizando as receitas 1 e 2 para temperaturas na faixa de $22^{\circ} \mathrm{C}$ a $90^{\circ} \mathrm{C}, \mathrm{pH}$ na faixa de 3,7 a 10,0 e ativação em solução de paládio por tempos de 15s ou 30s. 
Tabela 5.7-1- Síntese das amostras fabricadas

\begin{tabular}{|l|c|c|c|c|c|}
\hline $\begin{array}{l}\text { Nome } \\
\text { Da } \\
\text { Amostra }\end{array}$ & Receita & $\begin{array}{c}\text { Tempo de } \\
\text { deposição } \\
\text { de Co } \\
\text { (minutos) }\end{array}$ & $\begin{array}{c}\text { Tempo de } \\
\text { deposição } \\
\text { de Pd }\end{array}$ & $\begin{array}{c}\text { Temperatura } \\
\text { de deposição }\end{array}$ & pH \\
\hline Co1 & 1 & 30 & $15 \mathrm{~s}$ & $65^{\circ} \mathrm{C}$ & $3,7 \pm 0,05$ \\
\hline Co2 & 1 & 30 & $15 \mathrm{~s}$ & $22^{\circ} \mathrm{C}$ & $3,7 \pm 0,1$ \\
\hline Co3 & 1 & 3 & $15 \mathrm{~s}$ & $22^{\circ} \mathrm{C}$ & $3,7 \pm 0,1$ \\
\hline Co4 & 1 & 10 & $15 \mathrm{~s}$ & $22^{\circ} \mathrm{C}$ & $8.7 \pm 0,05$ \\
\hline CoCu1 & 1 & 3 & $15 \mathrm{~s}$ & $65^{\circ} \mathrm{C}$ & $8.2 \pm 0,1$ \\
\hline Co5 & 2 & 10 & $15 \mathrm{~s}$ & $90^{\circ} \mathrm{C}$ & $4,8 \pm 0,1$ \\
\hline Co6 & 2 & 30 & $15 \mathrm{~s}$ & $90^{\circ} \mathrm{C}$ & $4,8 \pm 0,1$ \\
\hline Co7 & 2 & 3 & $15 \mathrm{~s}$ & $90^{\circ} \mathrm{C}$ & $9,4 \pm 0,1$ \\
\hline Co8 & 2 & 5 & $15 \mathrm{~s}$ & $90^{\circ} \mathrm{C}$ & $9,4 \pm 0,1$ \\
\hline Co9 & 2 & 5 & $15 \mathrm{~s}$ & $90^{\circ} \mathrm{C}$ & $8,7 \pm 0,1$ \\
\hline Co10 & 2 & 0,5 & $15 \mathrm{~s}$ & $78^{\circ} \mathrm{C}$ & $9,1 \pm 0,05$ \\
\hline Co11 & 2 & 1 & $15 \mathrm{~s}$ & $78^{\circ} \mathrm{C}$ & $9,2 \pm 0,05$ \\
\hline Co12 & 2 & 3 & $15 \mathrm{~s}$ & $78^{\circ} \mathrm{C}$ & $9,1 \pm 0,05$ \\
\hline Co120 & 2 & 0,3 & $15 \mathrm{~s}$ & $80^{\circ} \mathrm{C}$ & $9,4 \pm 0,1$ \\
\hline Co130 & 2 & 0,5 & $15 \mathrm{~s}$ & $80^{\circ} \mathrm{C}$ & $9,4 \pm 0,1$ \\
\hline Co140 & 2 & 1 & $15 \mathrm{~s}$ & $80^{\circ} \mathrm{C}$ & $9,4 \pm 0,1$ \\
\hline Co150 & 2 & 2 & $15 \mathrm{~s}$ & $80^{\circ} \mathrm{C}$ & $9,4 \pm 0,1$ \\
\hline Co160 & 2 & 3 & $15 \mathrm{~s}$ & $80^{\circ} \mathrm{C}$ & $9,4 \pm 0,1$ \\
\hline Co200 & 2 & 0,5 & $30 \mathrm{~s}$ & $80^{\circ} \mathrm{C}$ & $9,4 \pm 0,1$ \\
\hline Co210 & 2 & 1 & $30 \mathrm{~s}$ & $80^{\circ} \mathrm{C}$ & $9,4 \pm 0,1$ \\
\hline Co220 & 2 & 2 & $30 \mathrm{~s}$ & $80^{\circ} \mathrm{C}$ & $9,4 \pm 0,1$ \\
\hline Co230 & 2 & 3 & $30 \mathrm{~s}$ & $80^{\circ} \mathrm{C}$ & $9,4 \pm 0,1$ \\
\hline Co240 & 2 & 4 & $30 \mathrm{~s}$ & $80^{\circ} \mathrm{C}$ & $9,4 \pm 0,1$ \\
\hline Co250 & 2 & 5 & $30 \mathrm{~s}$ & $80^{\circ} \mathrm{C}$ & $9,4 \pm 0,1$ \\
\hline Co260 & 2 & 6 & $30 \mathrm{~s}$ & $80^{\circ} \mathrm{C}$ & $9,4 \pm 0,1$ \\
\hline
\end{tabular}




\subsection{CARACTERIZAÇÃO DAS AMOSTRAS}

Os filmes depositados foram caracterizados por espectroscopia de retroespalhamento de Rutherford (RBS), para se obter a concentração planar total, espessura de cobalto e identificação de eventuais contaminantes depositados junto com o filme de cobalto. As análises foram realizadas em um acelerador tipo Tanden, modelo 55DH/NEC, com um feixe de $\mathrm{He}^{++}$, com energia de 2,4 MeV e ângulo de retroespalhamento de $170^{\circ}$.

A técnica de microscopia de força atômica (AFM) foi utilizada para obtenção de imagens da morfologia de superfície dos filmes de cobalto depositados sobre substrato de silício ativado com paládio. Foi obtida a rugosidade média, RMS e vale-pico pelo sistema de processamento de imagem do AFM modelo nanoscope $\mathrm{E}$ da Digital Inc. Também, foram utilizados os gráficos $\mathrm{w}(1, \mathrm{t}) \times \mathrm{I}$ dos filmes de cobalto para obtenção dos expoentes de escalamento da rugosidade além das medidas de espessura por perfilometria em algumas das amostras. Os expoentes de escalamento foram empregados especialmente para quantificar a dependência da rugosidade com o tempo de deposição e determinar se o escalamento era normal ou anômalo. 


\section{RESULTADOS E DISCUSSÃO}

Neste capítulo, apresentaremos os resultados das deposições de químicas de cobalto sobre substratos de silício utilizando as receitas 1 e 2 descritas no capítulo 5. A discussão será baseada nas caracterizações físicas empregando as técnicas RBS, AFM e perfilometria, já descritas também no capítulo 4.

\subsection{DEPOSIÇÃO QUÍMICA DE COBALTO}

Após realizar as deposições de cobalto seguindo o procedimento descrito no item 5.7, as amostras foram encaminhadas para a análise de Retroespalhamento de Rutherford (RBS) de forma a monitorar a deposição de cobalto e determinar a sua espessura. Mais tarde, foram feitas análises por microscopia de força atômica (AFM) para analisar a morfologia da superfície.

\subsubsection{UTILIZAÇÃO DA RECEITA 01}

Inicialmente, utilizamos a receita 1 na tentativa de realizar a deposição química de cobalto sobre superfícies polidas de silício previamente ativadas com paládio conforme receita também descrita no capitulo 5 (item 5.4). No entanto, verificamos que não ocorreu deposição para temperaturas na faixa de $22^{\circ} \mathrm{C}$ e à $65^{\circ} \mathrm{C}$ e pH variando de 3,7 a $8,7$.

A Figura 6.1-1 mostra um espectro RBS típico para a amostra Co2 (veja Tabela 5.7-1). O mesmo ocorreu para as amostras Co1, Co3 e Co4, isto é, não houve deposição de cobalto para uma ampla faixa de variação de temperatura $\left(22^{\circ} \mathrm{C}\right.$ a $\left.65^{\circ} \mathrm{C}\right)$ e $\mathrm{pH}(3,7$ a 8,7$)$. Dos espectros de RBS, constatamos que as amostras não apresentavam sinais de cobalto, mas apenas o sinal de paládio. As concentrações planares resultantes de paládio foram de cerca de $1.10^{16}$ a $2.10^{16}$ átomos $/ \mathrm{cm}^{2}$ para todas as amostras submetidas à pré-ativação por $15 \mathrm{~s}$. A 
rugosidade RMS típica para todas as amostras ficou na faixa de 15,2 a $35 \mathrm{~nm}$ após a deposição do paládio seguido das tentativas de deposição.

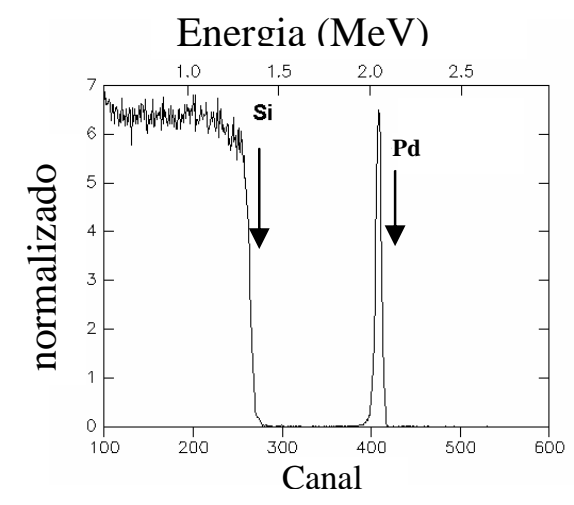

Figura 6.1-1 - Espectro de RBS típico; amostra Co2 (receita1: 0,005 $\mathrm{M} \mathrm{CoCl}_{2}+0,15$ $\mathrm{M} \mathrm{NaH}_{2} \mathrm{PO}_{2} . \mathrm{H}_{2} \mathrm{O}+2,0 \mathrm{M} \mathrm{NH}_{4} \mathrm{Cl}, 30$ min. à $65^{\circ} \mathrm{C}, \mathrm{pH}=3,7, \mathrm{~T}=22^{\circ} \mathrm{C}$ ).

A rugosidade RMS variando na faixa de 15 a $35 \mathrm{~nm}$ foi atribuída à distribuição esparsa dos sítios de paládio que não "fecham" a superfície (silício fica exposto), como observado por Marques (2003) em seu trabalho de doutorado.

Por outro lado, como não houve sucesso na deposição química de cobalto através da receita 1 sobre superfícies de silício ativadas por paládio, partimos para um teste em superfícies de cobre. Realizamos a deposição da amostra CuCo1, composta por um filme de cobre $(10 \mathrm{~nm})$ sobre níquel $(300 \mathrm{~nm})$ depositado sobre silício. A deposição química de cobalto neste caso foi facilmente constatada a olho nu. Da análise de RBS, foi calculada a espessura cobalto sobre cobre com valor de aproximadamente $307 \mathrm{~nm}$ (Figura 6.1-2) para solução $0,005 \mathrm{M} \mathrm{CoCl}_{2}+0,15 \mathrm{M}$ $\mathrm{NaH}_{2} \mathrm{PO}_{2} \cdot \mathrm{H}_{2} \mathrm{O}+2,0 \mathrm{M}$ de $\mathrm{NH}_{4} \mathrm{Cl}$ na temperatura de aproximada de $65^{\circ} \mathrm{C}$, pH de 8,2 por um tempo de 3 min. 


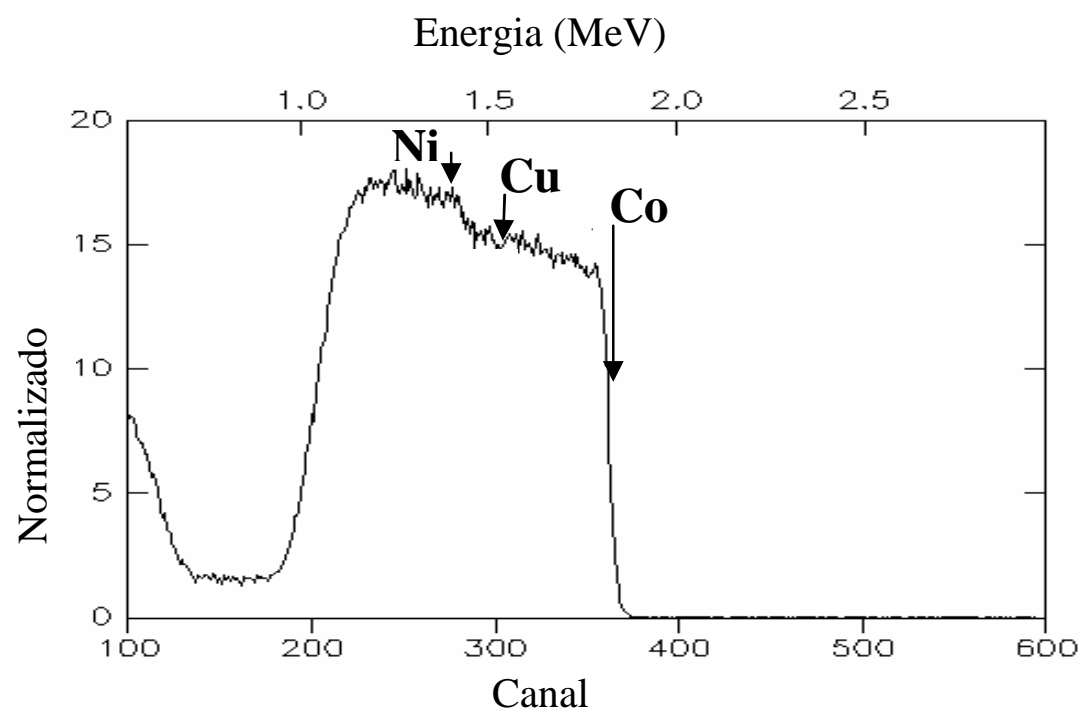

Figura 6.1-2-Espectro RBS da amostra CuCo1. (receita 0,005 $\mathrm{M} \mathrm{CoCl}_{2}+0,15 \mathrm{M}$ $\mathrm{NaH}_{2} \mathrm{PO}_{2} . \mathrm{H}_{2} \mathrm{O}+2,0 \mathrm{M} \mathrm{NH}_{4} \mathrm{Cl}, 4 \mathrm{~min}, \mathrm{pH}=8,2$ e temperatura de aproximadamente $\left.65^{\circ} \mathrm{C}\right)$.

Baseado no fato da deposição ter ocorrido em superfícies de cobre e não ter ocorrido em superfície de silício pré-ativadas com paládio, é importante destacar que o silício deve estar impedindo a deposição apesar da presença dos sítios de paládio. É fato bem conhecido da literatura (MALLORY, 1990) que a receita 1 permite a deposição de cobalto em superfícies de vidro ou carbono préativadas com paládio. Portanto, apesar do paládio estar servindo como agente catalisador do processo de deposição, o silício deve estar oxidando devido à presença das hidroxilas $\left(\mathrm{OH}^{-}\right)$e o cobalto residual que deposita sobre os sítios esparsos de paládio deve também estar oxidando impedindo que a deposição de cobalto residual ocorra. Isto é, o processo de contenção da deposição química poderia ser resumido através das seguintes reações resumidas: 
a) No silício Exposto

$\mathrm{Si} \stackrel{\text { Alcalino }}{\longrightarrow} \mathrm{SiOH}$

b) Junto aos sítios de paládio (EZE, 1999).

$\mathrm{Co}^{2+} \underset{\mathrm{SiOH}}{\stackrel{\text { alcalino }}{\longrightarrow}} \mathrm{CoO} .6 \mathrm{H}_{2} \mathrm{O}$

Por outro lado, o agente tamponante $\mathrm{NH}_{4} \mathrm{Cl}$ além de conservar a solução alcalina, induz a formação do complexo $\left[\mathrm{Co}\left(\mathrm{NH}_{3}\right)_{6}\right]^{2+}$ o que de forma conjugada desfavorece a deposição do cobalto, isto é, a quantidade de hidroxilas permanece estável e o pouco cobalto que escapa do complexo junto aos sítios de paládio é imediatamente oxidado.

Para lograr sucesso na deposição de cobalto, decidimos utilizar um outro agente tamponante e um outro agente complexante: o citrato de sódio e o sulfato de amônio, respectivamente. Vamos descrever a seguir os resultados obtidos utilizando a receita 2 .

\subsubsection{UTILIZAÇÃO DA RECEITA 02}

A receita 2 é composta de sulfato de cobalto (fonte de metais), hipofosfito de sódio (agente redutor), citrato de sódio (agente tamponante), sulfato de amônio (agente complexante) e hidróxido de amônio (agente regulador de $\mathrm{pH}$ ) conforme já descrito no capítulo 5. Inicialmente, ajustamos um pH levemente ácido de 4,8 na temperatura de $90^{\circ} \mathrm{C}$ (amostras Co5 e Co6 na Tabela 5.7-1). Como resultado, não houve deposição de cobalto. Isto já era esperado tendo em vista que as espécies $\mathrm{Co}^{2+}$ oxidam com a aeração da solução e acabam agindo no sentido de inibir a deposição (MALLORY, 1990). 
Da análise de RBS (Figura 6.1-3), foi identificado o paládio com concentração planar de $0,15.10^{17}$ at $/ \mathrm{cm}^{2}$ para a amostra Co5 e $0,25.10^{17} \mathrm{at} / \mathrm{cm}^{2}$, para a amostra Co6. Detectamos também cobre com concentração planar de $0,12.10^{17}$ átomos $/ \mathrm{cm}^{2}$ para a amostra Co5 e $0,21.10^{17} \mathrm{at} / \mathrm{cm}^{2}$, para a amostra Co6. O cobre observado na Figura 6.1-3 é possivelmente proveniente de contaminação residual cruzada dos béqueres.

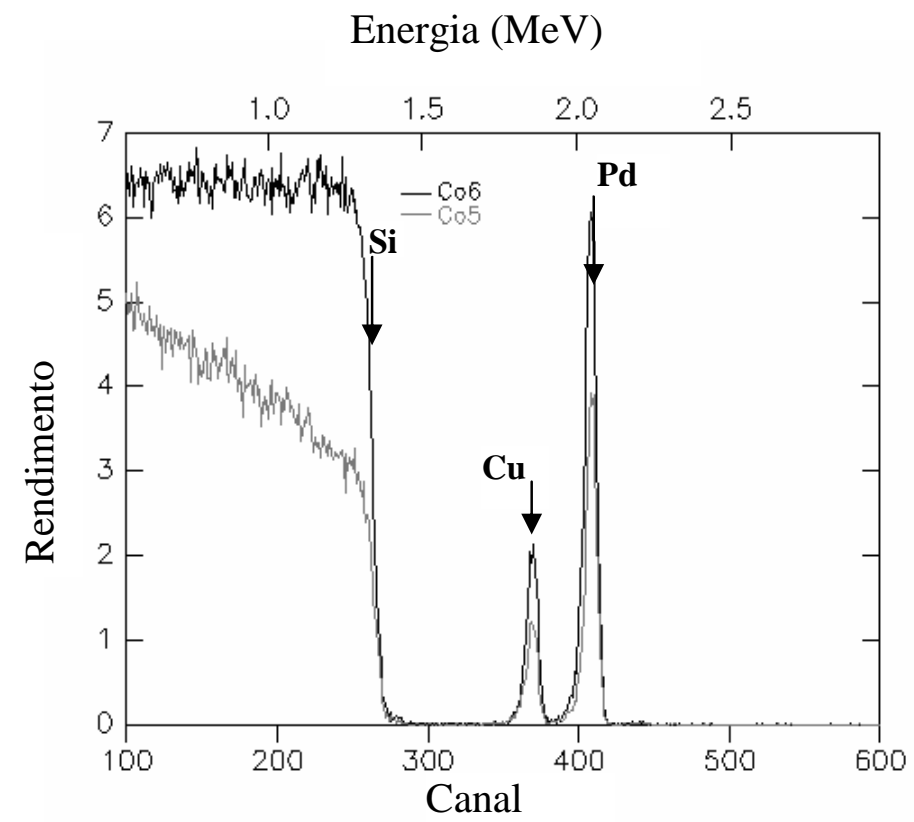

Figura 6.1-3-Espectros RBS em escala Log sobrepostos para as amostras Co5 e Co6.

Na seqüência, aumentamos o pH da solução para 9,4 através da adição de hidróxido de amônio. Na temperatura de $90^{\circ} \mathrm{C}$ e $\mathrm{pH}$ de 9 , 4, realizamos a deposição das amostras Co7 e Co8 para tempo de imersão de 3 min e 5 min, respectivamente. Notamos pela análise de RBS (Figura 6.1-4) que foi depositado cobalto ( $20 \mathrm{~nm}$ ), e também foi observada a presença de fósforo (3,6\% em peso) na amostra Co8.

Por outro lado, na amostra Co7, a espessura de cobalto resultou menor ( 15nm) sobre paládio ( 4nm) com presença de fósforo (3,6\% em peso). 
É importante também destacar na Figura 6.1-4 a presença de oxigênio distribuído no corpo dos filmes de cobalto (Co7 e Co8), isto é, além do cobalto, existe também oxigênio possivelmente ligado ao cobalto em uma porcentagem em peso de cerca de 4,8\%. A composição termodinamicamente estável para o óxido de cobalto é o $\mathrm{CoO}_{6} 6 \mathrm{H}_{2} \mathrm{O}$ nos processos de deposição química dos mesmos reportados na literatura (EZE, 1999).

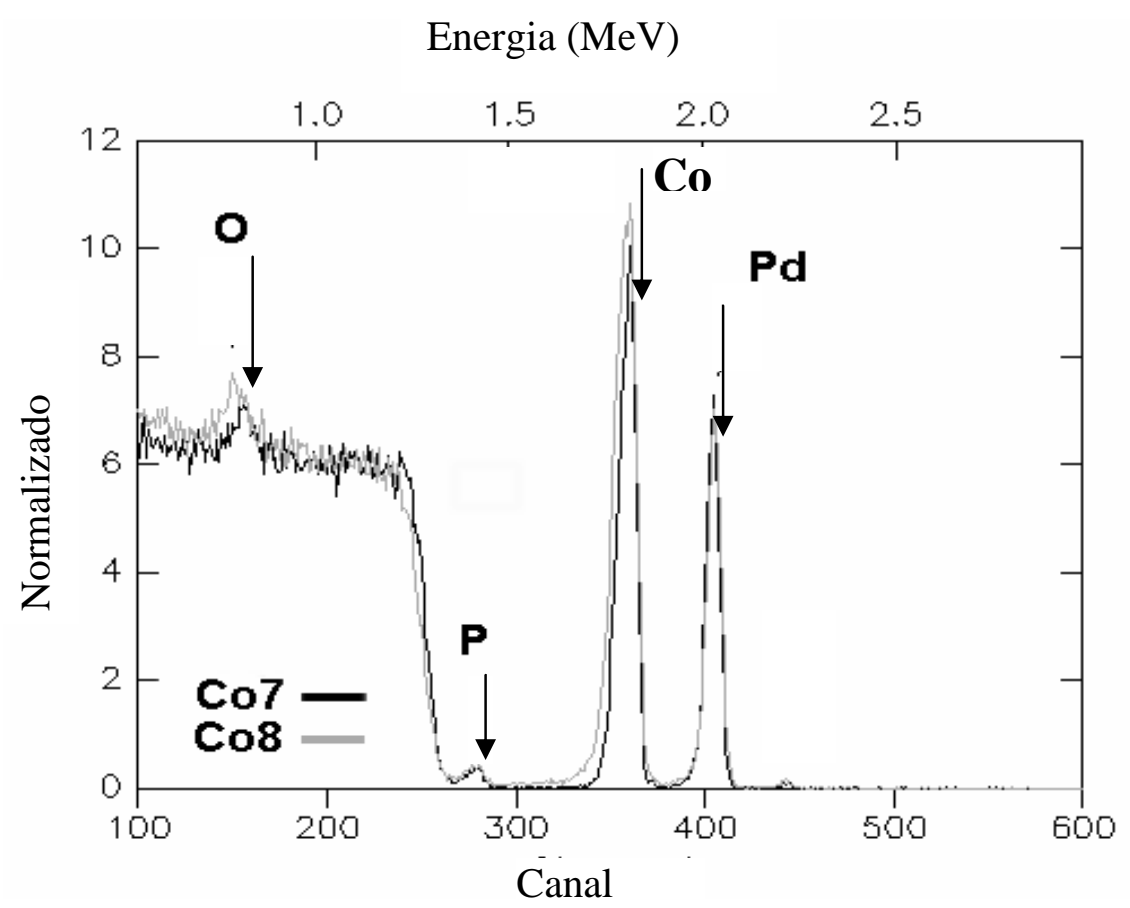

Figura 6.1-4 - Espectros RBS das amostras Co7 e Co8.

As rugosidades RMS obtidas a partir das análises AFM resultaram bem parecidas $(13,1 \mathrm{~nm}$ e $12,7 \mathrm{~nm})$ para as amostras Co7 e Co8, respectivamente. Também foi possível notar que os grãos com tamanho típicos na faixa de $0,1 \mu \mathrm{m}$ a 0,3 $\mu \mathrm{m}$ recobrem inteiramente a superfície do silício. (Figura 6.1-5.) 

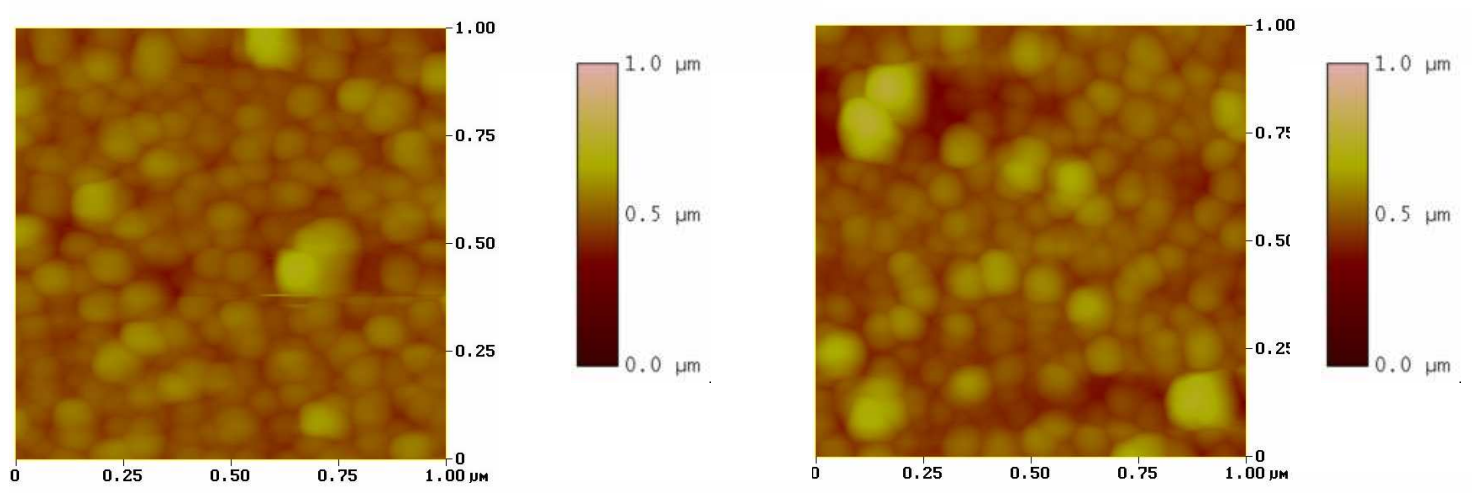

Figura 6.1-5 - Imagens AFM típicos das amostras Co7 e Co8.

Preparamos em seguida a amostra Co9 na mesma temperatura da amostra Co8, mas em pH de 8,7 ao invés de 9,4 após evaporação de parte do hidróxido de amônio do béquer da solução na temperatura de $90^{\circ} \mathrm{C}$. Com a redução do $\mathrm{pH}$, a espessura resultou surpreendente maior para o mesmo tempo de deposição de 5 min. $O$ espectro de RBS para a amostra Co9 está mostrado na Figura 6.1-6.

Da análise RBS, constatou-se que foi depositado um filme de $183,1 \mathrm{~nm}$ de cobalto. Juntamente com o cobalto notou-se que existe fósforo com concentração planar de $8,31 \%$ em peso. O paládio ficou localizado na interface Co/Si.

Também no caso da amostra Co9 observamos oxigênio distribuído ao longo do filme de cobalto (veja Figura 6.1-6) significando oxigênio ligado ao cobalto numa porcentagem em peso de $1,5 \%$ que é substancialmente menor comparado ao caso da amostra Co8 (4,8\%). Este fato esta diretamente associado ao valor do pH que foi de 9,4 para a amostra Co8 e 8,7 para a amostra Co9. Baseado nesse dado experimental pode-se concluir que a formação de menor quantidade de óxido de cobalto no filme deve estar inibindo em menor grau o processo de deposição de cobalto comparado ao caso da amostra Co8. Esta extensão por nós proposta servirá para explicar e corroborar outras observações experimentais que analisaremos mais adiante. 


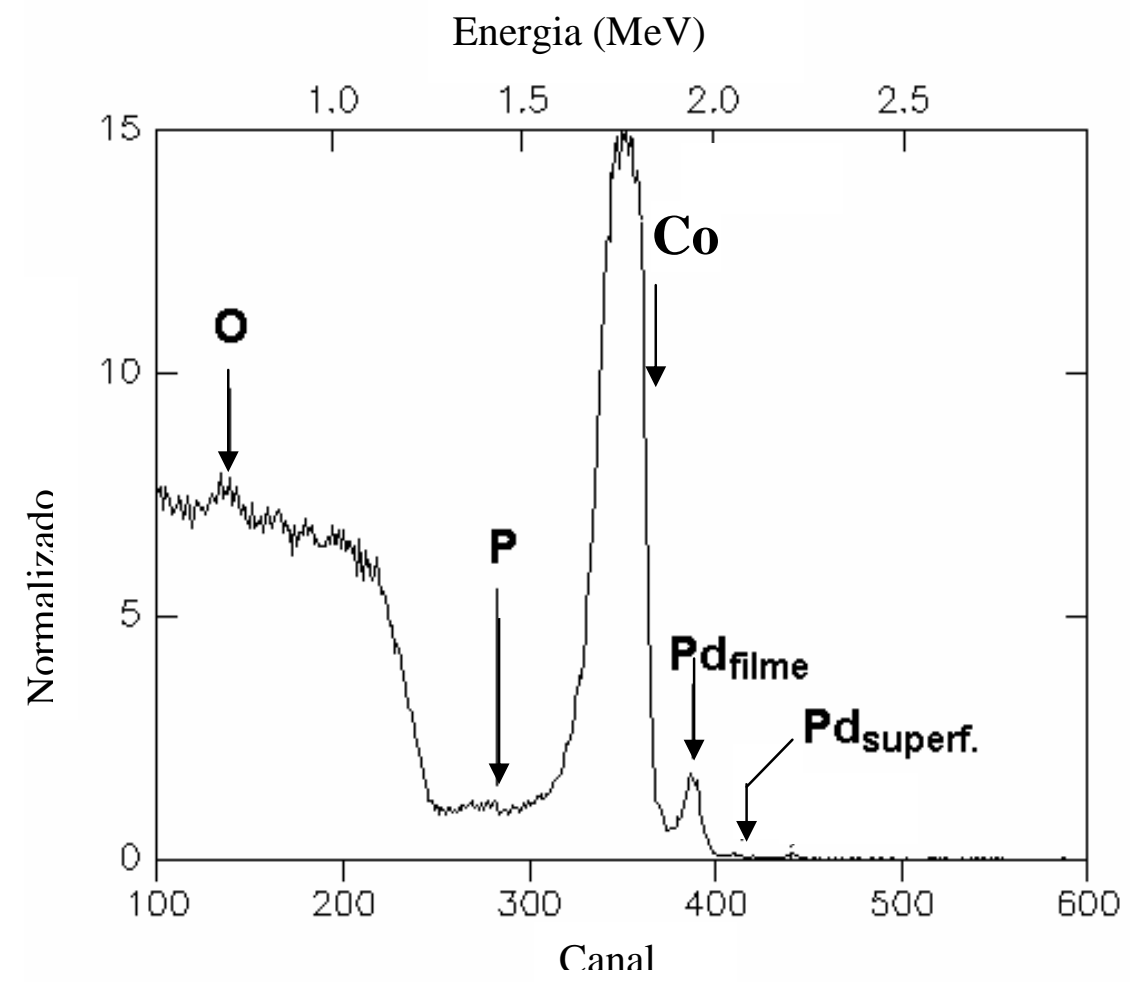

Figura 6.1-6 - Espectro RBS da amostra $\mathrm{Co9}$ (receita 0,19M de $\mathrm{CoSO}_{4} .7 \mathrm{H}_{2} \mathrm{O}$, $0,28 \mathrm{M}$ de $\mathrm{NaH}_{2} \mathrm{PO}_{2} . \mathrm{H}_{2} \mathrm{O}, 0,14 \mathrm{M}$ de $\mathrm{Na}_{3} \mathrm{C}_{6} \mathrm{H}_{5} \mathrm{O}_{7} . \mathrm{H}_{2} \mathrm{O}, 0,65 \mathrm{M}$ de $\left(\mathrm{NH}_{4}\right)_{2} \mathrm{SO}_{4}$ e 200 $\mathrm{ml}$ de $\mathrm{NH}_{4} \mathrm{OH}, 5$ min, $\mathrm{pH}=8,7$ e temperatura de $90^{\circ} \mathrm{C}$ ).

A Tabela 6.1-1 resume os principais resultados obtidos para as amostras Co7, Co8 e Co9.

Tabela 6.1-1-Resultados dos espectros de RBS para as amostras Co7, Co8 e Co9.

\begin{tabular}{|l|l|c|c|}
\hline $\begin{array}{l}\text { Nome } \\
\text { Da }\end{array}$ & $\begin{array}{l}\text { Tempo de } \\
\text { deposição }\end{array}$ & $\begin{array}{c}\text { Concentração } \\
\text { Amostranar de Co } \\
\text { de Co }(\mathrm{s})\end{array}$ & $\begin{array}{c}\text { Espessura } \\
(\mathrm{Co}) \\
\left.\left(10^{16} \mathrm{At} / \mathrm{cm}^{2}\right)\right)\end{array}$ \\
\hline Co7 & $3 \mathrm{~mm})$ \\
\hline Co8 & $5 \mathrm{~min}$. & 1,3 & 14,8 \\
\hline Co9 & 5 min. & 18,5 & 20,6 \\
\hline
\end{tabular}

Na seqüência, para as amostras Co10, Co11 e Co12, reduzimos a temperatura para $78^{\circ} \mathrm{C}$ e mantivemos o $\mathrm{pH}$ controlado entre 9,2 e 9,4 para tempos de deposição de $30 \mathrm{~s}, 60 \mathrm{~s}$ e $180 \mathrm{~s}$, respectivamente. Na Tabela 6.1-2 a seguir, apresentamos as espessuras dos filmes de cobalto e paládio e as porcentagens de 
fósforo. O oxigênio, por sua vez, não aparece nas amostras Co10 e Co11 e está presente em pequena quantidade no canal de superfície da amostra Co12 (veja Figura 6.1-7). Isto significa que a diminuição da temperatura diminui a incorporação de oxigênio associado à formação de óxido de cobalto. Um ponto importante a destacar foi à obtenção de um filme substancialmente mais espesso para a amostra Co12 para tempo e temperatura menor comparado às amostras Co8 e Co9. Tal fato corrobora ainda mais a suposição de que a formação de óxido de cobalto concomitantemente ao processo de deposição deve estar induzindo inibição ou diminuição da taxa de deposição nas amostras Co10 e Co12.

Tabela 6.1-2 - Resultados dos espectros de RBS para as amostras Co10, Co11 e Co12.

\begin{tabular}{|l|l|l|l|l|}
\hline Amostra & $\begin{array}{l}\text { Espessura } \\
\text { do filme de } \\
\text { Cobalto }\end{array}$ & $\begin{array}{l}\text { Espessura } \\
\text { do filme de } \\
\text { Paládio }\end{array}$ & $\begin{array}{l}\text { \% de P no } \\
\text { filme de } \\
\text { Cobalto }\end{array}$ & $\begin{array}{l}\text { Tempo de } \\
\text { deposição }\end{array}$ \\
\hline Co10 & $12,1 \mathrm{~nm}$ & $3,1 \mathrm{~nm}$ & 1,9 & $30 \mathrm{~s}$ \\
\hline Co11 & $34,8 \mathrm{~nm}$ & $3,6 \mathrm{~nm}$ & 2,2 & $1 \mathrm{~min}$. \\
\hline Co12 & $254,2 \mathrm{~nm}$ & $2,4 \mathrm{~nm}$ & 2,3 & $3 \mathrm{~min}$. \\
\hline
\end{tabular}

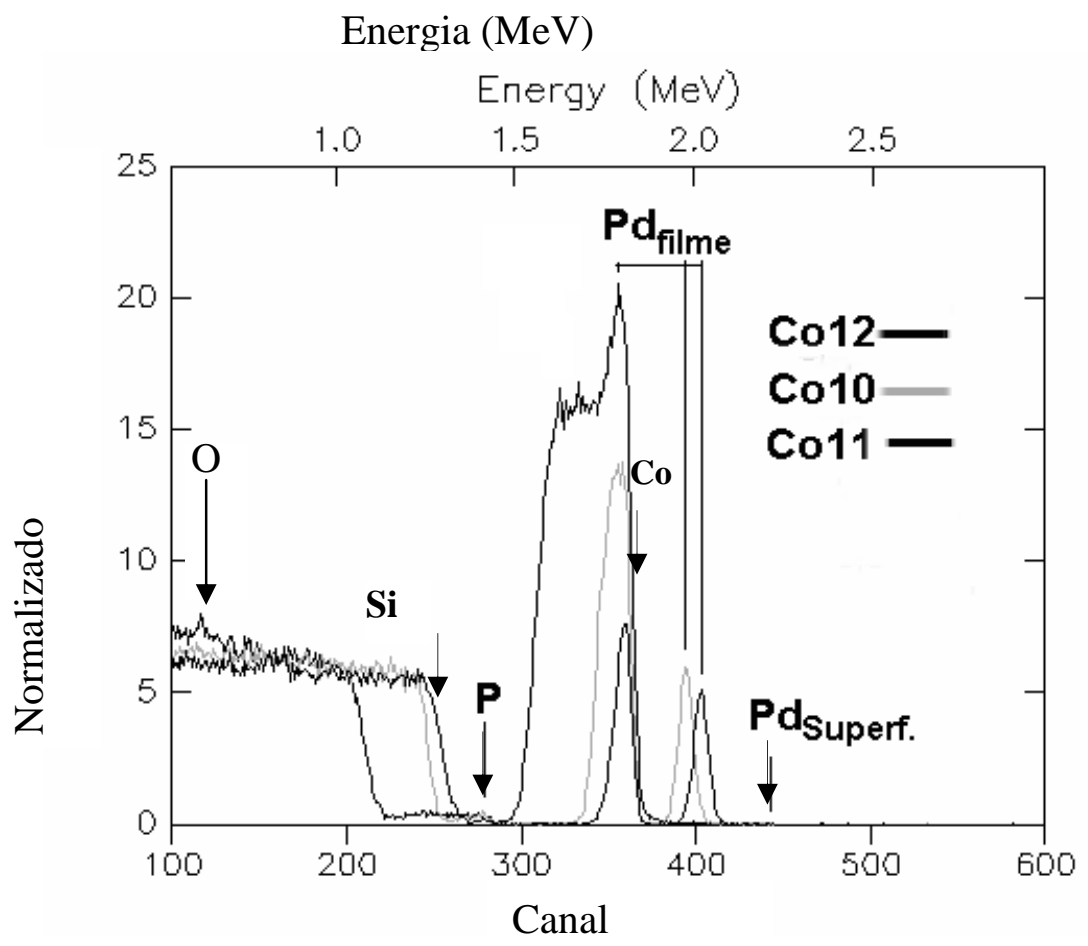

Figura 6.1-7 - Espectros RBS das amostras Co10, Co11, Co12 sobrepostos. 
As análises de AFM revelaram tamanhos de grão evoluindo gradualmente

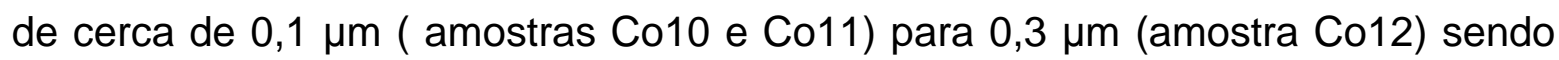
que a rugosidade RMS das amostras Co10, Co11, Co12 foram de 7,84 nm, 6,48nm e 11,56 nm, respectivamente. A Figura 6.1-8 ilustra as imagens AFM obtidas.

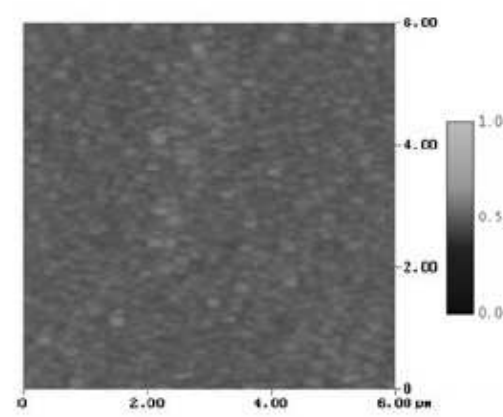

(a)

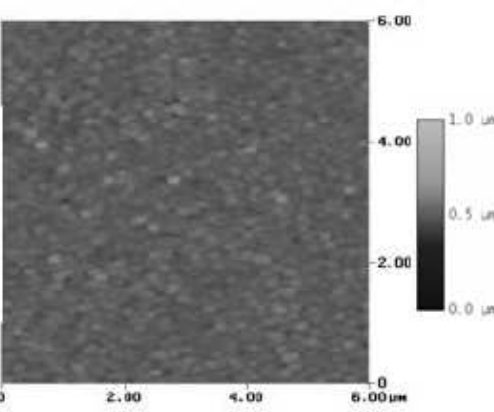

(b)

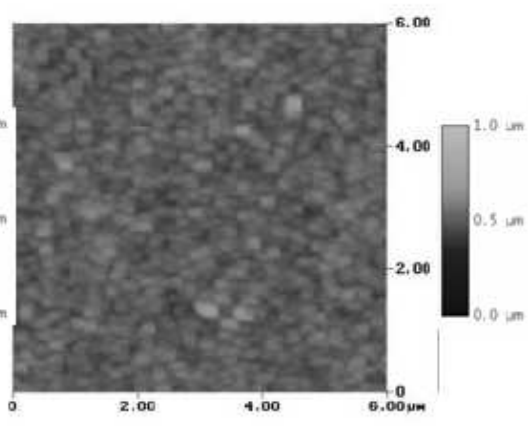

(c)

Figura 6.1-8 - Imagens AFM $\left(6 \times 6 \mu \mathrm{m}^{2}\right)$ das amostras: (a) amostra Co10(30s), (b) amostra Co11(1 min) e (d) amostra Co12 (3 min).

Percebe-se claramente na Figura 6.1-8 grãos pequenos $(\sim 0,1 \mu \mathrm{m})$ bem formados e recobrindo toda a lâmina. Na Figura 6.1-8 (a) observa-se que a formação do filme de cobalto se inicia possivelmente na forma de "ilhas" que posteriormente se juntam formando um filme contínuo como na Figura 6.1-8(b).

Até este ponto analisamos a influência da temperatura e do $\mathrm{pH}$ na deposição química de cobalto utilizando a receita 2. Nesse estudo estivemos utilizando sistematicamente a solução $0,0005 \mathrm{M}$ de $\mathrm{PdCl}_{2}$ em solução diluída de dHF $\left(40 \mathrm{H}_{2} \mathrm{O}: 1 \mathrm{HF}(49 \%)\right)$ durante $15 \mathrm{~s}$ para fazer ativação das superfícies de silício tipo P com orientação (100). A Figura 6.1-9 (a) mostra uma foto SEM da superfície de silício após a etapa de ativação (MARQUES,2003). Nesta foto podemos notar claramente os sítios de paládio e regiões expostas de silício. A Figura 6.1-9 (b) mostra outra micrografia SEM utilizando a mesma solução de ativação, mas por tempo de 30s. Nesta última, é possível observar o aumento do tamanho dos sítios de paládio e a menor área exposta de silício. 


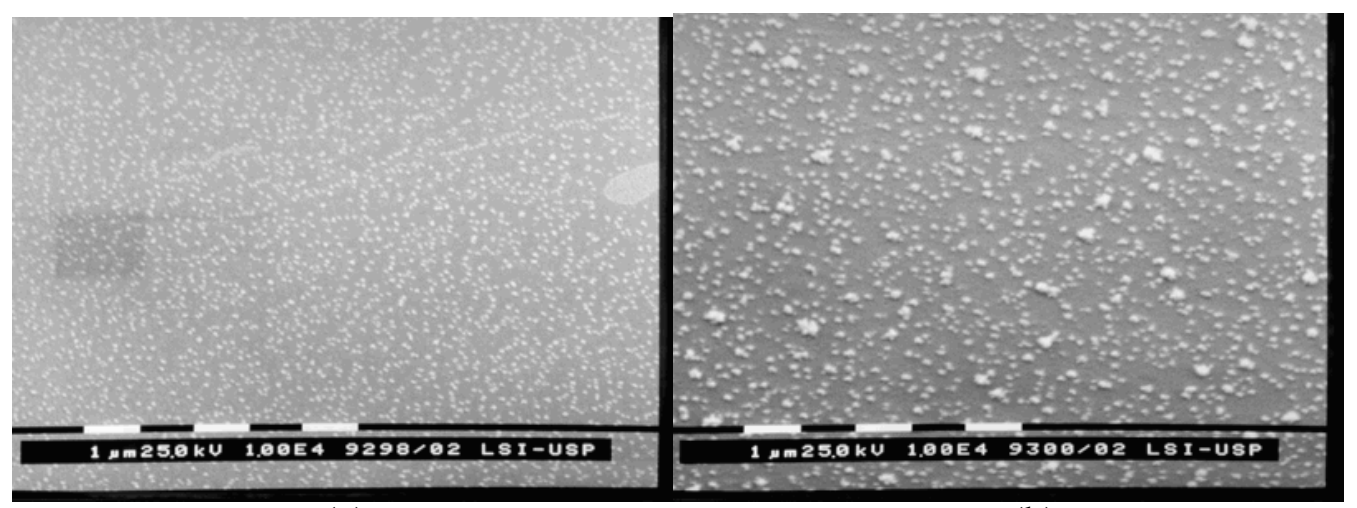

(a)

(b)

Figura 6.1-9 Fotos SEM típicas de superfícies polidas de silício pré-ativadas com solução $0,0005 \mathrm{M}$ de $\mathrm{PdCl}_{2}$ em dHF $\left(40 \mathrm{H}_{2} \mathrm{O}: 1 \mathrm{HF}(49 \%)\right)$ por: a) $15 \mathrm{~s}$; b) $30 \mathrm{~s}$ (MARQUES,2003).

No conjunto de experimentos que vamos analisar a seguir utilizamos a receita 2 na temperatura de $80^{\circ} \mathrm{C}$ para tempos de deposição variando de $20 \mathrm{~s}$ a $180 \mathrm{~s} \mathrm{e} \mathrm{pH}$ ligeiramente maior comparado com as amostras Co10, Co11 e Co12 (Veja Tabela 5,7-1). Durante a deposição das amostras o $\mathrm{pH}$ foi monitorado tendo variado cerca de 9,4 até cerca de 9,8 nas deposições em ordem seqüencial das amostras Co120, C0130, Co140, Co150 e Co160. Esta variação ocorreu devida à evaporação do hidróxido de amônio durante as deposições desse lote de amostras. A partir dos espectros de RBS extraímos a concentração planar total de cobalto e paládio e também as respectivas espessuras. Também extraímos a rugosidade RMS em varreduras de $1 \mu \mathrm{m} \times 1 \mu \mathrm{m}$. A tabela $6.1-3$ resume o conjunto de parâmetros extraídos para cada tempo de deposição.

Tabela 6.1-3 - Resultados dos espectros de RBS e AFM para as amostras Co120, Co130, Co 140, Co 150 e Co 160.

\begin{tabular}{|l|r|c|c|c|c|c|}
\hline $\begin{array}{l}\text { Nome } \\
\text { Da } \\
\text { Amostra }\end{array}$ & $\begin{array}{l}\text { Tempo de } \\
\text { deposição } \\
\text { de Co }(\mathrm{s})\end{array}$ & $\begin{array}{c}\text { Concentração } \\
\text { Planar de Co } \\
\left.\left(10^{16} \mathrm{At} / \mathrm{cm}^{2}\right)\right)\end{array}$ & $\begin{array}{c}\text { Espessura } \\
(\mathrm{Co}) \\
(\mathrm{nm})\end{array}$ & $\begin{array}{c}\text { Concentração } \\
\text { Planar de Pd } \\
\left(10^{16} \mathrm{At} / \mathrm{cm}^{2}\right)\end{array}$ & $\begin{array}{c}\text { Espessura } \\
(\mathrm{Pd}) \\
(\mathrm{nm})\end{array}$ & $\begin{array}{c}\text { Rugosidade } \\
(\mathrm{RMS}) \\
(\mathrm{nm})\end{array}$ \\
\hline Co120 & 20 & 0,25 & 0,27 & 2,19 & 3,23 & 16,39 \\
\hline Co130 & 30 & 1,86 & 2,07 & 1,82 & 2,69 & 17,48 \\
\hline Co140 & 60 & 11,4 & 12,68 & 2,24 & 3,31 & 24,38 \\
\hline Co150 & 120 & 44,98 & 50,04 & 2,68 & 3,96 & 32,73 \\
\hline Co160 & 180 & 100,35 & 111,62 & 1,96 & 2,9 & 50,99 \\
\hline
\end{tabular}

Pelos espectros de RBS abaixo podemos notar a evolução da concentração planar do cobalto pelo aumento da área do sinal correspondente. Também podemos 
observar que o oxigênio não esta presente em nenhum filme o que permite concluir que na temperatura de $80^{\circ} \mathrm{C}$ não ocorre oxidação do cobalto mesmo para $\mathrm{pH}$ variando na faixa de 9,4 a 9,8.
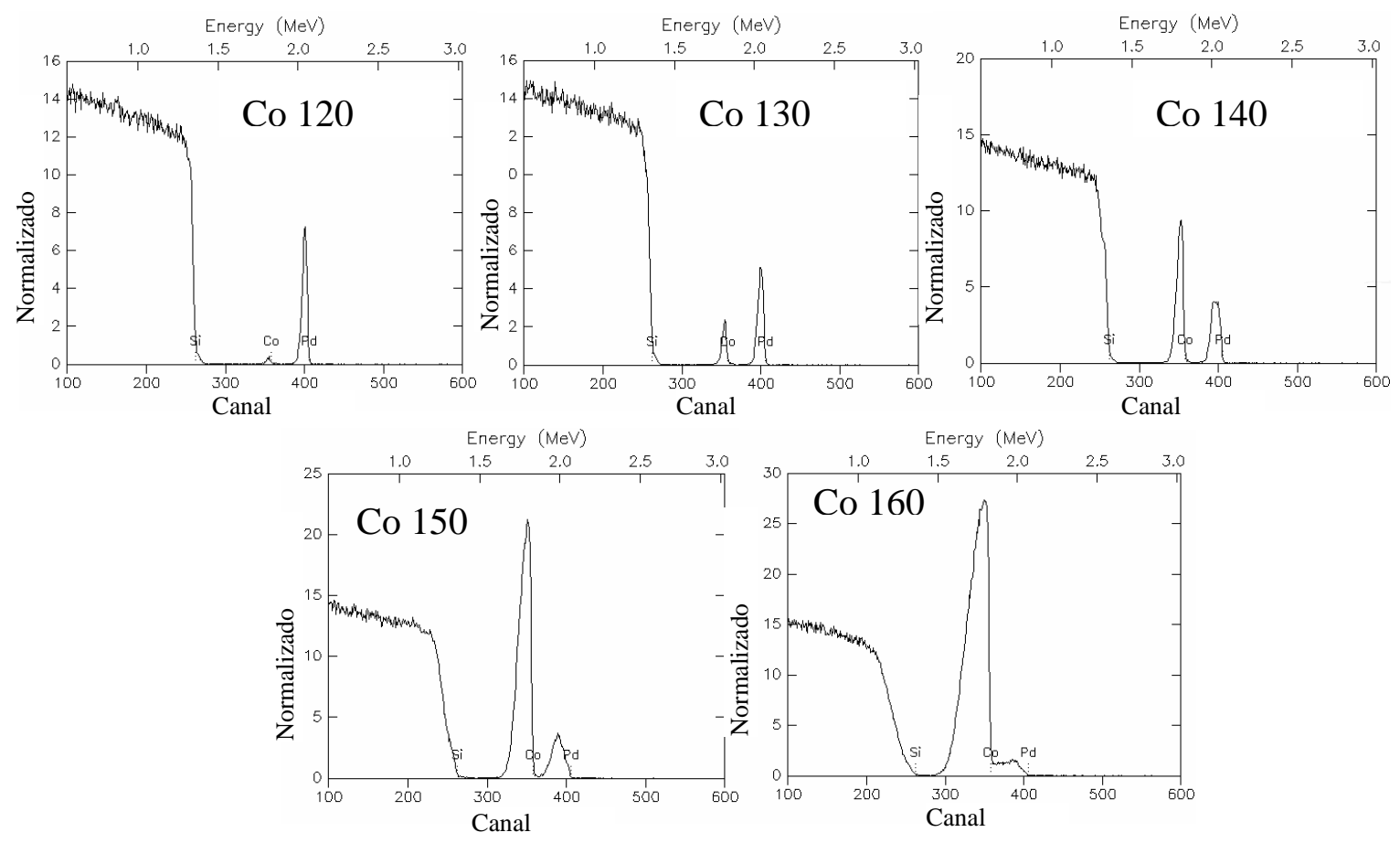

Figura 6.1-10 - Espectros RBS das amostras Co120, Co130, Co140, Co150 e Co160, com tempos de deposição de 20s, 30s, 60s, 120s, e 180s, respectivamente. Foi empregada a receita 2 na temperatura de $80^{\circ} \mathrm{C}$ e pH variando de 9,4 a 9,8 durante as deposições.

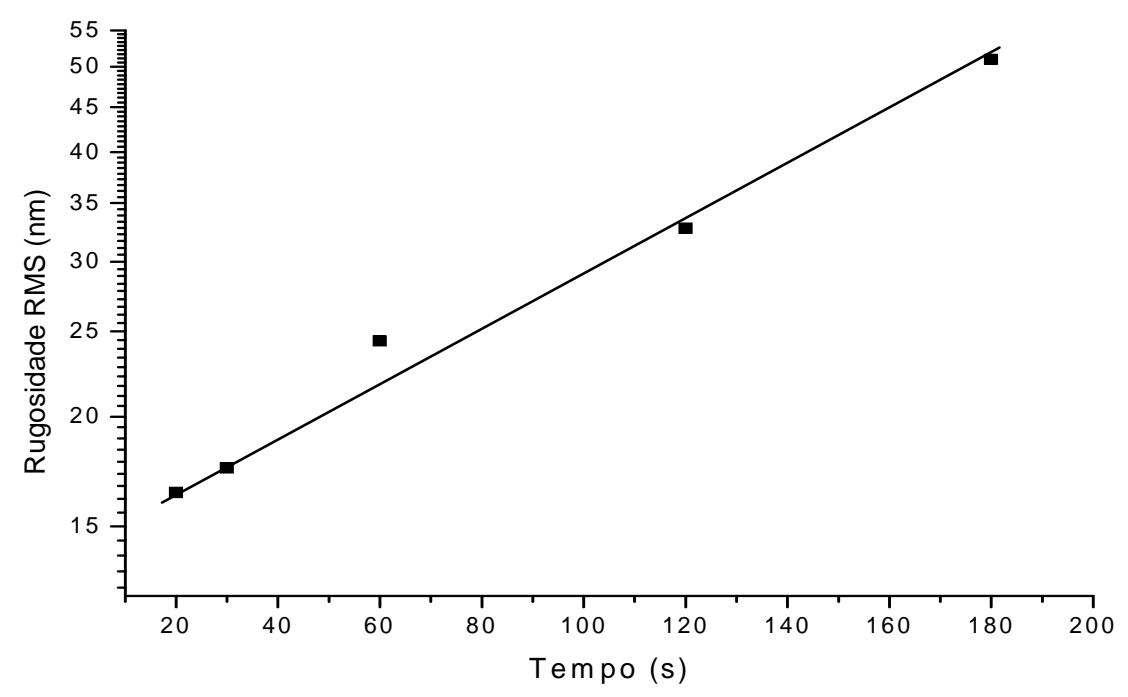

Figura 6.1-11 - Rugosidade RMS em função do tempo de deposição das amostras Co120, Co130, Co140, Co150 e Co160.Utilizando a receita $2\left(\mathrm{Na}_{3} \mathrm{C}_{6} \mathrm{H}_{5} \mathrm{O}_{7} . \mathrm{H}_{2} \mathrm{O}\right.$ (citrato de sódio) $0,14 \mathrm{M},\left(\mathrm{NH}_{4}\right)_{2} \mathrm{SO}_{4}-0,65 \mathrm{M}, \mathrm{CoSO}_{4} .7 \mathrm{H}_{2} \mathrm{O}-0,19 \mathrm{M}, \mathrm{NaH}_{2} \mathrm{PO}_{2}$. $\mathrm{H}_{2} \mathrm{O}-0,28 \mathrm{M}$, na temperatura de $80^{\circ} \mathrm{C}$ e $\left.\mathrm{pH}=9,4-9,8\right)$. 
A Figura 6.1-11 mostra a rugosidade RMS em função do tempo onde se observa um aumento logarítmico contínuo da rugosidade a medida em que a espessura do filme aumenta (veja Tabela 6.1-3). A partir da inclinação desse gráfico, conclui-se que a rugosidade escala com $\mathrm{t}^{0,7}$ para a faixa de tempos analisados.

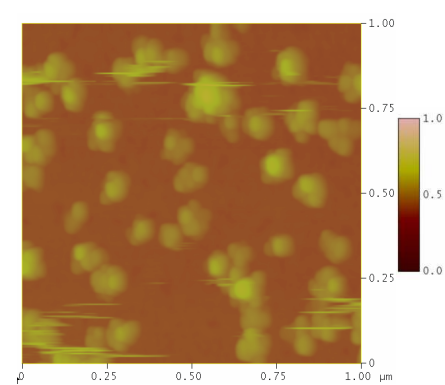

(a)

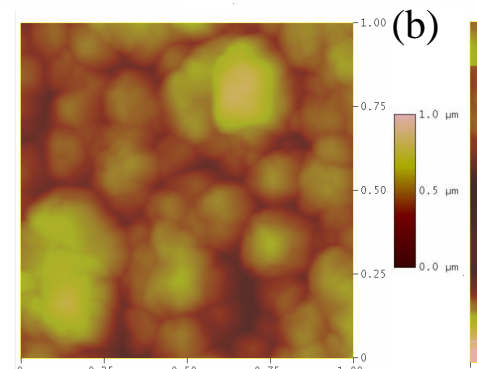

(d)

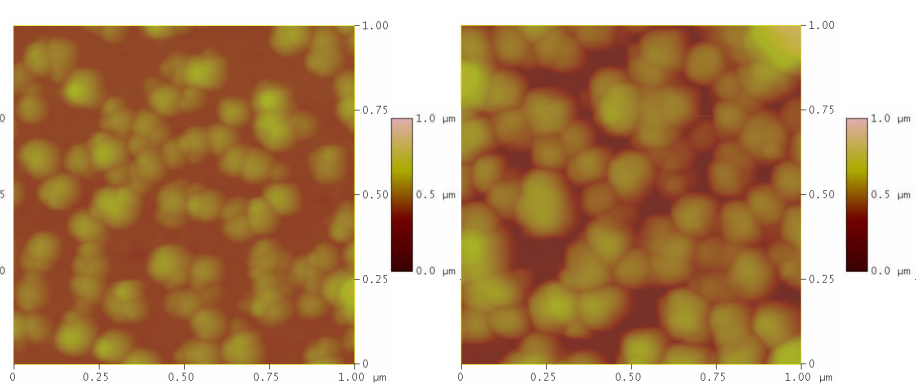

(c)

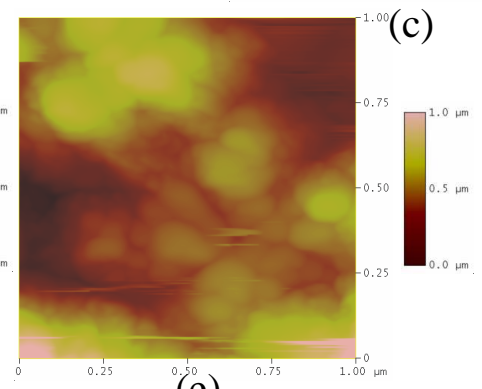

(e)

Figura 6.1-12 - Imagens AFM $\left(1 \times 1 \mu \mathrm{m}^{2}\right)$ típicos das amostras: (a) Co120 - $20 \mathrm{~s}$, (b) Co130-30 s, (c) Co140-60 s, (d) Co150-120 s e (e) Co150 - 180 s.

Podemos observar na Figura 6.1-12 a evolução da morfologia no processo de deposição do filme de cobalto sobre paládio. Percebe-se nitidamente que a formação do filme se inicia em pequenas ilhas distribuídas uniformemente sobre toda a superfície da amostra junto aos sítios de paládio. Após o aparecimento destas ilhas existe uma preferência do cobalto se depositar sobre as ilhas pré-existentes até "fechar" inteiramente a superfície (modelo de crescimento na forma de ilhas)

A Figura 6.1-13 mostra o gráfico da largura de superfície em função do comprimento de escala I e do tempo de deposição. Nesse gráfico observamos que $w(l, t)$ é proporcional a $I^{H}(H=0,99 \pm 0,08)$ indicando um escalamento aproximadamente normal. Por outro lado, $w(l, t)$ satura para I grande $\left(|>>|_{c}\right)$ e é proporcional à $t^{\beta}(\beta=$ $0,15 \pm 0,02)$. 


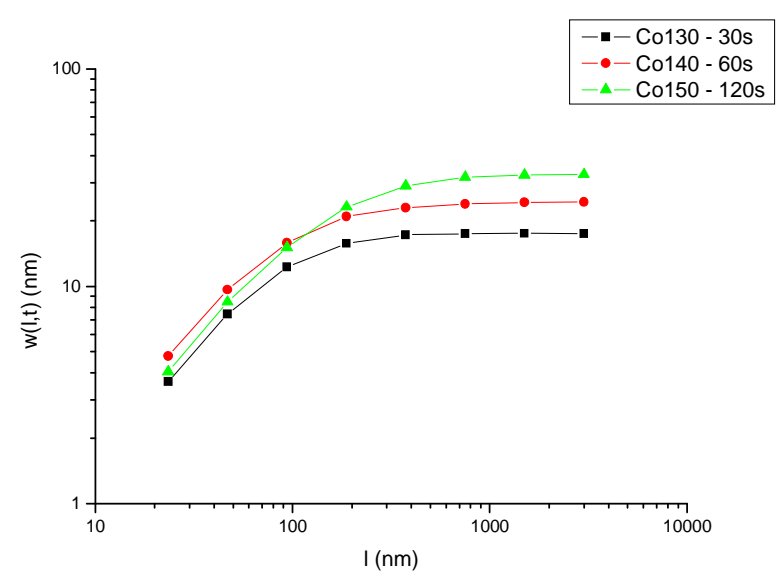

Figura 6.1-13 - Largura de superfície ( $w(1, t))$ em função do comprimento de escala e do tempo de deposição para a receita 2 em $\mathrm{t}=80^{\circ} \mathrm{C}$ e $\mathrm{pH}=\sim 9,4-9,8$ para amostras Co130, Co140 e Co150.

No conjunto de amostras que vamos analisar a seguir apenas variamos 0 tempo de pré-ativação em solução de paládio de $15 \mathrm{~s}$ para $30 \mathrm{~s}$ comparado com o anterior (Tabela 6.1-3). Na Tabela 6.1-4 a seguir, mostramos as espessuras e concentrações planares dos filmes de cobalto e paládio além do tempo de deposição e rugosidade RMS obtidas das análises AFM. Nestas amostras, foi observada a presença de oxigênio para tempos de deposição a partir de 180s (amostra Co230). $\mathrm{Na}$ Tabela 6.1-4, as amostras Co200, Co210, Co220, Co230, Co240, Co250 e Co260 foram pré-ativadas em solução de paládio por $30 \mathrm{~s}$ seguido de deposição na temperatura de $80^{\circ} \mathrm{C}$ com o $\mathrm{pH}$ monitorado na faixa de 9,4 à 9,8 .

Tabela 6.1-4- Resultados dos espectros de RBS e AFM para as amostras Co200, Co210, Co220, Co230, Co240, Co250 e Co 260

\begin{tabular}{|l|c|c|c|c|c|c|}
\hline $\begin{array}{l}\text { Nome } \\
\text { Aa } \\
\text { Amostra }\end{array}$ & $\begin{array}{c}\text { Tempo de } \\
\text { deposição } \\
\text { de Co (s) } \\
\text { (minutos) }\end{array}$ & $\begin{array}{c}\text { Concentração } \\
\text { Planar de Co } \\
\left.\left(10^{16} \mathrm{At} / \mathrm{cm}^{2}\right)\right)\end{array}$ & $\begin{array}{c}\text { Espessura } \\
(\mathrm{Co}) \\
(\mathrm{nm})\end{array}$ & $\begin{array}{c}\text { Concentração } \\
\text { Planar de Pd } \\
\left(10^{16} \mathrm{At} / \mathrm{cm}^{2}\right)\end{array}$ & $\begin{array}{c}\text { Espessura } \\
(\mathrm{Pd}) \\
(\mathrm{nm})\end{array}$ & $\begin{array}{c}\text { Rugosidade } \\
(\mathrm{RMS}) \\
(\mathrm{nm})\end{array}$ \\
\hline Co200 & 0,5 & 1,49 & 1,7 & 4,64 & 6,9 & 33,6 \\
\hline Co210 & 1 & 33,51 & 37,3 & 4,92 & 7,3 & 20,7 \\
\hline Co220 & 2 & 98,19 & 109,2 & 4,45 & 6,6 & 45,2 \\
\hline Co230 & 3 & 78,59 & 87,4 & 4,24 & 6,3 & 41,3 \\
\hline Co240 & 4 & 63,43 & 70,6 & 4,2 & 6,2 & 33,1 \\
\hline Co250 & 5 & 116,84 & 130,0 & 4,49 & 6,6 & 48,7 \\
\hline Co260 & 6 & 219,03 & 243,7 & 1,06 & 1,6 & 36,8 \\
\hline
\end{tabular}


Nos espectros de RBS mostrados a seguir podemos observar a evolução da concentração planar dos filmes de cobalto e do oxigênio presente em função do tempo de deposição.
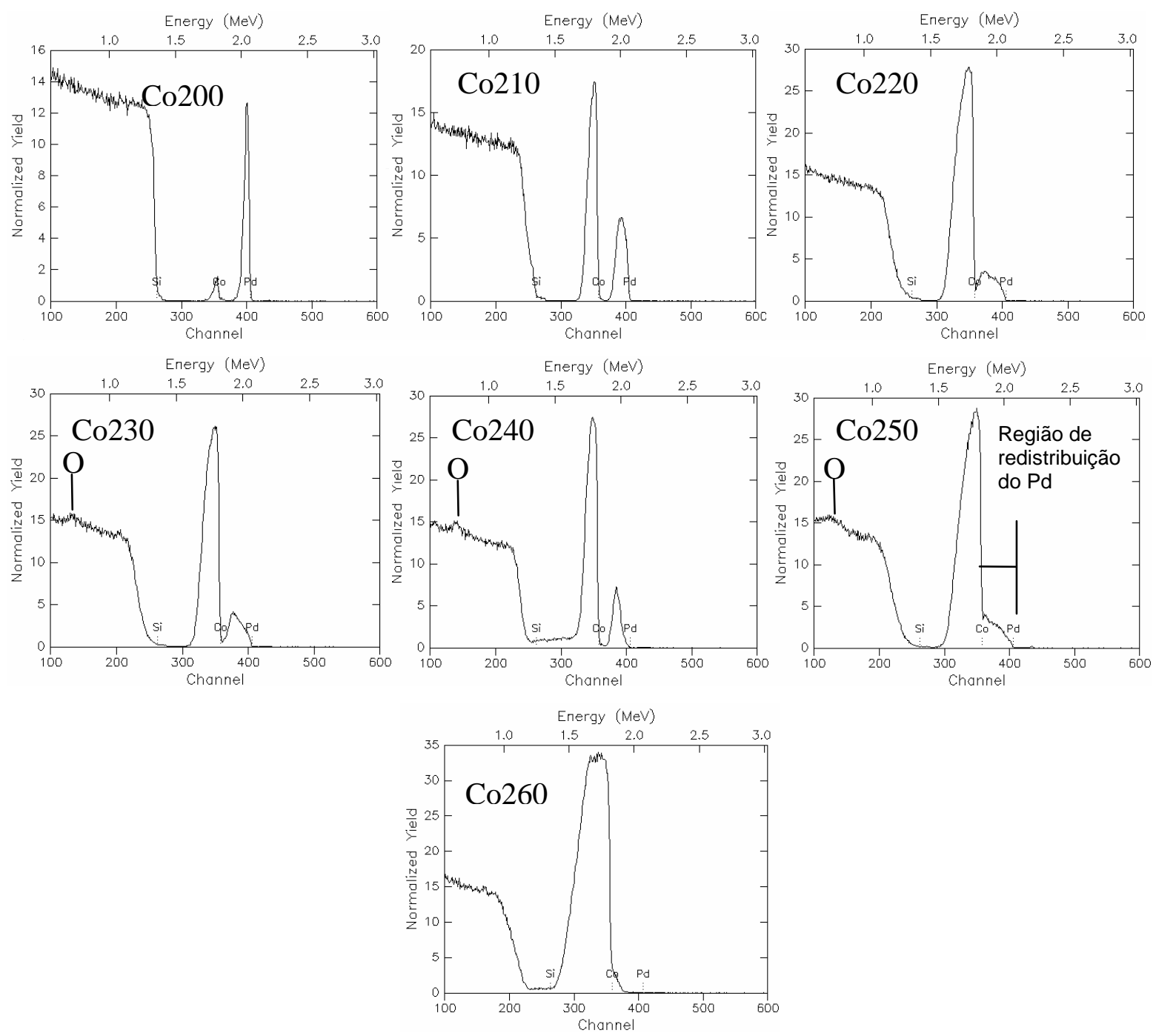

Figura 6.1-14 -- Espectros RBS das Amostras Co200, Co210, Co220, Co230, Co240, Co250 e Co260 com tempos de deposição de 1, 2, 3, 4 e 5 min na receita 2 com Pd de 0,5 min.

Para tempos de deposição superiores a 2 min, o paládio começa a redistribuir no filme de cobalto e para tempos a partir de $3 \mathrm{~min}$, temos um sinal visível de oxigênio começando na superfície do filme formado e tendendo a redistribuir ao longo de todo o filme para tempos maiores de deposição. A redistribuição do paládio ocorre concomitantemente com a incorporação de oxigênio ao longo do filme na forma de óxido de cobalto. Esse processo de 
redistribuição/incorporação ocorre acompanhado pela diminuição da concentração planar total de cobalto como mostrado na Figura 6.1-15. A principal diferença entre o conjunto de experimentos na Tabela 6.1-3 (amostras Co120, Co130, Co140, Co150 e Co 160) e na Tabela 6.1-4 (amostras Co200, Co210, Co220, Co230, Co240, Co250 e Co 260) é apenas o tempo de pré-ativação em solução de paládio que passou de $15 \mathrm{~s}$ para $30 \mathrm{~s}$. Assim, como o número de sítios de paládio é maior no segundo caso, ocorre a tendência dos núcleos de cobalto crescerem rapidamente promovendo cobertura mais rápida da superfície pelo cobalto para tempos de 30s e 60s (veja Figura 6.1-14 e compare com a Figura 6.1-10). No entanto, o processo de redistribuição de paládio /incorporação de oxigênio faz com que o cobalto momentaneamente pare de crescer e até seja removido da superfície como podemos observar na figura 6.1-15 para tempos na faixa de 120s a 240s. O mecanismo pelo qual o cobalto deixa de depositar deve estar associado à oxidação do paládio em solução cuja reação de semicélula conhecida é dada pela equação 6.3 (LURIE, 1975):

$$
\mathrm{Pd}^{0}+2 \mathrm{OH}^{-} \longrightarrow \mathrm{Pd}(\mathrm{OH})_{2}+2 e \quad\left(\mathrm{E}^{0}{ }_{\text {ox }}=-0,07 \mathrm{~V}\right)
$$

onde o potencial padrão de oxidação é próximo de zero.

Esta reação proposta deve estar ocorrendo porque a quantidade de paládio é maior comparado ao lote anterior além do fato de estar ocorrendo redistribuição do mesmo ao longo do filme conforme revelado nos espectros de RBS (figura 6.1-14). 


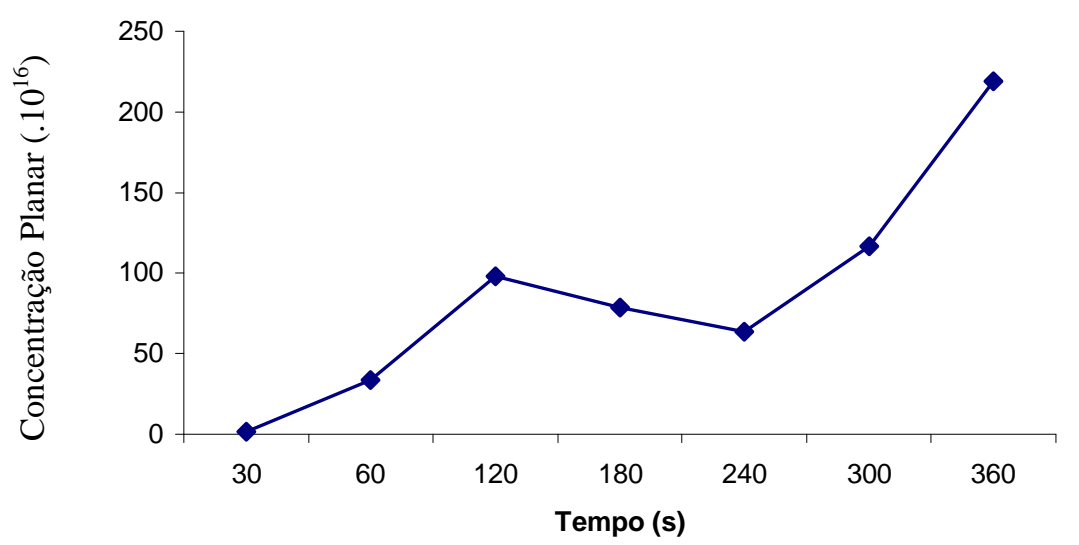

Figura 6.1-15- Gráfico da concentração planar em função do tempo das amostras Co200, Co210, Co220, Co230, Co240, Co250 e Co260 e receita 2a $\mathrm{Na}_{3} \mathrm{C}_{6} \mathrm{H}_{5} \mathrm{O}_{7} . \mathrm{H}_{2} \mathrm{O}$ -(citrato de sódio) $0,14 \mathrm{M},\left(\mathrm{NH}_{4}\right)_{2} \mathrm{SO}_{4}-0,65 \mathrm{M}, \mathrm{CoSO}_{4} .7 \mathrm{H}_{2} \mathrm{O}-0,19 \mathrm{M}, \mathrm{NaH}_{2} \mathrm{PO}_{2}$. $\mathrm{H}_{2} \mathrm{O}-0,28 \mathrm{M}, 300 \mathrm{ml}$ hidróxido de amônia (38\%) em 400ml de água)

No entanto, para que a reação de oxidação do paládio possa ocorrer, a reação de deposição $\left(\mathrm{Co}^{2+}+2 \mathrm{e}^{-} \rightarrow \mathrm{Co}^{0}\right)$ deve estar sendo inibida pela reação de oxidação do cobalto na superfície do filme a qual pode ser descrita pela reação:

$$
\mathrm{Co}^{2+}+2 \mathrm{OH}^{-} \longrightarrow \mathrm{Co}(\mathrm{OH})_{2}
$$

Após tempos de deposição suficientemente elevados ( $>4 \mathrm{~min}$ ), o filme fica suficientemente compacto a ponto de impedir a difusão das espécies $\mathrm{OH}^{-}$de forma que o cobalto pode voltar a se depositar. 


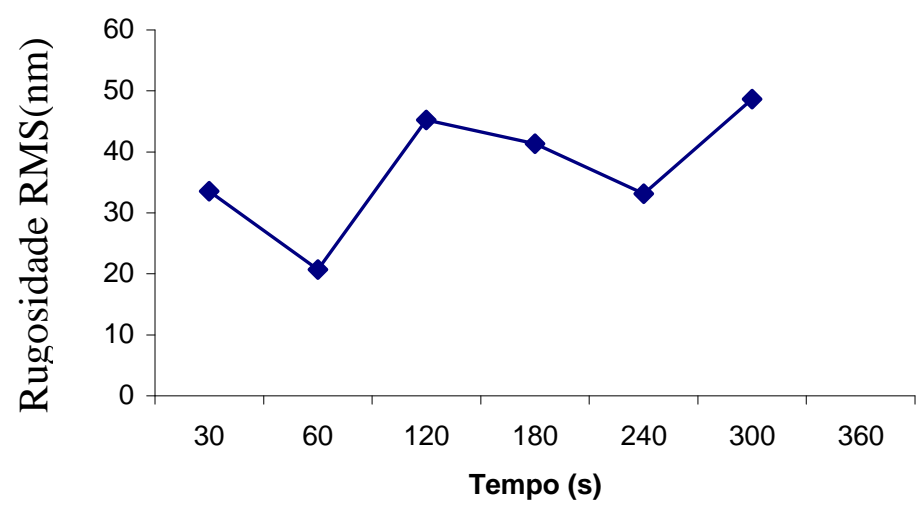

Figura 6.1-16- Rugosidade RMS em função do tempo de deposição: amostras Co200, Co210, Co220, Co230, Co240, Co250 e Co260 receita $2 \mathrm{a}\left(\mathrm{Na}_{3} \mathrm{C}_{6} \mathrm{H}_{5} \mathrm{O}_{7} . \mathrm{H}_{2} \mathrm{O}\right.$ -(citrato de sódio) 0,14M, $\left(\mathrm{NH}_{4}\right)_{2} \mathrm{SO}_{4}-0,65 \mathrm{M}, \mathrm{CoSO}_{4} .7 \mathrm{H}_{2} \mathrm{O}-0,19 \mathrm{M}, \mathrm{NaH}_{2} \mathrm{PO}_{2}$. $\mathrm{H}_{2} \mathrm{O}-0,28 \mathrm{M}, 300 \mathrm{ml}$ hidróxido de amônia (38\%) em 400ml de água)

Por outro lado, os elétrons gerados pela oxidação do paládio devem ser coletados por um agente redutor. Vários processos de redução podem estar ocorrendo durante a redistribuição do paládio. Um exemplo de processo de redução com potencial padrão de redução suficientemente grande e que pode estar acontecendo em solução é dado por (O'Sullivan, 2001):

$$
\mathrm{O}_{2}(\text { dissolvido })+2 \mathrm{H}_{2} \mathrm{O}+4 e^{-} \longrightarrow 4 \mathrm{OH}^{-}
$$

A evolução da rugosidade com o tempo também revela um comportamento distinto durante o processo de redistribuição de paládio/ incorporação de oxigênio. A figura 6.1-16 apresenta a rugosidade RMS em função do tempo de deposição. Observe que a mesma é inicialmente alta (30s) devido em sua maior parte aos sítios de paládio, diminui de valor quando o cobalto começa a recobrir inteiramente as regiões entre sítios de paládio (60s) e volta a subir à medida que o filme de cobalto cresce (60s-120s). No entanto, no intervalo que vai de 120s a 240 onde ocorre o processo de redistribuição/incorporação de oxigênio, a rugosidade RMS volta a diminuir concomitantemente com a inibição do processo de deposição de cobalto. Tal fato indica modificação da morfologia superficial 
compatível com a oxidação do cobalto dada pela equação 6.5 isto é, a oxidação deve estar suavizando a superfície (veja figura 6.1-17).

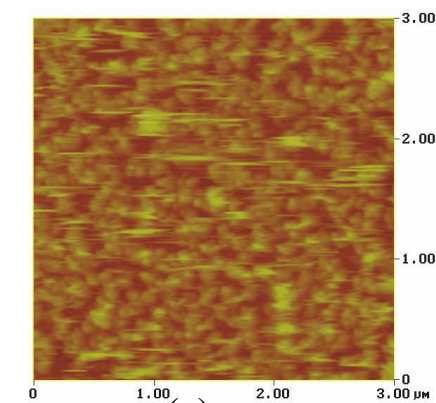

(a)

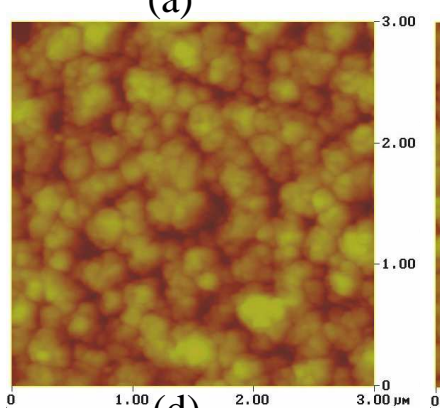

${ }^{1.00}(\mathrm{~d})$

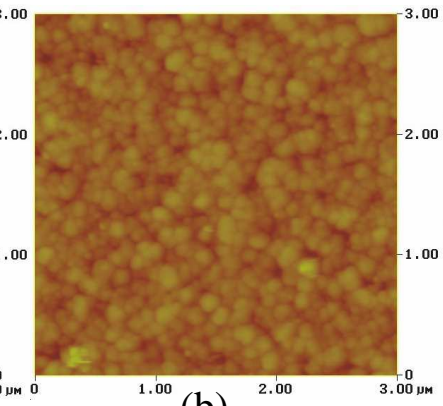

(b)

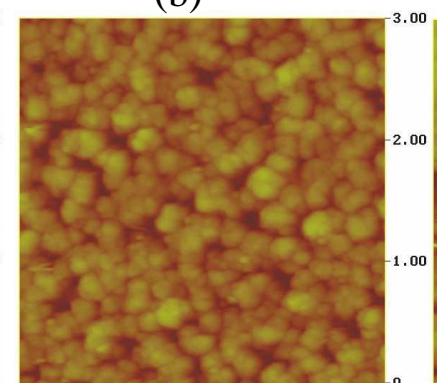

(e)

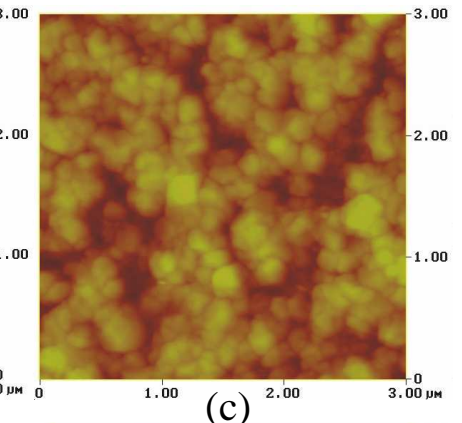

(c)
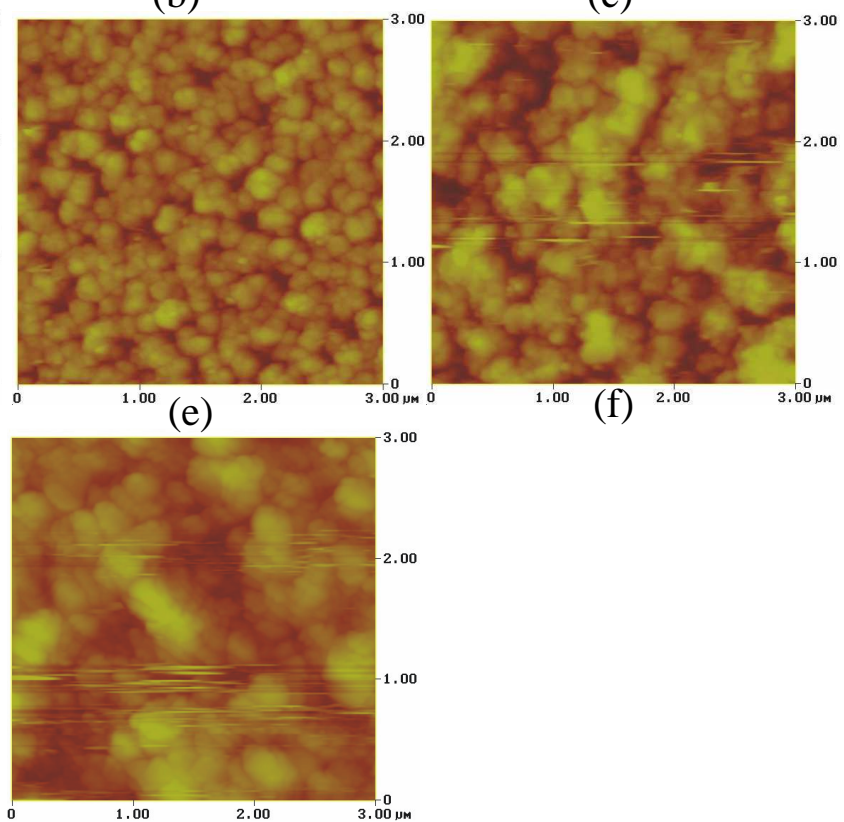

(g)

Figura 6.1-17 Imagens AFM $\left(3 \times 3 \mu \mathrm{m}^{2}\right)$ das amostras: (a) Co200 - $30 \mathrm{~s}$, (b) Co210 60 s, (c) Co220 - 120 s, (d) Co230 - 180 s, (e) Co240 - 240 s (f) Co250 - 300 s e (g) $\mathrm{Co} 260-360 \mathrm{~s}$.

A figura 6.1-18 mostra o gráfico da largura de superfície $w(1, t)$ em função do comprimento de escala (I) para tempos de deposição na faixa de 120 s a 240 s onde ocorre o processo de redistribuição de paládio / incorporação de oxigênio. Para comprimentos de escala pequenos $\left(\mid<<l_{c}\right)$, a largura de superfície $w(l, t)$ escala com $\mathrm{I}^{\mathrm{H}}$ $(H=0,96 \pm 0,07)$ é independente do tempo de deposição seguindo dessa forma um escalamento do tipo normal. Para comprimentos de escala grandes $\left(|>>|_{c}\right), w(l, t)$ satura no valor da rugosidade RMS e escala $\operatorname{com~t}^{\beta}(\beta=-0,37741)$. $O$ valor do expoente $\beta$ serve para quantificar a evolução da rugosidade RMS com o tempo de deposição durante o processo de redistribuição /incorporação. 


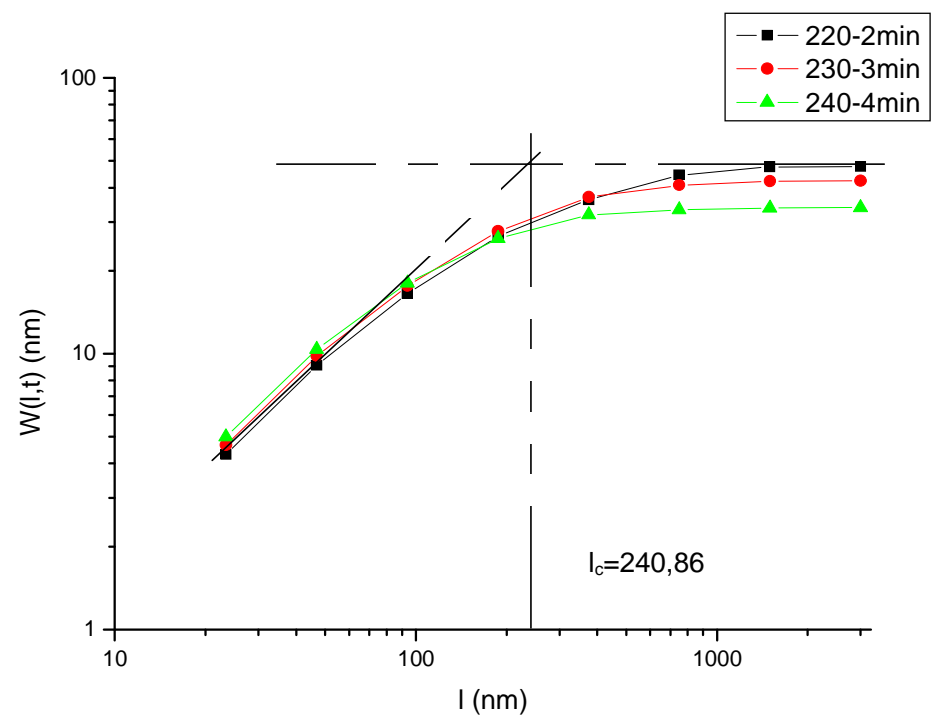

Figura 6.1-18 - Largura de superfície em função do comprimento de escala e do tempo de deposição para receita 2 a $80^{\circ} \mathrm{C} \mathrm{e} \mathrm{pH} \sim 9,4$, para as amostra Co220, Co230 e Co240.

$\mathrm{Na}$ Figura 6.1-19 podemos observar que para comprimentos de escala pequenos o escalamento continua do tipo normal com $\mathrm{I}^{\mathrm{H}}(\mathrm{H}=0,93 \pm 0,07)$ assim como no caso da Figura 6.1-18 e patamar (rugosidade RMS) escala com $t^{\beta}$ $(\beta=1,73)$.

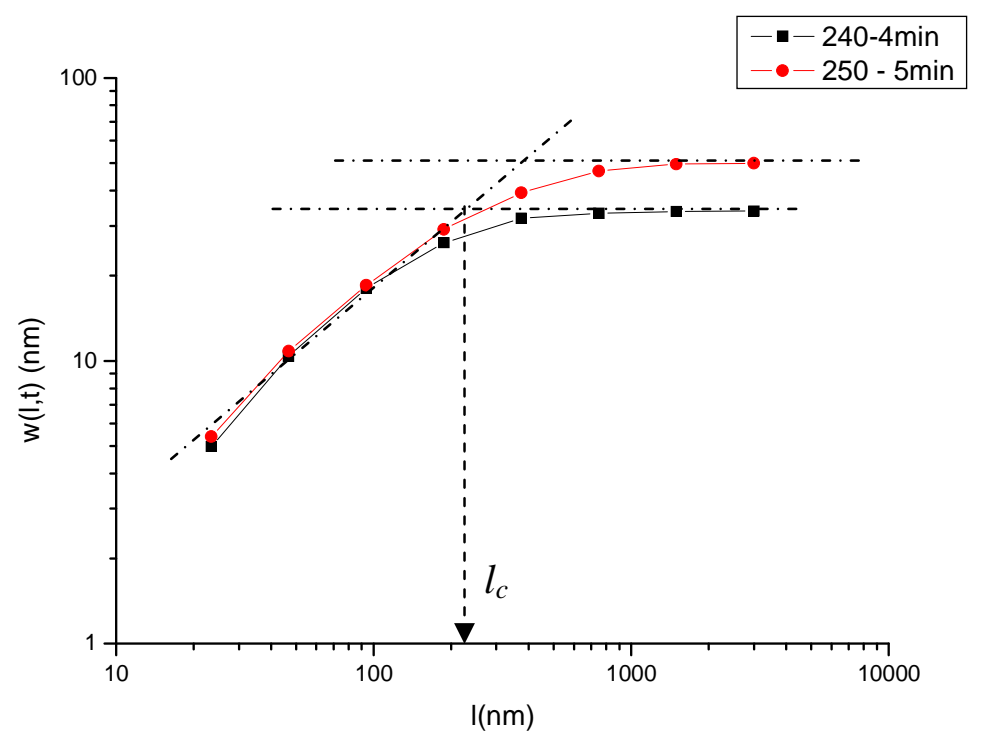

Figura 6.1-19 - Largura de superfície em função do comprimento de escala e do tempo de deposição para receita 2 a $80^{\circ} \mathrm{C}$ e $\mathrm{pH} \sim 9,4$, para as amostra Co240, Co250. 


\section{CONCLUSÕES E PERSPECTIVAS FUTURAS}

Neste trabalho, investigamos a deposição de cobalto sobre superfícies de silício pré-ativadas utilizando dois tipos de banhos eletroquímicos. De acordo com os resultados obtidos, a deposição de cobalto sobre superfícies de silício com orientação (100) tipo P ativada por paládio, resulta em filmes contínuos, brilhantes e aderentes.

$\mathrm{O}$ processo de deposição utilizando-se banho contendo $\mathrm{NH}_{4} \mathrm{Cl}(0,005 \mathrm{M}$ $\mathrm{CoCl}_{2}+0,15 \mathrm{M} \mathrm{NaH}_{2} \mathrm{PO}_{2} \cdot \mathrm{H}_{2} \mathrm{O}+2,0 \mathrm{M} \mathrm{NH}_{4} \mathrm{Cl}$ ) não foi eficiente para a deposição de cobalto sobre a lâmina de silício pré-ativada com paládio. Mas foi eficiente sobre superfície de cobre. Tal fato foi atribuído ao $\mathrm{NH}_{4} \mathrm{Cl}$ que teve o duplo papel de agente complexante e agente tamponante deixando o banho não degradado e estável durante os experimentos. Por outro lado, a mudança do agente complexante para sulfato de amônio e do agente tamponante, para citrato de sódio, permitiu a realização da deposição química de cobalto em amplas faixas de $\mathrm{pH}$ básico $(6-10)$ e temperaturas $\left(65^{\circ} \mathrm{C}-90^{\circ} \mathrm{C}\right)$ sobre superfícies pré-ativadas de silício tipo P com orientação (100). É importante destacar que as maiores taxas de deposição foram obtidas em temperaturas próximas a $80^{\circ} \mathrm{C}$ e $\mathrm{pH}$ próximo a 9,0. Além disso, o aumento da concentração de paládio na superfície do silício, apesar de aumentar a taxa de deposição nos instantes iniciais, acabou por promover processos de redistribuição de paládio ao longo dos filmes de cobalto juntamente com a incorporação de oxigênio em diminuição progressiva da espessura do cobalto depositado. Tal fato foi atribuído a um mecanismo concorrente de oxidação tanto do paládio como do cobalto.

Através do estudo da evolução da rugosidade dos filmes de cobalto com o tempo, sobre a superfície de silício pré-ativado com paládio identificamos um escalamento do tipo normal para filmes obtidos pela receita 2 baseada em citrato de sódio e sulfato de amônio.

Da análise da morfologia dos filmes obtidos através de AFM, notamos que a nucleação de cobalto sobre Si (100) pré-ativado com Pd através da receita 2 inicia-se pelo aparecimento de grãos esparsamente distribuídas nas superfícies dos filmes. Estes grãos aumentam em número e em altura à medida que se 
aumentava o tempo de imersão. Verificou-se a presença de grãos com tamanhos na faixa de 0,1 a $0,3 \mu \mathrm{m}$.

Como continuação do presente trabalho, a investigação da receita 2 para deposição química de cobalto:

a) Em superfícies de silício com orientação superficial (111) e concentrações variadas de paládio a fim de estabelecer um possível mecanismo de oxidação do silício.

b) Em superfícies de silício com diversos graus de rugosidade préativadas com paládio visando também estabelecer um possível mecanismo de oxidação do silício.

c) Em superfícies de silício pré-ativadas com outros metais a fim de eliminar a redistribuição do paládio como observado no presente trabalho.

Finalmente propomos melhorar o modelo proposto no presente trabalho sobre a redistribuição de paládio /incorporação de oxigênio através de medidas físicas para detectar ligações químicas de Pd-O e Co-O. 


\section{BIBLIOGRAFIA}

ADAMS, D.P; PARFITT, L.J; BILELLO, J.C; YALISOVE, S.M.; REK; Z.U

Microstructure and residual stress of very thin MO films Thin Solid Films 1995 p.52-57

ALKIRE R C., KOLB D M. Advances in Electrochemical Science and Engineering, Wiley-VCH Verlag GmbH, 2001, V. 7.

ANDRICACOS, PC; UZOH, C; DUKOVIC, JO; HORKANS, J; DELIGIANNI, H. Damascene copper electroplating for chip interconnections So IBM Journal Of Research And Development; SEP 1998; p.567- 574, V. 42 ,

ANDRICACOS, PC; HARPER, JME; CABRAL, C; Mechanisms for microstructure evolution in electroplated copper thin films near room temperature; Journal Of Applied Physics ; SEP 1999 , p. 2516-2525 , V. 86.

ANTTILA, O. J., TILLI, M.V., SCHAEKERS, M., E CLAEYS, C. L., Effect of Chemicals On Metal Contamination On Silicon Wafer,,J. Electrochem. Soc., April 1992, p.1180 - 1185, V.139.

AHMETOGLU, M. ; ALPER, M.; SAFAK, M.; ERTURK, K.; GURPINAR, B.; KOCAK, F.; HACIISMAILOGLU, C.; Electrical properties of $n$-Si/Cu Schottky diodes formed by electrodeposition J. Optoelectron Adv Mater, 2007, p.818-821.

BAYLIS, B. K. W.; HEDGECOCK, N. E. ; E SCHLESINGER ,M. Tin (IV) Sensitizer for Photoselective Metal Deposition of Cobalt and Nickel from Alkaline Baths J. Electrochem. Soc., March 1977, p. 346-349, V.124

BRENNER, A., RIDDELL,G. , Nickel Plating On Steel By Chemical Reduction Journal Of Research Of The National Bureau Of Standards , 1946 , p. 31-34, V.37.

CALLISTER JR, w.d. Materials Science and Engeneering an Introduction 2000 5ed Material

CAMPBELL, S.A The Science and Engineering of Microelectronic Fabrication Oxford University Press 20012 ed

CHU, W K Backscattering Spectrometry 1978 Academic Press, Inc.

BRETT, C.M.A. e BRETT,A.M.O. Electrochemistry Principles, Methods, and applications oxford university press 1993

DADVAND,N, JARJOURA, G, KIPOUROS,G Preparation and characterization of Co-Fe-B thin films produced by Electroless deposition Journal Materials SciMaterial Electrochemical AUG 1007 
DELATORRE, R. G; MUNFORD, M. L.; ZANDONAY, R.; ZOLDAN, V. C.; PASA, A. A. ;SCHWARZACHER, W.; MERUVIA, M. S.; HÜMMELGEN, I. A. p-type metalbase transistor App. Phys. Lett., 2006, p. 2335.

DUBIN, V. Electroless Ni-P Deposition on Silicon with Pd Activation Journal Of The Electrochemical Society, MAY 1992, p.1289-1294, V. 139.

DUHIN, A.; SVERDLOV,Y.; TORCHINSKY, I.; FELDMAN , Y.E SHACHAMDIAMAND, Y. NiSi contact metallization using electroless Ni deposition on Pdactivated self-assembled monolayer (SAM) on p-type Si(1 0 0) Microeletronic Engneering May 2007, p.2506-2510, V. 84

DULAL, S. M. S. I. ; YUN, A. H. J.; SHIN, C. B.;KIM, CK Electrodeposition of CoWP Film: I. Electrochemical and Compositional Analyses; Journal of The Electrochemical Society, 2007 p.D494-D501.

ELY,H.F. Metalização por aluminio evaporado no vácuo aplicada circuitos integrados monolíticos 1973 dissertação de mestrado, Escola Politécnica, Universidade de São Paulo.

ENTANI , S.; KIGUCHI,M.; SAIKI, K.; Fabrication of polar CoO(1 1 1) thin films on Pt(1 1 1), Surface Science, 2004, p. 165-169

EZE,F.C. Electroless deposition of CoO thin Films, J. Phys. D: Appl. Phys, May 1998, p.533-540, V. 32

GAUDIELLO JG, BALLARD GL. Mechanistic Insights Into Metal-Mediated Electroless Copper Plating Employing Hypophosphite As A Reducing Agent IBM Journal Of Research And Development, 1993 , p. 107-115, V. 37 .

HASSAN, N M Estudo Experimental Da Deposição Eletroquímica E Análise Do Escalamento Dinâmico Da Rugosidade Superficial De Filmes Finos De Cobre 2002 p.122 tese de doutorado - Escola Politécnica, Universidade de São Paulo

HERSCH, P. Mechanisms Of Self-Discharge Of The Negative

Of Alkaline Accumulators Dept., The Mond Nickel Company Limited,

Birmingham June 1954 p.1442

HWANG, B J; LIN S H Reaction Mechanism of Electroless Deposition:

Observations of Morphology Evolution during Nucleation and Growth Via

Tapping Mode AFM J. Electrochem. November 1995 Soc., p.3749-3754, V. 142.

HUO, S.; SCHWARZACHER, W anomalous scaling of the surfacewidth during Cu eletro-deposition, Physical Review Letters 2001, p72-75 V. 86.

JAGANNATHAN, R; KRISHNAN, M; Electroless Plating Of Copper At A Low Ph Level IBM Journal Of Research And Development. MAR 1993, p. 117- 123, V. 37.

KIFLAWI, I; SCHLESINGER, M Tin(IV)-Based Photoselective Metal Deposition of Cobalt and Nickel from Alkaline Baths J. Electrochem. Soc., Volume 130, Issue 4, pp. 872-874 April 1983 
KIM, J; WEN, SH; JUNG, DY; JOHNSON, RW. Microstructure Evolution During Electroless Copper Deposition IBM Journal Of Research And Development, 1984, Vol 28 n 6, p. 697- 710

LIU, C.M. ; LIUB, C.M. ; HSIEHB, C.M. ; TSAIB, V W.; CHENC, J. Interfacial reactions of electroless nickel thin films on silicon 2004

LURIE, J. Handbook of Analytical Chemistry. Moscou, Mir Publishers, 1975.p. 76.

MALLORY, G O.; HAJDU, J B. Electroless Plating - Fundamentals and Applications William Andrew 1990

MARQUES, A.E.B. estudo experimental da deposição química autocatalítica de níquel para aplicações em microeletrônica 2003 Tese de doutorado -Escola Politécnica- Universidade de São Paulo

MIZOKAMI, Y.;AJIOKA, T. E TERADA N. "Chemical Analysis Of Metalic Contamination On A Wafer After Wet Cleaning" leee Transactions On Semiconductor Manufacturing, nov. 1994, p.447-453, V. 7

NARAYANAN, TSNS, SELVAKUMAR,S STEPHEN,A Electroless Ni-Co-P ternary alloy deposits: preparation characteristics Surface Coat Technology JUL 2003 p.298-307

OHNO, I Electrochemistry of electroless plating Materials Science and Engineering , January 1991

OSAKA, T.;TAKANO,N. ; KUROKAWA,N. E UENO,U. Fabrication of Electroless NiReP Barrier Layer on $\mathrm{SiO}_{2}$ Without Sputtered Seed Layer Electrochem. SolidState Lett ,January 2002 , p. C7-C10, V. 5

OSAKA, T.; YOSHINO, M. New formation process of plating thin films on several substrates by means of self-assembled monolayer (SAM) process

ELECTROCHIMICA ACTA 2007, p. 271-277, V.53

O'SULLIVAN EJ, SCHROTT AG, PAUNOVIC M, SAMBUCETTI CJ, MARINO JR, BAILEY PJ, KAJA S, SEMKOW KW. Electrolessly Deposited Diffusion Barriers For Microelectronics IBM Journal Of Research And Development 1998, p. 607-620, V. 42 .

PERES, N Electrochemistry And Corrosion Science Kluwer Academic Publishers 2004

PAUNOVIC, M.; NGUYEN, T.; MUKHERJEE, R. ; SAMBUCETTI, C.; ROMANKIW, L. Empirical Modeling and Response Surfaces for Electroless Co Deposition Process J. Electrochem. Soc., 1995 , p.1495-1500, V.142 .

ROBERTIS, E.;NEVES, R.S.; ABRANTES, L.M.; MOTHEO, A.J. Pd-P electroless deposition on carbon steel: An electrochemical impedance spectroscopy study January 2005 
RUDINIK, E.; SKRZYNIARZ,P. Influence of Temperature on electroless deposition of Co-P Maney Publishing, march 2007 p. 82-86

SANTOS FILHO, S.G.D. Oxidação térmica rápida do silício: influência dos procedimentos de limpeza e dos perfis temporais de temporais de temperatura na qualidade dos óxidos de porta MOS. Outubro 1996 p.224 Tese de doutorado Escola Politécnica, Universidade de São Paulo.

SCHUEGRAFT, K.K.; LA PLACA, S.J. Handbook of thin film deposition process and techniques Park Ridge New Jersey, noyes publication 1988

SHACHAM-DIAMAND,Y ; SVERDLOV,Y et al. A Surface Adsorption model for electroless cobalt alloy thin film Journal of Solid state Electronic, July 2007 p929938

TING, C.H. et al. Selective electroless metal deposition for integrated circuit fabrication Journal of the Electrochemical Society FEB 1989, p.456-461, V. 136

TING, C.H. et al. Selective electroless metal deposition for via hole filling in VLSI multilevel interconetion structures. Journal of the Electrochemical Society, FEB 1989, p.462-46, Vol 26.

VASKELIS, A JACIAUSKIENE, $J$ et al. Accelerating Effect Of Ammonia On Electroless Copper Deposition In Alkaline Formaldehyde-Containing Solutions Journal Electroanal Chemistry FEB 2007, p.6-12

VASKELIS, A; JACIAUSKIENE, J;STANKEVICIENE,I Anodic Oxidation of Co(II) complexes with amines on a rotating Au electrode: ligant effects in relation to the application for autocalytic metal deposition Electrochim acta FEB 2006 p. 2215-2220 